\title{
How One Makes Two: Epistemological Crises and Ontological Intensities in the Experimental Travelogue Film
}

\author{
By \\ Christopher Rohde, B.A.
}

A thesis submitted to the Faculty of Graduate Studies

in partial fulfillment of the requirements for the degree of Master of Arts

Carleton University

Ottawa, Ontario

August 2007

(C) 2007 by Christopher Rohde 


$\begin{array}{ll}\begin{array}{l}\text { Library and } \\ \text { Archives Canada }\end{array} & \begin{array}{l}\text { Bibliothèque et } \\ \text { Archives Canada }\end{array} \\ \begin{array}{l}\text { Published Heritage } \\ \text { Branch }\end{array} & \begin{array}{l}\text { Direction du } \\ \text { Patrimoine de l'édition }\end{array} \\ \begin{array}{l}\text { 395 Wellington Street } \\ \text { Ottawa ON K1A ON4 }\end{array} & \begin{array}{l}\text { 395, rue Wellington } \\ \text { Ottawa ON K1A ON4 } \\ \text { Canada }\end{array}\end{array}$

Your file Votre référence ISBN: 978-0-494-33764-6 Our file Notre référence ISBN: 978-0-494-33764-6

NOTICE:

The author has granted a nonexclusive license allowing Library and Archives Canada to reproduce, publish, archive, preserve, conserve, communicate to the public by telecommunication or on the Internet, loan, distribute and sell theses worldwide, for commercial or noncommercial purposes, in microform, paper, electronic and/or any other formats.

The author retains copyright ownership and moral rights in this thesis. Neither the thesis nor substantial extracts from it may be printed or otherwise reproduced without the author's permission.
AVIS:

L'auteur a accordé une licence non exclusive permettant à la Bibliothèque et Archives Canada de reproduire, publier, archiver, sauvegarder, conserver, transmettre au public par télécommunication ou par l'Internet, prêter, distribuer et vendre des thèses partout dans le monde, à des fins commerciales ou autres, sur support microforme, papier, électronique et/ou autres formats.

L'auteur conserve la propriété du droit d'auteur et des droits moraux qui protège cette thèse. $\mathrm{Ni}$ la thèse ni des extraits substantiels de celle-ci ne doivent être imprimés ou autrement reproduits sans son autorisation.
In compliance with the Canadian

Privacy Act some supporting forms may have been removed from this thesis.

While these forms may be included in the document page count, their removal does not represent any loss of content from the thesis.
Conformément à la loi canadienne sur la protection de la vie privée, quelques formulaires secondaires ont été enlevés de cette thèse.

Bien que ces formulaires aient inclus dans la pagination, il n'y aura aucun contenu manquant.

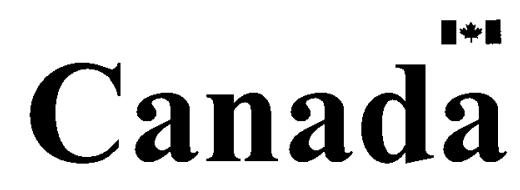




\section{Abstract}

The form of the travelogue has to date gone largely unrecognized by critical literature on experimental cinema. The reason for this absence of attention lies not with a scarcity of films suitable for the appellation, but rather with the deficiency of historical perspectives within the field of experimental film criticism. The existing body of criticism tends to focus too exclusively on relations with modernist art practices when a wealth of connections can be found to older cultural movements that are usually neglected. This study is an historical investigation into the genealogy of the travelogue form, tracing the aspects that will eventually define the characteristics of the travelogue in experimental cinema as they appear in several disparate temporal epochs. Among the most prominently recurring concepts are ideas of vision and subjectivity, curiosity and wonder, presence and distance, and knowledge and experience. I show how these primary concerns are manifested and developed in the Romantic period, in early cinema, and in contemporary experimental film since the 1980s. By drawing upon analyses of Romantic travel literature and poetry, a selection of early films, and in-depth examinations of six experimental films, this thesis demonstrates how the method of juxtaposing distant historical points is entirely appropriate to the object of study. The experimental travelogues discussed in this study take up a variety of approaches to representing travel and movement based on misrecognition, overlap and transitivity to find new ways of exploring space and time. By demonstrating these typical operations, it is hoped that this thesis will take a tentative step forward in defining the experimental travelogue as a distinct genre of filmic practice. 


\section{Acknowledgements}

An enormous debt is owed to my thesis supervisor, Professor Chris Faulkner, for his immense knowledge of history, poetry, literature and art, and his passion for things

that quicken the heart. Thanks are also due to André Loiselle, who always thought I could be doing better, and to James Missen, who ignited my enthusiasm for experimental cinema. I could not have completed this thesis without the continued generous encouragement and support of my parents and my friends, especially Scott Birdwise and Holly Price. 


\section{Table of Contents}

1. Introduction:

Inauguration of the Experimental Travelogue

Matters of definition / Overview of the thesis as a whole / Matters of methodology

2. Chapter One:

An Art of Perception: Aesthetics of Curiosity in the Romantic Travelogue Discourses of curiosity / Romantic travelogues / George Forster \& Alexander Von Humboldt / Tourism in the Romantic period / Wordsworth and the principles of Romanticism / Aesthetics of curiosity in twentieth century film criticism

3. Chapter Two:

Unseen Energies: The (Experimental) Travelogue in Early Cinema

Early cinema and Romanticism / Staging perspective / Images of mobility

4. Chapter Three:

Centres of Calculation: Tourism and Epistemological Crises of 'Knowledge'

Sifted Evidence / Mexice / Somewhere Between Jalostotitlan and Encarnation

5. Chapter Four:

Experiments in Disorientation: 'Spots of Time,' the Sublime and Ontological Intensities

Eastern Avenue / Reading Canada Backwards / Chimera

6. Conclusion:

A Veiled Flight: The Experimental Travelogue as Historiography

Kitchener-Berlin

7. Bibliography 


\section{Introduction:}

Inauguration of the Experimental Travelogue

The purpose of this thesis is to broach the invention of a new category of filmic practice: the experimental travelogue. Over the course of the next four chapters, I will attempt to trace the stylistic, formal, structural and aesthetic features of this category as well as attempt to define its most prominent thematic and topical concerns. By way of an introduction, this part of the thesis will acquaint the reader with some contextual background to the issues that lie behind my methodology and my system of approach. The first matter to be dealt with is the definition of the individual terms that comprise the name of the object of study. A discussion of the relative merits of using the term 'experimental' in place of other alternatives, like 'avant-garde,' will illuminate the ways in which the experimental films examined later in this thesis articulate values of newness and are able to take up a politicized stance in their investigations of practices of travel and encounters with the foreign or the distant. After a brief note on the difference between the experimental travelogue and 'experimental ethnography,' I will outline the distribution of subject matter in the thesis and explain the logic behind its comparison and juxtaposition of several seemingly disparate historical epochs.

'Travelogue' refers to a long-standing tradition that precedes the cinema of accounts of travels and voyages given by a lecturer, typically accompanied by a slideshow or some other form of visual accompaniment. An expanded history of this tradition will form the backbone of Chapters One and Two, by looking at how the travelogue form was defined and developed in the Romantic period and how it was changed by its adaptation to motion pictures in early cinema. In general, however, I want to employ the term 'travelogue' in a more literal sense: as a travel log, as the writings, markings, 
recordings or traces of travel. Defining 'experimental,' however, proves to be much more complicated. What follows is a sketch of the comparative meanings and implications of using the term to refer to a certain oeuvre.

A plethora of terms are available for describing this corpus of works, including 'underground,' 'fringe film' and 'New American Cinema,' but 'experimental' and 'avantgarde' are easily the most prominent and the most hotly debated. Beyond the definition of a body of texts, what is at hand is the definition of an encompassing spectrum of techniques, strategies, textual instances and discourses. To begin, we can list the practical terms of definition given by John G. Hanhardt (1976); they are issues of production, exhibition and distribution that are relevant to this cinematic assembly regardless of its nomenclature. ${ }^{1}$ These are films that for economical reasons are primarily made using $16 \mathrm{~mm}$ or $8 \mathrm{~mm}$ film stock, as opposed to the costly $35 \mathrm{~mm}$ format standardized by the commercial film industry. $16 \mathrm{~mm}$ and $8 \mathrm{~mm}$ cameras are also embraced because of their portability, meaning that large crews are not required for their operation, and because developing the film they carry can be done by a commercial processor rather than in a special laboratory. ${ }^{2}$ These factors allow for an individualist model of production, rather than the division of labour found in studio-produced films. Filmmakers can rent subsidized equipment from co-ops, which also often distribute the work. These films are also typically of a length or exhibition format unsuitable for commercial theatrical exhibition or for individual standalone broadcast. The work is made without the resources nor the financial rewards usually afforded by commercial cinema and, as a result, it has a

\footnotetext{
${ }^{1}$ See: Hanhardt (1976) esp. $21,37$.

2 These are advantages to the filmmaker also provided by video production.
} 
more limited audience as well as a smaller pool of practitioners. However, these practical terms say little about the pragmatisms and priorities of these endeavors.

Alain-Alcide Sudre (1991) acknowledges that while the terms 'avant-garde' and 'experimental' have often been used to designate the same field of practice, each term carries with it a distinct conception of filmic practice which precludes different assumptions about the roles of politics and aesthetics. Historically, Sudre suggests, the idea of an 'avant-garde' has been founded upon a notion of 'active' (or more accurately, 'reactive') resistance, and that the identity of the avant-garde cinema has been figured in terms of denial and subversion. 'Avant-garde' is understood to designate an artistic practice that radically departs from instituted traditions and norms, positing itself in counter to them, not merely at the moment of departure, but as an ongoing commitment to being "continuously in revolt" (Sudre 1991, 53). The avant-garde strives towards the assertion of an idea of free expression and, as such, its alleged legitimacy "is sited in the emancipating character of a practice" (Sudre 1991, 53). Germaine Dulac, in her 1932 article "The Avant-Garde Cinema," defines it as "any film whose technique, employed with a view to a renewed expressiveness of image and sound, breaks with established traditions to search out...new emotional chords" (Dulac 1978, 43).

Sudre characterizes the historical avant-gardes of the art world (painting, sculpture, poetry) as programmatic, concerned with emplacing their work within doctrinal historical debates that contribute to an idea of progress, or development. Thus, Sudre suggests, the most emblematic materialization of this set of desires and principles is the manifesto, most associated with the modernist art movements of Futurism, Dadaism and Surrealism. Theoretical writings and manifestos were not merely adjunct 
complements that accompanied the works, but rather formed part of the avant-garde's larger apparatus. As with the Enlightenment, Sudre observes, this progressive aim is teleological and future-oriented (see Chapter One). Dulac claims that the avant-garde film "is isolated from every concern other than progress," moving inexorably "toward the cinematic form of the future" (Dulac 1978, 43).

Sudre also identifies within the historical avant-gardes a consistent rejection of academicism for its perceived sense of hegemonic dominance, thus leading the avantgarde to secede from formal art history practices and intellectual art establishments. These separatist sentiments continue in the filmic avant-garde's rejection of Hollywood, the 'dominant' cinema, which performs the role of academicism in its imposition of a hegemonic rhetoric of classical narration. P. Adams Sitney (1979) crystallizes this common sentiment when he states that "the precise relationship of the avant-garde cinema to American commercial film is one of radical otherness. They operate in different realms with next to no significant influence on each other" (Sitney 1979, VIII). Sitney is referring to filmmaking practices in an era $(1940 \mathrm{~s}-1970 \mathrm{~s})$ when participation in the cinema industry was guarded by a rigid caste system of apprenticeship and by high costs of production. A more accessible model of individualism, allowing for ideas of the artist as maker of the work was at the time more readily found in the European avantgarde schools of modernist art practice, as well as in the forces operating in twentieth century American painting, poetry and dance. Modernist schools of art in particular have been a consistent point of reference in characterizing the activities of the filmic avantgarde. Hanhardt even goes so far as to define the avant-garde cinema as "the expression 
of an artist engaged in such vanguard aesthetic movements as surrealism, cubism, abstract expressionism or minimalism" (Hanhardt 1976, 21).

However, as will be demonstrated continually throughout this thesis, this supposedly radically 'other' cinema in fact responds to, is implicated in and bisects with popular, mainstream and commercial practices just as much as it is involved with 'high' art. This intersection is partly my reasoning in using the term 'experimental,' a more inclusive term that allows for overlap between areas of cultural production to be recognized. Although Sitney claims that the term 'experimental' is limited because it "implies a tentative and secondary relationship to a more stable cinema" (Sitney 1979, VIII), in this study it will more positively signify a cinema with a continued commitment to negotiation and dialogue with all areas of culture, not limited to classical Hollywood cinema, its industry, or its type of narrative. Judy Radul (2002) makes the point that unlike terms such as 'avant-garde' or 'underground,' using 'experimental' connotes less the valorization of anti-hegemonic or independent idealisms, and the sort of binaristic opposition to Hollywood cinema that has been so persistently imposed upon this spectrum of creativity. ${ }^{3}$ Using the term 'experimental,' moreover, also connotes less of a teleological prioritization of notions of 'progress.'

Throughout the history of avant-garde film and video, but perhaps more particularly beginning in the $1980 \mathrm{~s}$, a trend appears in which artistic aims become divorced to a certain extent from utopian (or dystopian) ideological projects and

\footnotetext{
${ }^{3}$ In all fairness, this spirit of opposition is manifest in a substantial proportion of experimental/avant-garde film and video work, where a recurrent critical position towards the culture and economy of dominant or mainstream practices often takes the form of anti-hegemonic rhetoric. Richard Serra's video Television Delivers People (1973) is an apt example of how, since the late 1960s, Hollywood cinema was joined by commercial broadcast television as a readily available opponent.
} 
projections. Historically, the application of the term 'avant-garde' designated a collection of activities where form and content were politically synthesized, as in the tradition of the Dadaists or the Surrealists. In support of an argument that the term 'avant-garde' is becoming outdated, not only with reference to newer work, but also in retrospect, Sudre points to an alternate strain of avant-garde practices that exhibit this utopian tendency with less ferocity. Citing an interview with filmmaker Carl Brown conducted by Mike Hoolboom, Sudre singles out a passage in which Brown, when asked if an avant-garde still exists, responds in the positive, but strongly rejects the notion that such a practice necessarily entails taking on the character of a political 'movement.' Brown's reasoning is that:

That's bullshit. Theory and politics are as fashionable as changing your underwear every day. The work will last not the politics. Politics confuses people's motives for making work. Do they really want to make this film or is it something that's politically viable? Or politically important? Who cares? Art is about the politics of seeing and feeling. I don't believe in any of that other shit (Brown, quoted in Sudre 1991, 55). ${ }^{4}$

The work, as such, will always remain political, and yet it can never be made reducible to an agenda or a doctrine and will always inevitably 'exceed' whatever theory is ascribed to it. Sudre claims that the point of avant-garde practice is precisely to offer "a world of sense and enjoyment above and beyond that which a discourse can signify" (Sudre 1991, 59 , original emphasis).

Even if a synthesis between aesthetics and politics proves to be a cultural anachronism in the contemporary avant-garde, what can be retained from the historical model of avant-garde practice is the continuing claim to artistic autonomy on the level of

\footnotetext{
${ }^{4}$ From an unpublished interview with Mike Hoolboom entitled, "This Interview Has Nothing To Do With My Work: Carl Brown on the Record."
} 
form, style, aesthetics and method. This does not preclude the possibility of even overtly politicized operations. Although the avant-garde's strict synthetic relationship with an agenda may be waning (and may not have even been so stringent all along), Sudre suggests that its aspect of difference deserves renewed consideration. Sudre argues that on account of various factors in the mode of production, including the generally multicultural composition of practitioners, and their widely dispersed geographical distribution, the avant-garde maintains a 'mulitpolar' or polycentric organization of creativity, a "conglomerate of practices of clashing aims" (Sudre 1991, 56) that contribute to a culturally pluralistic character. "It is this very pluralism, this openmindedness of the practices towards potentialities and adventures raised by curiosity, which is in itself liberating, and not the adhesion to a creed or the search for unity whether this be cultural, national, ideological or aesthetic" (Sudre 1991, 56). ${ }^{5}$ In other words, Sudre posits that the very 'strength' and potential for political change or awareness in the avant-garde stems from its fundamental heterogeneity and irreconcilablility.

It is thus that Sudre proposes the adoption of the term 'experimental,' which he concisely defines as "an exploratory practice that requires the elaboration of an autonomous filmic thinking"' (Sudre 1991, 56). He is insistent that 'experimental' not function as an identifying definition, as the work, even if it is of the type to interest itself in transgression and opposition, is bound to 'exceed' its very difference from what it is not. Gary Kibbins (2002) encourages a similar consideration of 'experimental,' claiming that the usefulness of the term derives precisely from its vagueness and inaccuracy.

\footnotetext{
${ }^{5}$ For more on curiosity and its tensions with 'searches for unity,' see Chapter One.
} 
'Experimental' performs some 'initial sorting by referring to some provinces of artistic production and not others," thus pointing to a tentative grouping of "loosely knit formal and topical characteristics" (Kibbins 2002, 148). The term's utilitarian value manifests itself in practical usages like distributor's catalogues, university syllabuses, and film festivals, where it acts as a 'depository' for works that might be otherwise categorically misrepresented as 'fiction,' 'documentary,' or fall among other equally nondescript heuristic boundaries.

Kibbins points out that the term 'experimental' has been in circulation since the time of the historical avant-gardes, but was frequently disregarded as an appropriate appellation. ${ }^{6}$ Artists and critics alike rejected the term on the grounds that it suggested an approach based on 'trial and error' and inquiry, rather than the sort of willfully personal expression that was privileged by the avant-garde. ${ }^{7}$ Kibbins argues that these artists and critics position themselves against 'experimentation-for-its-own-sake' because experimentation is not being coupled with definite political and aesthetic goals or teleological concerns. Experimentation, however, can be entirely self-justifying, "having no other purpose than.... a sustained program of innovation, or its accomplishments as innovation are means by which other possibly non-aesthetic goals are attained" (Kibbins $2002,149)$.

Experimentation and innovation, were not necessarily radically separate from avant-garde practice, as they were also intimately historically connected to modernism, as

\footnotetext{
${ }^{6}$ See also: Sitney (1979)

${ }^{7}$ Critic Caroline Alice Lejeune (1931) remarked that "the value of the experimental film lies less frequently in achievement than in suggestion, in the fact that it precedes mature work" (Lejeune 1931, 205). The notion that experimental work is the precedent to more serious and thoroughly prepared undertakings is mirrored in the distinctions made between curiosity and wonder in the Romantic period (See Chapter One).
} 
evident in modernism's consistent pursuit of the 'new' and the 'untried.' Kibbins suggests that the reason why the contemporary experimental scene may not adhere exactly to the principles of newness inherited from modernism is that the etymological value of 'new' within this circle has in itself changed. Although values of newness and innovation continue to garner currency, "making it reasonable to ask why a work would be labeled experimental if it does not test new avenues of thought and work" (Kibbins $2002,149)$, experimental media is increasingly becoming identifiable by a set of familiar stylistic devices, formal designs, and topical concerns. Identifying experimentalism as a set of recognizable conventions, Kibbins argues, qualifies experimental media as a genre in the conventional sense, and as with any genre, within it there are innovators and innovations, and there are those who instead merely follow suit:

Being not absolute but relative, contemporary newness is a secondary or subordinate value, a variation or modification of existing themes and practices. A new work or practice is not brand new, it is a new somethingor-other, the something-or-other being already there (Kibbins 2002, 149 $150)^{8}$

'Newness' in contemporary experimentalism is more 'adjectival' than competitive, "refraining from making the triumphalist claim that it consigns other, now 'older' or obsolete forms to the ashcan of history" (Kibbins 2002, 150).

This interpretation of experimentalism is wholly appropriate to a climate of production that embraces the sort of pluralism described by Sudre. Experimentation, in the traditional modernist sense, stems from a judgement that existing forms are somehow inadequate, and must be modified or superseded. In a pluralistic environment, however,

\footnotetext{
${ }^{8}$ Kibbins remarks that one of the surest signs that experimental film and video constitutes a genre in its own right is that it has produced definite and recognized sub-categories - the experimental documentary, the experimental narrative, the experimental autobiography and, as we will add, the experimental travelogue.
} 
no method is specially privileged over another, and even a modification based on a programmatic agenda inevitably will "only be taken as seriously as pluralism will allow" (Kibbins 2002,15). This is not to suggest that the pluralistic character of contemporary experimentalism reproduces exactly the utopian fantasies of free expression treasured by the avant-garde, but rather functions as a sort of meta-doctrine. In this way, pluralism is ironically hegemonic, in that it "forbids any particular program under its endlessly expanding umbrella from having hegemonic ambitions" (Kibbins 2002, 150). Kibbins sardonically states that:

Pluralism emerges when debates regarding basic historical and artistic principles become unresolvable. Pluralism can continue to tolerate such debates, provided that they continue to provide more evidence of pluralism. But pluralism does not present the best conditions for such debates, and they will necessarily take a back seat to pluralism's proper vocation: proliferation and diversity in the absence of fixed categories. (Kibbins 2002, 150).

The picture painted here of the contemporary scene is of a somewhat futile creative environment, one in which historical relevance, agency, and political urgency are increasingly difficult to validate. Trends and movements are nigh-on impossible to begin. Gone are the schools of work that, up until the relatively cohesive grouping of Structural/Minimalist filmmaking of the 1960 s and 1970s, characterized avantgarde/experimental practice. ${ }^{9}$ This has a definite impact not only upon the content of the work, but also upon style, as "pluralism is clearly a more congenial environment for some aesthetic ideas than others" (Kibbins 2002, 151). It is not that pluralism's 'great projects,' its claim to a struggle against commodification, its critiques of dominant and reactionary forms of representation, and its advocacy of personal, social and sexual freedoms have

\footnotetext{
${ }^{9}$ These are the films produced throughout the 1960s and 1970s by Andy Warhol, Michael Snow, David Rimmer, Ken Jacobs, Malcolm Le Grice, Ernie Gehr, Al Razutis and others.
} 
become any less valid in light of Kibbins' criticisms. Rather, it is that the banner of diversity under which pluralism is supposedly constituted is becoming increasingly situated exclusively within a highly institutionalized framework of art production, "producing a bland neo-conceptual sameness" (Kibbins 2002, 151).

Kibbins is nevertheless optimistic, affirming that there exists a type of experimental practice which can possibly work towards overcoming the restrictions the pluralistic state of contemporary media art has placed upon its own political scope and its aesthetic innovativeness. Quite simply, this type of experiment privileges assumption over conviction. Whereas conviction, of the sort needed to produce a manifesto, produces judgments and familiarities, assumption produces a set of 'imaginary beliefs,' creating an irresolvable and unsettling ambiguity in the work that ideally prolongs and sustains experimentation without necessarily falling back into a dialectic between genrefication and expansion. "The purpose of using the assumption as a form of expression, in this case, is not to promote higher quality judgements, but higher quality assumptions" (Kibbins 2002, 156). In drawing upon Gilles Deleuze's (1994) idea of experiment, Kibbins suggests that experimentalism can avoid models of artistic production (and criticism) that 'domesticate' response by insisting upon explicating and interpreting associations. In Deleuze, Kibbins sees the possibility for renewal of the modernist principle of the 'new,' by calling for a bypassing of 'appearances of truth' in favour of producing that which is "more demanding than [truth] is." (Deleuze 1994, 111). In other words, experimentalism should not concern itself with the solving of problems, which bases all new forms and innovations upon an idea of finding truth through improvement or progress. Instead, experimentation should take up a position that is without principles, 
and therefore cannot be figured within structures of critique or refutation.

Experimentalism in this sense is properly 'active,' rather than 'reactive,' perpetually adding and proliferating new ideas without insisting upon synthesizing them into 'communication. ${ }^{10}$ This, Kibbins offers, draws closer to the ideals of pluralism that much of contemporary experimental practice is often unable to realize. Avoiding 'synthesis' and 'communication' is also what typifies how the experimental films examined in this thesis take up a politicized stance with regard to their subject matter.

By discarding 'argument' in favour of a more dialectical approach, the films discussed in this thesis frequently implicate the filmmaker, the text, and the processes of production into the subjects they criticize, without the inherent claim to superiority and radical separation typical of explicitly avant-garde practice. In these films, taking up the ethical dilemmas of subjects like imperialism and tourism, for instance, usually involves positioning the figure of the filmmakers themselves as tourists, or suggesting that the very production of the work is an act of imperialistic territorialization. In this respect, the concerns of many of these works are not unlike the priorities sketched out by Catharine Russell (1999) for what she terms 'experimental ethnography.' A brief look at Russell's approach, however, will make clear why I have opted to use the term 'travelogues' in place of other alternatives, like 'ethnographic films,' and what the differences are between Russell's category of 'experimental ethnography' and my 'experimental travelogue.'

Influenced by postcolonial theory, Russell proposes the category 'experimental ethnography' as a way of circumventing the empiricist and objectivist stance of

\footnotetext{
${ }^{10}$ As we will see in Chapter One, this combinatorial or 'relational' mode of organization also manifests itself in forms like the wunderkammer and the cabinet of curiosity.
} 
traditional ethnography and anthropology. Russell's project is to reconceptualize the role of aesthetics in the matter of representing 'other' peoples, races, cultures and societies. Sidestepping claims to authenticity conventionally made in depictions of encounters between the First and the Third World, or between modern and traditional cultures, Russell centralizes ideas of desire, fantasy and projection. The practice of 'experimental ethnography' amounts to a cultural critique that "challenges the various structures of racism, sexism, and imperialism that are inscribed implicitly and explicitly in so many forms of cultural representation" (Russell 1999, XII). These critical issues of identity certainly play a part in the operations of the experimental films I will introduce, and the influence of postcolonial theory will inform some of my analysis. However, my category of 'experimental travelogues' differs from the band of films Russell selects in a substantial way. Rather than focusing on ritual, cultural tradition, language, fashion, biography, family, ethnicity, and other such anthropocentric concerns, the films discussed in this thesis often de-emphasize the human element, privileging the presentation of movement, mechanics, maps, technologies, industries and networks. Before any in-depth analysis of the travelogue in the realm of contemporary experimental film can take place, however, a generous amount of fore-history must be given in order to show how experimental film practice owes many debts to deeply rooted and enduring traditions.

In our first chapter, a look at travel writing of the Romantic period and a selection of some Romantic poetry will articulate core issues of curiosity and vision. The conflicts between Romantic culture and the Enlightenment will provide the background for a discussion of the deployment of subjectivity and identity, with regard to issues of presence, distance, knowledge and experience. The second chapter will show how the 
travelogue adapts to turn-of-the-century culture and to the logic of motion pictures. A discussion of early cinema, including the way in which contemporary critics have historicized it, will trace the further development of curiosity and vision in the context of modernity. Chapters Three and Four will show how contemporary experimental travelogues reflect both the histories and the critical issues introduced in the preceding two segments with some in-depth textual analysis. Each chapter will represent one of two major strains of practice in this ongoing history: experimental travelogues with a strong emphasis on raising epistemological problems of knowledge and understanding, and those that are more concerned with the production of ontological intensities. Finally, we will come full circle, concluding with an examination of the experimental travelogue's engagement with historiography, and the roots of that method of enquiry in the traditions of Romanticism.

While at first, Romanticism may seem like an arbitrary choice for a precursor to experimental cinema, the association between the two is not unprecedented. Romanticism represents a key influence upon much of Sitney's critical writing on avant-garde cinema, and is a guiding principle behind many of his analyses of films. Informing his creation of the subcategories 'Visionary Film,' 'Mythopoetic Film,' and 'Lyrical Film' is the assertion that:

The preoccupations of the American avant-garde film-makers coincide with those of our post-Romantic poets and Abstract Expressionist painters. Behind them lies a potent tradition of Romantic poets. Wherever possible, both in my interpretation of films and discussion of theory, I have attempted to trace the heritage of Romanticism (Sitney 1979, LX). ${ }^{11}$

\footnotetext{
${ }^{11}$ Sitney's mention of Abstract Expressionism refers to his discussion of animation work by Len Lye, Harry Smith, Jordan Belsen, and also of certain works by Stan Brakhage.
} 
Sitney sees in Romanticism and avant-garde filmmaking a mutual valorization and prioritization of vision, subjectivity, colour, feeling, sense, and impression. In differing from the avant-garde's typical break with the past and its self-imposed position of total exclusion from other areas of culture, Sitney's admission of debt to the Romantics situates avant-garde filmmaking as part of the former's extended genealogy. It was also Sitney who suggested a connection between early cinema and the avant-garde, which has inspired a modest but consistent body of critical literature. ${ }^{12}$

Critics writing on the topic of connecting early cinema to the avant-garde are often eager to forge connectivities across points of film history and are willing to partake in the willful misrecognition necessary to make such a critical leap. Within this body of criticism, the sentiment frequently recurs that early cinema and the avant-garde could not be more different in terms of technological, economic and ideological factors, and the particular social and cultural contexts that inform each of their modes of production. ${ }^{13}$ In acknowledging that the apparent linkage between the two modes involves a perceptual doubling-over, Tom Gunning (1983) calls the critics' relationship between the avantgarde and early cinema 'pseudomorphic,' presenting 'an attractive appearance of affinity that cloaks a basic discontinuity in genus and species" (Gunning 1983, 355). Anomalies of vision remain a consistent metaphor in describing this critical activity. When referring to the role of perspective in this critical operation, Leo Steinberg (1979) offers the observation that:

\footnotetext{
${ }^{12}$ In his article "Structural Film" (1970), Sitney claimed that "Lumière's style, from the turn of the century, with composed and random movement into and out of a single fixed frame, implies an extension into the structural," and thus represents an important predecessor to the work of avant-garde filmmakers like Tony Conrad, George Landow, Hollis Frampton, Joyce Wieland and Paul Shartis (Sitney 1970, 329). The visual dynamics Sitney describes will be discussed in depth in Chapter Two.

${ }^{13}$ See: Gunning (1983), Cornwell (1980), Testa (1992), and Burch (1986).
} 
The legitimacy of retrojecting from our immediate experience to remote fields of study touches on the issue of relevance. No one imagines that relevance attaches to particular subject matter. Making things relevant is a mode of seeing (Steinberg 1972, 317).

Despite its irrational qualities, overlapping two basically discontinuous modes of cinema, like coloured transparencies, can create productive resonances. Nevertheless, another prominent feature of this body of literature is an attempt to disavow the aspect of misrecognition by appealing to ideas of early cinema connecting with the avant-garde through convoluted causal chains. This approach recuperates the legitimacy of the comparison by 'proving' the existence of direct influences passed on from generation to generation. The routes and inroads charted from the reference point of early cinema often lead to a single, already-retired chapter in the cinematic avant-garde: the films sometimes grouped under the Structural/Minimalist banner. ${ }^{14}$ These critics are especially eager to point out instances where Structural/Minimalist filmmakers reappropriate or directly refer to iconic footage from early cinema, or appear to be conducting an investigation into the types of framing or of staging action familiar to early cinema. ${ }^{15}$ However, Noël Burch (1986) warns against allowing the observation of resemblances between early cinema and the avant-garde to take a nostalgic form, noting the tendency to regard the similarities with "the coincidence of apparently fortuitous encounters or with the consciously assumed shock of rediscovery and recognition" (Burch 1986, 500). The construction of proximities and resemblances between early cinema and Structural/Minimalist film makes the act of misrecognition inherent in the comparative criticism practice more

\footnotetext{
${ }^{14}$ Structural/Minimalist film, as a recurring point of reference, sheds some light upon why the New Historicists privilege the term 'avant-garde' over 'experimental.' Structurally, formally, and aesthetically speaking, it is also the strain of filmic avant-garde practice that bears the closest resemblance to typically modernist values, as it frequently stages investigations into the illusory nature of film and privileges a materialist appreciation of the medium.
} 
plausible, reliant as it is upon the expectant confirmation of a set of well-worn familiarities.

In this study, I attempt to discuss selected works from the domain of early cinema not as predecessors or prototypes for the operations carried out in experimental travelogues, but rather as a part of the same canon. Beyond bearing certain uncanny resemblances to experimental cinema, these early films, I propose, can be considered 'experimental' in their own right for the way that they are born of a context of experimentation. ${ }^{16}$ According to Bart Testa (1992), early cinema has provided a suitable container to film historians for ideas of origins, beginnings, or a point of departure. ${ }^{17}$ Rather than seeing early cinema as a precursor to a congealed and finished cinematic form (usually narrative cinema), Testa suggests it can be understood as being organized only by a loosely cohering principle of invention or experimentation.

Like Kibbins' depiction of experimental media, what Testa is describing is a corpus defined by its own unmanageable heterogeneity. It is in this environment that values of invention and experimentation are able to pollinate early film culture. Invention becomes possible from the sense of free play to be found in the various ways in which early filmmakers took to the task of adapting varied representational or pictorial codes to the logic of motion pictures. Experimentation nests in the ways in which these often

\footnotetext{
${ }^{15}$ Malcolm Le Grice's After Lumière (1974) and Ken Jacobs' Tom, Tom, the Piper's Son (1969) are frequently singled out as evidence of an irrefutable lineage and an extended life for early cinema.

${ }^{16}$ These early films also possess an experimental quality for the ways in which they experiment with vision and subjectivity (See Chapter Two).

${ }^{17}$ The insistence upon seeing early cinema as 'formative' or generative in some sense depicts the relationship between early cinema and what followed in terms of a process of maturation and development. Such a historical model paints the history of cinema teleologically, reaching towards a summit, with early cinema as the base. "Film history is a story and, like any other, has to begin somewhere and needs some place to go" (Testa 1992, 23). This mythic view is also consonant with a typical conceptual model of travel, suggesting that if 'progress' was to be achieved in the cinema, early cinema must have been temporally and spatially 'left behind.'
} 
contradictory codes could be combined and juxtaposed with sometimes unpredictable results (See Chapter Two). However, just as with Lejeune and Sitney's dismissals of 'experimentalism,' the principle of invention in early cinema is not always historically privileged, and is sometimes judged moralistically. ${ }^{18}$ Testa proposes that such prejudices are gradually being reassessed, and early cinema is becoming "privilleged today as the laboratory of a new historicism" (Testa 1992, 27). It is for these reasons that Burch proposes that we look upon early cinema first as a historically located mode of production, and second also as a meta-discourse on the filmic process.

Early cinema is a mode of production in which aesthetics are not dominated by ideas of progress, but rather a willingness for discontinuity, however much an idea of 'advancement' may have played a part. The idea that early cinema struggles towards either total narrativization by introducing crosscutting or eyeline matches, or towards the mythical 'total cinema' described by Bazin (1946) through additions of colour or sound, places such advancements within a non-existent overarching project. ${ }^{19}$ Louis Lumière famously prophesized that "the cinema is an invention without a future" (Lumière, quoted in Cornwell 1980,67), and although the statement is usually understood to reflect the pioneer's doubt in the medium's industrial or economic future, it could just as easily be taken as a statement of intent. A consideration of this non-linear character should be kept in mind when delving into the histories of forms like experimental cinema, for it can reveal networks of associations that might be otherwise dismissed by conventional historical accounts.

\footnotetext{
${ }^{18}$ Early cinema's context of production itself fell under moral suspicion: "Waiting for its artistic career to begin, the illegitimate waif of technology fell into bad company and developed questionable morals in the era of penny arcades and second-string music halls" (Testa 1992, 33).

${ }^{19}$ See: Bazin (1991)
} 
Walter Benjamin (1999) sees the potential for valuable historical observation in critical perspectives like those of Sitney and the critics who he inspired, which cross over conventional boundaries of subject matter and spatiotemporal periods:

For the materialist historian, every epoch with which he occupies himself is only prehistory for the epoch he himself must live in. And so, for him, there can be no appearance of repetition in history, since precisely those moments in the course of history which matter most to him, by virtue of their index as 'fore-history,' become moments of the present day and change their specific character according to the catastrophic or triumphant determination nature of that day (Benjamin 1999, 474).

Romanticism (and the general cultural developments of the Romantic period) thus serves as a fore-history of early cinema, which in turn will serve as a fore-history of experimental cinema. ${ }^{20}$ Although many commonalties will make themselves apparent as we shift from one epoch to another, what is at hand is not simply the repetition of features or the establishment of continuity among these discrete sites of history. ${ }^{21}$ Rather, visiting each of these sites are tellings of the present, of experimental film, in that my recounting of these fore-histories establish the preconditions that allow the present to exist, and for its images and designs to be articulated. The principle of pseudomorphism that enables this description is worth keeping in mind, moreover, for the reason that in the experimental travelogue, themes of misrecognition and defamiliarization, and of blurred distinctions between perspectives, places, times, objects and points in history, are particularly abundant and profuse.

\footnotetext{
${ }^{20}$ In addition to leaping across several sites of history, this study also forges connections between various disparate national contexts. While the experimental films are all Canadian, the early films are all of American manufacture and much of the writings of the Romantic period under discussion here as well as the aspects of Romantics culture in general are British in origin. These choices were influenced by factors of availability and access. Yet, issues of national identity are not of chief priority, as such considerations would produce 'bridging' activities that my combinatorial method of analysis does not necessarily require. ${ }^{21}$ Burch claims that it is experience with 'alternative' filmic practices like experimental cinema "which has made it possible for us today simply to read many of the phenomena encountered in the earliest films" (Burch 1986, 485, original emphasis).
} 


\section{Chapter One:}

An Art of Perception: Aesthetics of Curiosity in the Romantic Travelogue

The relationship between curiosity and vision has been of crucial importance within the history and criticism of the travelogue form. As a metaphoric or rhetorical device, and as a trope or organizing principle, curiosity has consistently been central to the travelogue since the Renaissance. The specific focus of this chapter is curiosity's role as the principal aesthetic framework of the travelogue since the Romantic period, and how it was shaped by changes in other fields of cultural practice. The developments in science, museology, art and popular culture during this period (roughly 1770 - 1840) charted by Nigel Leask (2002) produced a set of sometimes conflicting discourses of curiosity that used metaphors of vision to articulate and to validate ideas of presence, distance, knowledge, experience and desire. A look at the development of curiosity and vision in the Romantic period will illuminate the aesthetics of the travelogue as it develops as a literary genre. It will also enhance our appreciation of the significance the emergence of the cinema holds to the genealogy of Romanticism, by outlining the aesthetic models of travel available and legible to the makers of the early cinema travelogue.

\section{Discourses of curiosity}

Leask characterizes travelogues by their interdisciplinary or transgeneric quality, their tendency to cross boundaries of subject matter and freely juxtapose methods conventionally belonging to conflicting epistemological regimes. Although typically subordinated to an itinerary narrative structure, the travelogue is frequently "punctuated with reports on botany and zoology alongside ancient ruins and monuments, mineralogy alongside modern manners, 
ancient history alongside contemporary politics" (Leask 2002, 2). However, in the Romantic period, this pluralizing tendency comes to operate in an ambiguous relationship with the larger cultural project of the Enlightenment, and with its emergent modern divisions of knowledge. Although the Enlightenment reform of knowledge affected a wide variety of cultural sites and activities, Leask suggests that changing trends in museology correspond especially with travel writing of the period, since both involve similar practices of collection and display, accumulation and synthesis.

The interdisciplinary travelogue described above shares certain aesthetic and structural similarities with pre-modern museological practices (especially wunderkammers and 'cabinets of curiosity') as well as with nineteenth century popular entertainments and spectacles. These arrangements of artifacts are typified as assemblies of heterogeneous elements, a 'free' intermingling of objects and associations. In the pre-modern museum, display spaces were not compartmentalized categorically, and divisions and associations between elements were rarely based upon apparent differences of origin, species, type, or size. A 'natural' object, like a botanical specimen, might be juxtaposed with an 'artificial' one, like a musical instrument. According to Barbara Maria Stafford (2001), these arrangements are by no means unkempt or disorganized, but rather represent more 'prismatic' systems or theories of order, arranged according to the taste and curiosity of the collector. Spanning multiple and overlapped spatial and temporal epochs, the pre-modern museum resembles earlier Renaissance 'magical' discourses about the interconnectedness of animals and elements, despite their surface dissimilarities of appearance. ${ }^{1}$ In fact, the apparent dissonance between elements is precisely what facilitates their elicitation of wonder.

\footnotetext{
${ }^{1}$ Such an appeal to the interactivity of things can be interpreted as a response to the unfamiliar or the unknown, a way of making sense of the distant (in terms of both time and space) and its relations to the present of the museum. Stafford calls this a "physiognomic impulse" (Stafford 2001, 4), a desire to connect visible or
} 
Forms like the wunderkammer and the 'cabinets of curiosity' accommodate a desire

for the rare, the ingenious and the singular, but not for the typical, in the sense that a bird

specimen in a modern museum is taken to be a typical instance of its genus and species. For a

host of reasons, however, representatives of the Enlightenment reformation actively

discredited these prismatic types of presentation, as well as the style of knowledge and

aesthetic pleasures to be gained from them. ${ }^{2}$ Although by no means did the pre-modern style

of presentation disappear completely from nineteenth century culture, in the Victorian era

many culturally centralized museums underwent dramatic reorganization. ${ }^{3}$ Museums began

to be organized upon the ideal of "a collection of instructive labels each illustrated by a well-

selected specimen" (Goode 1896, 784), a categorical and archival organization of knowledge

otherwise apparent surface evidences based on their assumed 'inner' or essential qualities. Tom Gunning identifies the imagined relationship between early cinema and the avant-garde in similar terms, as 'pseudomorphic' (see Introduction).

${ }^{2}$ It might be suggested that the pre-modern styles of arranging and presenting artifacts represented the potential to produce certain anxieties in the modern consciousness, which were related to imperialistic sentiments circulating in Victorian culture. The wunderkammer, for instance, is a form that allows continual additions, associations and attachments, in spite of the physical limitations and restrictions of the presentation space, often seeming 'cluttered' and about to 'overflow.' In the Renaissance 'Age of Discovery,' these qualities may have sat more comfortably within a wider cultural awareness of geographical immensity, associated with the culture of exploration and the continual expansion of the idea of 'horizon' and of the boundaries demarcating the 'distant,' representing potentiality and adventure. Once the 'Age of Discovery' showed signs of coming to a close, however, notions of infinity and overlap came to represent more of a threat to the stability of the space of the spectator, an instability that might have encouraged the imposition of more definite spatiotemporal limits. "The pre-modern museum represented an inadequate realization of the 'centre of calculation.' Its curiosities were indeed mobilized and stabilized, but were not combinable in any systematic sense, representing merely anecdotal glimpses of incommensurable worlds" (Leask 2002, 31). The modernization of the museum works towards undoing the illegibility of the foreign and the distant, as a means of being able to synthesize them into a Western paradigm of knowledge, and thereby render them unthreatening and suitable for instrumentalization. ${ }^{3}$ Leask, however, notes that less 'official' institutions continued to use pre-modern styles: "Although the state's appropriation of the 'museum order' in the Romantic period brought with it a new form of legitimacy (as well as a new, systematic form of display), private collecting practices often continued to embody the values of élite curiosity or virtuosity ... values mimicked and transculturated in the popular, commercialist exhibition order" (Leask 2002, 32). Leask also questions the effectiveness of Enlightenment reform, suggesting that even after modernization, the boundaries between modern museums, elite private collections, and popular/commercial exhibitions remained somewhat permeable. Further, Leask suggests that even the modem museum remains haunted by "a risible incongruity between the totalizing ambition and a perceived entanglement in minor detail" (Leask 2002, 32). There exists a tension inherent in museal practice between the miscellaneous or the anecdotal, and the "antithetical project of reordering the world according to a philosophical systematic of time and space" (Leask 2002, 34). In addition to reorganizing their collection, museums were adapting to modernity in many other ways. Tony Bennett (1995) takes as an example the project of electrifying the British Museum in 1833 to allow evening openings to accommodate a growing public with leisure time at night (Bennett 1995, 71). 
based on the division and separation of calculable elements into distinct categories and deployed in the interest of education and instruction. ${ }^{4}$ These developments in museology reflect a broader cultural reevaluation of what ideally constitutes knowledge and experience, by privileging a type of learning based on pedagogic meanings, as well as by morally legitimizing a preference for more mannered styles of pleasure that appeal to classical aesthetic values.

Travelogues, often sponsored and authorized by the state, were similarly put under pressure to reform in order to comply with modern scientific standards, and it was their 'curious' aspects that underwent the most reevaluation. ${ }^{5}$ Curiosity in the travelogue was dismissed for its associations with imagination, fantasy, the fleeting and the ephemeral. The phenomenological style of relation familiar to the pre-modern travelogue, conveying the traveler's 'first impressions,' was derided as superficial and novel, construed as unaccountable or unreliable according to new standards of scientific accuracy for determining the worth of empirical evidence. In geographer John Pinkerton's introduction to his 1814 anthology of travel literature, he claims that travelogues written prior to 1768 are: rather to be regarded as curious, than useful... The old catalogues of pictures and statues, with trifling adventures by sea and land, which were called books of travels, have sunk into obscurity before the new and important works, which illustrate the phenomena of nature (Pinkerton 1814, XXVIII - XXIX).

Pinkerton's position was not, however, universally accepted, and curiosity was never abandoned or vacated entirely from travel literature. Rather, the aesthetics of curiosity were

\footnotetext{
${ }^{4}$ On the subject of instruction, Stafford points out that curiosity cabinets were in fact frequently used for demonstrative and educational purposes, giving the example of the deployment of dollhouses "as visual aids to help teach girls how to run an orderly home" (Stafford 2001,9).

${ }^{5}$ William H. Sherman (2002) notes how many travel writings, especially those by colonizers, explorers and scientists, have typically been either sponsored or authorized by the state since the Middle Ages, and that as such their accounts represented contributions to an 'official' or authoritative knowledge of foreign or distant lands.
} 
renegotiated within scientific discourse, and in addition either relocated or reclaimed at different sites of cultural production.

Within this context of negotiation, two opposing discourses concerning the role of curiosity emerge, each creating certain generic expectations and criteria for estimating the value of the artifact, collection, or narrative. The first discourse negatively associates curiosity either with a socially exclusive desire to possess rare and singular objects of antiquity, or with a vulgar popular or commercial interest in the exotic. ${ }^{6}$ The second discourse more positively associates curiosity with the attainment of knowledge and the processes of philosophical inquiry, with an aim towards articulating the singularity of the foreign or unfamiliar. The way in which the two discourses were kept mutually separate was by way of a semantic distinction (although as will be shown, this is a highly tenuous and fragile arrangement, prone to frequent collapse). 'Curiosity' was distinguished from 'wonder,' with 'curiosity' laid claim to by Enlightenment representatives of the rational sciences, who in turn relegated the term 'wonder' to describing the base experiences of gawking commoners and savage "natives."

'Curiosity' was reintegrated into a morally legitimized discourse of empirical methodology and research, dispatched in the service of an idea of progressive learning based on deduction. The key metaphor through which these values are articulated is one of vision, and so 'curiosity' became associated with diligent attentiveness, studious accuracy, and fastidious carefulness. To describe perception as 'curious' within this framework is to bestow

\footnotetext{
${ }^{6}$ Leask offers a description of the typical eighteenth century caricature of the elite antiquarian, hoarding a private collection of wonders: "A wealthy, licentious, yet impotent old man bent over an object of curiosity (often symbolized as a scantily-clad female bust of antique provenance), which he scrutinizes with the aid of a magnifying glass, the very negative of polite "distanced' viewing practiced in the period" (Leask 2002, 32). ${ }^{7}$ It was curiosity that separated the traveler from the 'native,' "who, although maybe possessing a sense of wonder, appeared incapable of curiosity" (Leask 2002, 27). John Hawkesworth makes a similar distinction in Account of the Voyages (1773): "Curiosity seems to be one of the few passions which distinguish men from brutes" (Hawkesworth 1773, vol. 1, 45).
} 
upon it a virtuosic quality, an ocular connoisseurship, implying a vision that is refined and disciplined. 'Curious' perspective is long-reaching and thorough in its penetration, yet restrained and disaffected enough to observe the boundaries of distance and 'polite taste' associated with classical aesthetics. Conversely, 'wonder' became associated with a sort of ocular incompetence, a "stupid gaze" (Dolan 2000, 155) that is superfluous, otiose, leisurely, and short in duration. In contrast to curiosity's embodiment of the ideal of sight, wonder was even described as being akin to 'blindness. ${ }^{, 8}$ Lord Kames, in Elements of Criticism (1762), outlines the prejudice against 'wonder' in Enlightenment culture:

The love of novelty ... prevails in children, in idle people, and in men of a weak mind.... Curiosity is a natural principle directed upon new and singular objects, in the contemplation of which its gratification consists, without leading to any end other than knowledge. The man therefore who prefers any thing merely because it is new, hath not this principle for his justification; nor indeed any good principle. Vanity is at the bottom, which easily prevails upon those who have no taste, to prefer things odd, rare, or singular.... The appetite for novelty... reigns chiefly among persons of a mean taste, who are ignorant of refined and elegant pleasures (Kames 1970, 333 - 334).

Whereas a 'curious' perspective, a compartmentalizing or catalogical gaze, facilitates accurate description and survey, 'wonder' seems to struggle with articulating itself, being too proximate, absorbed and unsystematic to explain the singularity of the object of desire. This is a characterization of wonder that actively denigrates the types of interaction and curious activity typical of the pre-modern museum, which Stafford more positively describes as intrinsically immersive spaces.

Presentation contexts like wunderkammers and cabinets of curiosity, according to Stafford, are spaces that invite 'entrance' into their imaginative space, encouraging associative activity and 'embedding' the spectator within a site that cannot be simply

\footnotetext{
${ }^{8}$ A popular 'exotic' spectacle or curiosity cabinet, for instance, might have been described as 'dazzling,' which is at once associated with an impressive astonishment or delight, and an overpowering or dimming of perceptual capabilities.
} 
comprehended with appeals to conventional linear logic. On account of the designed intensity and immersiveness of the experience, which is 'combinatorial,' rather than indexed, the wunderkammer and curiosity cabinet produce synaesthetic experience, offering mutlisensory affective charges and freely mixing the visual with the tactile. Whereas 'curiosity' privileges sight as the ideal instrument in the pursuit of truth or fact, it would appear that 'wonder' is not necessarily strictly a visual concept, but instead speaks more to ideas of emplacement. In the Enlightenment ideal of objective description, however, emplacement was typically subordinated to distance, or was thought to precede distance in the process of observation.

In some instances of the scientific writing of the period, curiosity and wonder are apparently reconciled in a rhetorical strategy that places them sequentially on an affective chain, effectively recuperating wonder into scientific methodology. Wonder was thought to precede and 'inflame' curiosity, catching the eye of the inquirer, whilst curiosity subsequently 'riveted' that attention in the service of more rigorous analysis. ${ }^{9}$ In other words, curiosity stabilized whatever unconscious desires or aspects of the irrational and the affective that lay beneath the veneer of 'objective' scientific interest, by locating these impulses within a Cartesian model of knowledge based on epistemic processes. Curiosity generally came to be conceived of as the corrective of 'vulgar' wonder, with the more traditionally pedagogic styles of knowledge that curiosity produced supplying the evidence for its superiority. Traveler Reginald Heber, in his 1813 review of E.D. Clarke's Travels - Greece, Egypt and the Holy Land, wrote:

We have still to complain of a reliance on first impressions, which is not altogether compensated by an acuteness of observation undoubtedly more

\footnotetext{
9 "Curiosity is implanted in human nature, for a purpose extremely beneficial, that of acquiring knowledge. New and strange objects, above all others, excite our curiosity; and its gratification is the emotion... known by the name of wonder" (Kames 1970, 320, original emphasis).
} 
than common...we have sometimes perceived a want of that previous

knowledge, without which, to travel is but to wander (Heber 1813, 162). ${ }^{10}$

Subjective response here becomes authorized insofar as it is preceded by knowledge, research and preparation that predetermine destination and itinerary, and is subsequently instrumentalized towards a rational end. Yet, the way that the meanings and definitions of 'curiosity' in this chain of affects seem absolutely to require the correlate of 'wonder' effectively construe it as curiosity's 'double. ${ }^{, 11}$ Their mutual interdependence might imply a deeply rooted uncertainty over the stability and permanence of perception, that vision might be more mutable and contingent than Cartesian science might allow. Simultaneously, it suggests the potential for curiosity to be overlapped or 'haunted' by wonder. ${ }^{12}$ Before detailing how curiosity and wonder were eventually reintegrated in scientific literature, it is worth introducing the ways in which the efforts described above at separating and managing curiosity and wonder are reflected in travelogues of the period.

\section{Romantic travelogues}

The changes wrought by the Enlightenment reform of knowledge were not specific to the scientific community, and travelogues in both literary and popular cultures responded to the developments by taking part in the formation of a counter-strategy. A Romantic ideology was actively being constructed by cultural and literary critics like Thomas De Quincey (1823), S.T. Coleridge (1817), and Charles Baudelaire (1846), and its attributes were being

\footnotetext{
${ }^{10}$ The distinction between traveling and wandering is an important one, and will inform later discussions of experience and space. Just as the wunderkammer's principles of organization foster a 'wandering gaze' of endlessly distracted and diverted perception, 'wandering' is also a principal mode of visual organization and observation in certain early films (Chapter Two) as well as in certain contemporary experimental travelogue films (Chapters Three and Four).

${ }^{11}$ They operate as 'doubles' in the sense of the word employed by Otto Rank (1971).

12 'Haunted' in the sense that Rank describes how the individual is 'haunted' by their doppelgänger.
} 
reworked and tested by various institutions of popular culture. ${ }^{13}$ The Romantic Movement was eager to reclaim wonder precisely because of its discredited status, as wonder was tied to a set of aesthetic signifiers situated oppositionally against the 'polite' neo-classical aesthetics the Enlightenment deemed appropriate. Not only did the Romantics reject the values and the aesthetics of the Enlightenment, but they also reclaimed and reinscribed as valuable the elements of wonder and emplacement that struggled to be accommodated within modern scientific practice. While the impulsive and irrational aspects of wonder compromised the epistemological prestige valued highly by the scientific cognoscenti and undermined efforts to rationally appropriate and instrumentalize the foreign and the distant, wonder's emphasis upon immersion, subjective impression and aesthetic 'transportation' only enhanced its literary value. De Quincey, discussing the inclusion of travelogues within the canon of High Romanticism, includes the proviso that to be excluded are "generally all books in which the matter to be communicated is paramount to the manner or form of its communication" (De Quincey 1897, 47). Much the opposite could be said of Enlightenment literature. So, to an extent, travel writing became characterized by a radical internal separation of rhetorical and aesthetic strategies.

\footnotetext{
${ }^{13}$ Leask notes that the centralization of Romanticism in popular culture coincided with the rise in mass readerships and literacy levels, which made its principles and priorities more generally accessible. "This process of cultural permeation was furthered by the institution of circulating and subscription libraries in the second half of the eighteenth century, which made expensive illustrated travel books in quarto or folio accessible to a wider public" (Leask 2002, 12). Moreover, Buzard observes that by the 1820s, Europe's global dominance had been sufficiently consolidated, and technologies and industries of travel expanded to a degree to accommodate the burgeoning of the commercial tourist market. "With the last fifteen years of this period $(1825-40)$ came the rise of the railways and a number of new businesses devoted to popularizing leisure travel, at first within Britain, but soon, inevitably, abroad as well" (Buzard 2002, 38). To primarily upper and upper-middle class tourists, 'distance' was no longer the tantamount obstacle and prize it had once been. Subsequently, subjective experience came to surpass objective study as the publicly favoured mode of 'new' experience. Objectivism was being emptied out of popular travel literature, which was also freighted with more commercially oriented generic expectations than its scientific cousin. This meant that popular travelogues were typically "evacuated of scientific or scholarly specificity, and increasingly came to privilege authorial 'egotism' and entertaining reflections, often motivated by pious, patriotic, and imperialistic ideologies" (Leask 2002, 7).
} 
To point out a dramatic example of this separation, Stephen Bann (1995) compares

Richard Pococke's account of the Sphinx from his 1743 travelogue A Description of the East

with A.W. Kinglake's 1844 description of the same object in Eothen:

I found by the quadrant that it is about 27 feet high, the neck and head only being above ground; the lower part of the neck, or the beginning of the breast is 33 feet wide, and it is 20 feet from the fore part of the neck to the back, and thence to the hole in the back it is 75 feet, the hole being 5 feet long, from which to the tail, if I mistake not, it is 30 feet long; which something exceeds Pliny's account, who says that it is 113 feet long (Pococke 1743, pg. 46).

Comely the creature is, but the comeliness is not of this world: the once worshipped beast is a deformity and a monster to this generation; and yet you can see that those lips, so thick and heavy, were fashioned according to some ancient mould of beauty (Kinglake 1920,181 ).

Bann observes that whereas Pococke's account “itemizes, in the literal sense of the word, and exposes the object to a relentless view" (Bann 1995, 102 - 103, original emphasis), Kinglake's version alludes to a 'hidden' aspect of the Sphinx, an indescribable and elusive mystery that surrounds the object like an aura. Kinglake directly aspires to the condition of poetry, relying on metaphor and impression as routes to a certain idea of 'truth,' contained within his subjective experience of being present before the object. Pococke's description, meanwhile, is notably void of any sign of the author's arousal, of his affective or emotional response to the object, and it makes no attempt at aesthetic evaluation, iconographic interpretation, or contextualization. Its concern is rather with interpreting classical antiquities (and rechecking classical descriptions) by way of close and careful measurement. Scientific disciplinarity necessitated the emptying out of literary aspects, to "evacuate the anecdotal...in order to establish a more objective epistemological authority" (Leask 2002, 6), but moreover, it also had to exclude any hint of the perceptual origins of knowledge, placing 'fact' in the tangible objective world. As Matthew Edney (1998) observes, "the representation of observed facts, of truth portrayed in various graphics and texts," by 
necessity "obscured the production of those representations" (Edney 1998, 79). ${ }^{14}$ There were, however, nostalgic sentiments circulating in literary culture by critics who bemoaned the way in which the separation of scientific and literary modes had thrown travel writing into what they thought was a state of disrepair. A reintegrated form of travelogue emerged, which by no coincidence also reinstated the figure of the author into the text, confirming the source and production of representation through renegotiated models of subjectivity and autobiography.

George Forster \& Alexander Von Humboldt

A nostalgic yearning for the 'literary' qualities of the pre-modern travel account was the expressed response of Romantic literary critics to the dominance in travel writing of the sort of dry objective description exemplified by Pococke. Leask singles out Coleridge among the champions of "the aesthetic achievement of those archaic, 'marvelous' travelogues" (Leask 2002, 9), although Coleridge's affiliation with literary Romanticism does not necessarily result in his prioritization of the 'subjective' over the 'objective.' Rather, "critical of the ostentatious egotism of popular travel writing, Coleridge singles out for praise the earlier combination of narrative drama and empirical curiosity" (Leask 2002, 9). For Coleridge, the omission of subjective response and personal narrative from the 'purely scientific' travelogue "left one with a geographical or statistical gazetteer, but not a travel book as such" (Leask 2002, 9). Conversely, the evacuation of empirical research and investigation from the popular travelogue hindered the presence of an element of discovery in the text. "The substitution of 'curious' description by authorial egotism also risked banalizing

\footnotetext{
${ }^{14}$ As Leask puts it, "'a plane projection of totalizing observations," was gradually winning out over the tour/story which had initially represented its condition of possibility" (Leask 2002, 7).
} 
the genre, offering sentiment, wit, or retro-irony in the place of the narrative project of representing the foreign" (Leask 2002, 9).

That there was an economy of gains and losses for proponents of either discourse was similarly recognized by Alexander Von Humboldt, whose 1849 work Cosmos lamented the "unity of composition" (Von Humboldt 1849, 68) lost from the 'integrated' travel narrative of the Middle Ages. While conceding that a purely empirical account has the advantage of the "increased value of the facts observed...in rendering natural descriptions clear and distinct," Von Humboldt laments the loss of the "wholly dramatic ... mixture of the marvelous which they so easily acquired, [and] gave them also somewhat of an epic coloring" (Von Humboldt 1849, 67). According to Leask, Cosmos struggles with the divorce of art and science prevalent in nineteenth century culture, acknowledging both "the deleterious effects of purging aesthetics from scientific discourse, and equally of relegating scientific content from literature" (Leask 2002, 6).

Leask uses the example of Von Humboldt to demonstrate that the separations of science and art, curiosity and wonder were not necessarily teleological. Prejudices at work and claims to superiority made in scientific, literary or popular cultures alike could not complete a total shift in the travelogue from objective to subjective emphasis, or vice versa. To figure the history of the travelogue genre in terms of a linear, forward-moving trajectory risks ignoring the continued balancing of the empirical and the poetic, the objective and the phenomenological throughout travel writing in the Romantic period and well into the twentieth century. The equilibrium between the two, however, is rarely easily sustainable, and the fragility of attempts in travel writing to synthesize utility and affect often point to evidence of shifting paradigms of knowledge and selfhood in Western culture at large. A growing awareness of the possibility of epistemic and ontological instabilities can be 
identified in the contributions to the genre made by George Forster and Alexander Von Humboldt, whose works reflect the growing cultural permeation of certain philosophical ideas that revised popular notions of experience and subjectivity.

George Forster's reformist and modernizing Voyage Round the World (1777), Leask claims, left a substantial mark upon travel writing to follow. Forster was hostile towards 'vulgar" popular forms of curiosity and dismissed the "frivolous observations, the uninteresting digressions, and sophistical principles" (Forster 1777, IX) of certain travelogues preceding his. However, Leask suggests that Forster's importance lies in his utter disregard for the generic convention "that the traveler be merely a collector of facts" (Leask 2002, 41). Against the Enlightenment values of 'pure' empiricism, Forster insisted on inserting himself within the diegesis and the rhetoric of the work's writing to produce a type of 'affective realism' that appeals to phenomenological models of experience:

Two travelers seldom saw the same object in the same manner, and each reported the fact differently, according to his sensations, and his peculiar mode of thinking... I have sometimes obeyed the powerful dictates of my heart, and given voice to my feelings...it was necessary for every reader to know the colour of the glass through which I looked (Forster 1777, XI XIII). ${ }^{15}$

Yet, rather than let this subjectivist stance 'spoil' the value of Forster's scientific investigations, he maintains that experience must be directed "in such a way that might indicate a disciplined programme for future research" (Leask 2002, 42). However much Forster introduces the destabilizing and unpredictable element of subjectivity, he also recuperates it into a systematic methodology. The wondrous 'first impressions' of the explorer remain discredited; Forster's autobiographical device places him within the text as a

\footnotetext{
${ }^{15}$ Forster's description of his subjective investment is noticeably based on a metaphor of vision, and uses an object that obstructs or impairs vision (a coloured looking glass) to refer to the 'dazzling' quality of wondrous forms of observation.
} 
proxy for the reader: a reasoning, regulated center of stability that reconfirms identity and assuages any anxieties that might be generated by the affects described. Forster's responses to phenomena, while acknowledged as subjectively circumstantial, still belong to a disciplined and experienced subjectivity that is able to objectively organize and articulate the singularities that have provoked it. "The aesthetic sensibility of the traveler must unify the manifold of sense experience which is his (or her) 'objective' task to describe... parading sensibility as the marker of a 'modern' Western self' (Leask 2002, 43, my emphasis). Forster's work was significantly influential within the genre and gave shape to further developments made by Alexander Von Humboldt, Forster's student and protégé. ${ }^{16}$

Von Humboldt's Journey to the Equinoctial Regions of the New Continent (1799 1804, published 1807) continues to strike the balance established by Forster's earlier work between empirical method and an explicitly subjective basis for curiosity and desire. Alain De Botton (2003) singles out Von Humboldt specifically as an important figure in Romanticism because Journey to the Equinoctial Regions represents an even more prominent centralizing of curiosity within the text. Von Humboldt's work is characterized by an omnivorous curiosity, taking on various disciplines and practices in a manner that recalls the voracious 'undisciplined' curiosity of the pre-modern travel relation. ${ }^{17}$ Against this tendency, however, is the obsessive fixation upon techniques of measurement that typifies Von Humboldt's writings and displays a practiced, patient, and disciplined sensibility. ${ }^{18}$ Yet,

\footnotetext{
${ }^{16}$ Leask traces the influence of Forster's incorporation of the traveler's sensibility into the text of Mary Wollstonecraft's A Short Residence in Sweden (1796): "I perceived that I could not give a just description of what I saw, but by relating the effect different objects had produced on my mind and feelings, whilst the impression was still fresh" (Wollstonecraft 1987, 62).

17 "The study of maps and the perusal of travel books aroused in me a secret fascination that was at times almost irresistible" (Von Humboldt, quoted in De Botton 2003, 104).

${ }^{18}$ Among many other varied achievements, Von Humboldt redrew the map of South America based on chronometer readings, and measured the effects on vegetation of air pressure and altitude (De Botton 2003, 105).
} 
beneath this instrumentalization of affective passion in the service of empirical observation, De Botton perceives an underlying uncertainty. Rather than introducing subjectivity as a way of reconfirming knowledge and stabilizing egotistical authority over what are taken to be officiated facts and realities, the prominence of subjective curiosity in Von Humboldt's work belies an impulse to try to rewrite accepted facts and received knowledge by testing them for one's self. Guiding Von Humboldt's curiosity for the minute and the trivial and inspiring the urgency of his investigations is a deeper and more pressing doubtfulness, an epistemological and ontological crisis that provokes a desire to test or experiment with perception and measure it against foreknowledge and awarenesses of change.

The works of Forster and Von Humboldt each have in common a requisite of demonstration that is crucial to their historical situation. While both authors enact a demonstration of self within the work, Von Humboldt goes further to perform a demonstration of understanding. According to Stafford, it was during this period in history that both knowledge and selfhood could no longer be taken for granted as a 'given' and now had to be continually and specifically demonstrated, performed and re-performed. ${ }^{19}$ Such performances of knowledge and selfhood were forced to mediate constantly between the limits of a finite and historically grounded imagination, and an increasing awareness of infinity and immensity, although not necessarily of a physical or geographical nature. ${ }^{20}$ The expansion of both physical and psychological borders, and its concomitant production of

\footnotetext{
${ }^{19}$ Stafford's comments on demonstration pertain specifically to the way forms like wunderkammers and cabinets of curiosity foster a 'relational perspective.' The observer is required to relate the available visible elements amongst themselves in an assembly of sense and meaning, rethinking and rearranging the parts as a way of navigating the space.

${ }^{20}$ While ongoing developments in transportation technologies as well as disciplines like cartography and astronomy continued to expand ideas of border and horizon, other areas of production like psychoanalysis, which expanded psychic space, were not far away. The notion that newer uncharted frontiers were opening up for exploration informs Baudelaire's definition of Romanticism: "To say the word Romanticism is to say modern art - that is, intimacy, spirituality, color, aspiration toward the infinite" (Baudelaire 1965, 47).
} 
anxieties over the state of the individual and over the validity of observed and recorded facts, are developments that occur at a specific juncture in the history of the travelogue. Forster and Von Humboldt's explorations and writings coincide with the emergence of discourses of philosophical empiricism and the sublime, which helped to redefine popular ideas of knowledge and of the self, respectively, and permeated ideas and uses of travel.

James Buzard (2002) notes how the theories of knowledge presented in John Locke's Essay Concerning Human Understanding (1690) had, by the time of the Enlightenment and the Romantics, reached widespread diffusion and general popular acceptance. Buzard claims that Locke's particular brand of philosophical empiricism significantly contributed to a culturally accepted sentiment that knowledge is drawn from, and only from, sensory impressions and experience. Understanding, enrichment, intelligence, character and wit were understood to be dependent upon personal history and action, rather than upon biological inheritance or class status. Travel becomes important within this philosophical model as a literalisation of the learning process and the development of self, which made the accumulation of 'experience' a desirable and valued commodity for tourists. By this time in history, the Renaissance 'Age of Discovery' could be fairly claimed to have run its course. Divorced to some degree from the responsibility to represent the nation or contribute to an officiated pool of knowledge, edification turns over to the individual explorer-cumempiricist, or, at least, those individuals with the wealth and resources to travel. Locke's ideas suggest that place and specificity of destination are ultimately irrelevant, because sense is equivocal and experience can be derived anywhere, thus making travel a conceptually abstract enterprise. Desire for travel, however, is not yet able to divorce itself from direction, and certain destinations as well as certain types of 'experience' become located within a hierarchy of value. 
To this effect, the writings of Edmund Burke on the sublime form an influential model for experience, as well as generating a repertoire of ideal locations for experiencing or witnessing it. Burke's A Philosophical Enquiry into the Origin of Our Ideas of the Sublime and the Beautiful (1757, published in 1759) was instrumental in challenging the dominance of rationalist aesthetics underlying classicism and neoclassicism and in popularizing notions of beauty based on sub-rational experience, affect and sensation. The Enlightenment school privileged a neo-classical aesthetic of proportion and symmetry, in which appreciation was intimately connected to an ocular domination of the object. It imagined an authoritative perspective that was able to comprehend the object in its totality through decisive observation. Burke's aesthetics, in contrast, were informed by the valuation of instinctual responses that could not necessarily recuperate beauty into intellectual procedure or judgement. The sublime, he proposed, is a framework of experience that mediates between often-commingled feelings of awe, desire or arousal, and discomfort, horror or frissons. This ambiguous bundle of affects is typically aroused in the presence of ruins, decay, defacements, 'roughness,' irregular lines, asymmetries, and other features of architecture, landscape and countryside that carry the potential to 'overwhelm' the subject. In Burke's model, sublime experience with Nature carries the potential to undermine the permanence of self by typically allowing only partial views of subjects that cannot be defined in their vast entirety, thus destabilizing the observer's relationship with the subject. Burke's model also suggests that 'man' has only a 'partial view' of Nature itself, as the ruins and decay that evoke the sublime provide evidence that Nature outlasts 'man,' countering the Enlightenment credo that 'man is the measure of all things.' Burke's ideas were influential in developing a model of interpreting place for travelers, inspiring a vocabulary of specific signifiers and attractive attributes, and contributing to the standardization of an itinerary of ideal locales to 
visit, although not necessarily for seeking out the sublime, but often its counterpart, the picturesque. As an explicitly aesthetic paradigm of experience, the picturesque, Buzard claims, marks the beginning of sightseeing as a historically specific mode of travel, thus anticipating the birth of mass tourism fast approaching.

\section{Tourism in the Romantic period}

Buzard identifies several historical factors that contribute to the popularization of picturesque sightseeing as a model of touristic practice in the Romantic period. Both the French Revolution (1789-1799) and the Napoleonic Wars (1790s to 1815) affected emergent tourist industries by effectively restricting access to Continental Europe, forcing travelers to remain inland. At the same time, road and railway systems were beginning a heterogeneous and haphazard process of expansion (roughly 1825 to 1840 ), making leisurely travel swifter and more economically viable for upper and upper-middle class tourists. While the roads and railways represented an unprecedented increase in the accessibility of travel technologies, political conflicts were guiding tourism inwards, meaning that prevailing cultural interests in the exotic, the primitive and the sublime were redirected towards domestic locations. Areas like the Scottish Highlands, and other areas of Celtic culture in Britain became preferential locations for sightseeing, where these aesthetics could easily be projected onto 'wild' natural features of landscape like mountains, waterfalls, rock formations and glaciers. One especially popular destination was England's Lake District, where tourists expected to be able to apperceive nature through the vocabulary established in Wordsworth's poetry, which Buzard 
identifies as a significant contributor to popular ideas of aesthetic experience. ${ }^{21}$ However, in touristic practices, 'wild' natural features that might produce sublime experience were typically framed and mediated in ways that 'tamed' their disruptive and de-subjectifying potentialities into the safe, commodified form of the picturesque. The invisible, intangible or indescribable qualities of landscape that sublime experience grapples with were manifested, secured and linguistically coded by devices and apparatuses for producing the picturesque. One such device was the 'Claude Glass. ${ }^{22}$

Apparently a standard instrument carried by tourists in search of the picturesque, Claude Glasses were a portable means of producing a Romantic 'sensibility' instantaneously. They were made of a darkly tinted convex glass that reflected the view behind the user's shoulder, framing the landscape through this act of reduction in size and recomposition, so that the user's view would come to resemble a typical Romantic painting. The glass tinting reduced the tonal range of the image to a near-monochrome while 'softening' the view, producing a 'painterly' approximation of the available landscape. The traveler's experience could then be matched against the aesthetic standards established by popular work like that of Claude Lorrain, after whom the device is named. The relationship these instruments have with the dynamics of the sublime is somewhat peculiar, for while they are designed to imitate an aesthetic of artwork that might be said to have been inspired by sublime experience, the device itself works to circumvent the effects of such experience on the tourist. While the expected result of their use is the inspiration of wonderment at the harmony, design and order of the natural world, Claude Glasses produce such a perspective by isolating, condensing and

\footnotetext{
${ }^{21}$ De Botton notes that during this period a plethora of new hotels were opened in the Lake District, offering tours of the sites referred to in Wordsworth's poems and in his travelogue Guide to the Lakes (1835) (De Botton 2003, 138). See also: Andrews (1989).

${ }^{22}$ See: Stafford (2001), esp. "Crystalline Machines," pg. 20 - 23. See also: Andrews (1989).
} 
encapsulating the vastness of landscape. The reflections they reveal produce an image of unity through recomposure, offering an omnipotent style of vision in which the totality of space and the mysteries of design are revealed. ${ }^{23}$ What this operation also does is render the physical landscape, from which the tourist is looking away, powerless to invoke the sorts of ontological intensities associated with encounters with the sublime. Instead, what the reflected images afford is a sort of aesthetic or moral satisfaction, as if "mellowing the environment's garish hues" (Stafford 2001, 23) were a corrective gesture, a making-over of the visible into the aesthetic, rather than the adoption of an aesthetic perspective which enlivens what is visible in the everyday. As a general principle, the objective of 'enlivening' the senses and the acquisition of a sensibility that is able to aestheticize the everyday is closer to the philosophy developed by the Romantics than to the popular touristic activities it inspired. A look at Wordsworth's work and his attitudes towards tourists and 'city-dwellers' will illuminate this distinction.

\section{Wordsworth and the principles of Romanticism}

According to De Botton, Wordsworth's chief poetic ambition was the induction of a mode of perception that observes the minutiae of the natural world that are typically overlooked or registered "only out of the corner of our eyes" (De Botton 2003, 150). Wordsworth's poems suggest inspirations of joy and visions of beauty to which the poet finds himself moved beyond reason to attempt to describe. Yet, their subject matter, while belonging to the Romantic terrain of 'Nature,' is frequently what could be called mundane, trivial, or 'everyday':

\footnotetext{
${ }^{23}$ "The convexity miniaturized the reflected landscape. Except in the foreground, details were largely lost, and something like a beau idéal emerged, freed from particularities and deformities" (Andrews 1989, 68).
} 
Look, five blue eggs are gleaming there!

Few visions have I seen more fair,

Nor many prospects of delight

More pleasing than that simple sight!

The Sparrow's Nest (1807) (Wordsworth 1987, pg. 93)

Wordsworth's certainty that beauty could be discovered in such "simple sights" is also demonstrated in his original preface to the Lyrical Ballads (1798), in which he alleged that "it is the honourable characteristic of Poetry that its materials are to be found in every subject which can interest the human mind" (Wordsworth 2006a, 193). According to De Botton, Wordsworth's notations of everyday occurrences are not merely frivolous or superficial expressions of curiosity, but are the expressions of a "well-developed philosophy of nature," one that proposed Nature as the "indispensable corrective to the psychological damage inflicted by life in the city" (De Botton 2003, 136). ${ }^{24}$ Wordsworth's poems served to counter "that most dreadful enemy to our pleasures, our own pre-established codes of decision" (Wordsworth 2006a, 193), and in particular, the habituated forms of perception learned by modern urban life. ${ }^{25}$ Although, as Ben Singer (1995) has noted, these habits were necessary protection against the array of shocks and stimuli assaulting the observer in the chaos of the new modern city, they also produced what Wordsworth thought was a restricted and superficial form of vision. This vision was prone to produce 'blind spots' in experience that

\footnotetext{
${ }^{24}$ De Botton points out that Wordsworth's basic assumption that place can have an impact upon perceptual capabilities is predicated upon the understanding that identities are "to a greater or lesser extent malleable; that we change according to whom - and sometimes what - we are with" (De Botton 2003, 147). Staging the adoption of alternative perspectives and demonstrating the unstable intransitive character of perception and identity are key characteristics of Romanticism, and are associated especially with sublime experience.

${ }^{25}$ In his later revisions of the preface to the Lyrical Ballads $(1800,1802)$, Wordsworth reasserts that "by the repetition and continuance of this act, our feelings will be connected with important subjects, till at length, if we be originally possessed of much sensibility, such habits of mind will be produced, that, by obeying blindly and mechanically the impulses of those habits, we shall describe objects, and utter sentiments, of a nature and in such connection with each other, that the understanding of the being to whom we address ourselves, if he be in a healthful state of association, must necessarily be in some degree enlightened, and his affections ameliorated" (Wordsworth 2006b, 410).
} 
overlooked the poetic qualities of everyday life, and could not, in Wordsworth's estimation, truly be satisfied. Only a return to the Natural world might restore inner tranquility:

...for she [Nature] can so inform

The mind that is within us, so impress

With quietness and beauty, and so feed

With lofty thoughts, that neither evil tongues,

Rash judgements, nor the sneers of selfish men,

Nor greetings where no kindness is, nor all

The dreary intercourse of daily life,

Shall e'er prevail against us...

...how oft,

In darkness, and amid the many shapes

Of joyless day-light; when the fretful stir

Unprofitable, and the fever of the world,

Have hung upon the beatings of my heart...

Lines written a few miles above Tintern Abbey (1798)

(Wordsworth 1998, 60-61)

Similarly, Coleridge claimed that the achievement of Wordsworth's poems had been to:

Give the charm of novelty to things of every day, and to excite a feeling analogous to the supernatural, by awakening the mind's attention from the lethargy of custom, and directing it to the loveliness and wonders of the world before us; an inexhaustible treasure, but for which, in consequence of the film of familiarity and selfish solicitude we have eyes, yet see not, ears that hear not, and hearts that neither feel nor understand (Coleridge 1817, 161).

Although initially ridiculed by critics and the public alike, Wordsworth's poems eventually garnered the cultural status of a manual for perceptual correction, teaching an art of curiosity and vision, and people began to visit the countryside to attempt a recovery of the receptivity to beauty lost in city life. ${ }^{26}$ In the second half of the eighteenth century, urbanites began to make organized tours and visits through the countryside seeking out the picturesque, and hoping that visions of Natural beauty would reinstate "health to their bodies and, more importantly, harmony to their souls" (De Botton 2003, 132). In Wordsworth's assessment,

\footnotetext{
26 "Harsh reviews of Poems, in Two Volumes (1807) and The Excursion (1814) paradoxically attested to Wordsworth's emerging centrality" (Longman 2006b, 385). See also: De Botton (2003).
} 
however, these tourists were inadequately equipped to truly achieve their restorative ambitions because their experiences with Nature were still governed by characteristically urban styles of perception.

"City-dwellers had no perspective," Wordsworth alleged, and "however well provided for, they had a relentless desire for new things" (De Botton 2003, 138). The problem lay in their searchings for the picturesque and for visions of poetic inspiration rooted in the logics of the visitation and the souvenir, which are ephemeral and disposable. As a result, tourists tended to experience Nature in the manner of an urban spectacle. ${ }^{27}$ Another problem was that tourists could not 'retain' a Romantic sensibility and perspective beyond the limits of their visitation, or 'fix' an image of Romantic beauty to take home with them as a reminder of the perspective that discovered it. Claude Glasses, for instance, reflect the landscape in the (presumably) desired manner, but they reflect without 'fixing' the image, without materializing the particular ephemeralities of light belonging to the passing moment onto a surface in the way that photography or the cinema would later be capable of doing. These problems highlight the confusion between the principles of Romanticism and the popular culture practices it inspired. Tourists were looking for poetry and inspiration lying dormant in Nature prior to their arrival, while Wordsworth's poems advocated a continual renewal of curiosity and vision in one's present surroundings, whatever they may have been. Although for Wordsworth and other Romantics, Nature is the ideal location for renewal, in

\footnotetext{
${ }^{27}$ This idea can be related to Siegfried Kracauer's (1926) suggestion that perceptual models for managing the city's incessant barrage of shocks and stimuli paradoxically create a lack of stimulus, spurring the bombarded city-dweller to seek out newer and more intense experiences. "Such a lack demands to be compensated, but this need can only be articulated in terms of the same surface sphere which imposed the lack in the first place" (Kracauer 1987, 93). Ben Singer (1995) notes that the relationship between forms of spectacle like the cinema and the barrage of modern urban life contained an inherent irony. While leisurely thrills and distractions offer some measure of escape "from the meaningless frenzy and tedium of alienated labour in the modern factory and bureaucratized office," at the same time, "the compensatory thrills of popular amusement reproduced the very register of hyperstimulus that vitiated modern experience to begin with" (Singer 1995, 93).
} 
the base philosophical reasoning of Romanticism location is ultimately irrelevant, and enlivening can happen anywhere. As Charles Baudelaire commented, "Romanticism is precisely situated neither in choice of subjects nor in exact truth, but in a mode of feeling" (Baudelaire 1965, 46). ${ }^{28}$ Nature was privileged, however, because a plethora of models for the aesthetic understanding of urban space had not yet developed. This period in history also marks the emergence of the urban as a relatively new kind of space, and as such the necessary strategies for enlightenment, spiritual edification, and aesthetic discovery were not yet established. Among these emerging strategies, of chief importance to Wordsworth were techniques of memory that could renew Romantic perception even after literal or physical travel and experience.

Memory, in Wordsworth's estimation, can serve as a spatial practice. One can be 'transported' by memory, or 'carried away' by it. Wordsworth took comfort in the survival of past impressions and feelings in his memory, and in the use of his own writings as renewals of those perceptions, which he termed 'spots of time':

There are in our existence spots of time, That with distinct pre-eminence retain A renovating Virtue, whence, depressed By false opinion and contentious thought, Or aught of heavier or more deadly weight, In trivial occupations, and the round Of ordinary intercourse, our minds Are nourished and invisibly repaired.

The Prelude, Book XII: Imagination and Taste, How Impaired and Restored (1798) (Wordsworth 1998, 216)

Though absent long, These forms of beauty have not been to me, As is a landscape to a blind man's eye:

But oft, in lonely rooms, and 'mid the din Of towns and cities, I have owed to them, In hours of weariness, sensations sweet...

\footnotetext{
${ }^{28}$ Baudelaire's distinction shows the influence of Locke's model of philosophical empiricism, and in particular its abstraction of space.
} 
With tranquil restoration.

(Lines written a few miles above Tintern Abbey) (1798)

(Wordsworth 1998, 57-58)

Memory can serve to recreate or revisit the conditions of perception, and ideally also reinstate that aesthetic perspective for the purposes of further observations in the present. Rather than require repeat visitations to a physical or geographic destination, as in the more touristic incarnations of Romanticism, the same "tranquil restoration" tourists sought out can be obtained simply by way of an imaginative exercise. In the late nineteenth and early twentieth centuries, however, the functions of memory outlined by Wordsworth become displaced onto the functions of the new medias of photography and cinema, which emerge as suitable repositories of past impressions. These media not only capture the singularity of the passing moment, but moreover allow for such moments to be continually revisited. Whereas Wordsworth's 'spots of time' served as an aid for remembering prior experience and travel, photography and the cinema represent means for enlivening perception and fostering an aesthetic sensibility without the necessity for literal or physical travel in the first place. Film producers and critics alike were not oblivious to this possibility and, as a result, the language of Romanticism infiltrated early film culture, providing a ready framework through which images of astonishment could be both created and experienced.

Aesthetics of curiosity in twentieth century film criticism

In anticipation of the discussion of early cinema that will follow in the next chapter, a concluding note can be offered about the persistence of discourses of curiosity and wonder for cultural criticism in the twentieth century. Not only are the discourses developed in the Romantic period significant for the ways in which emergent media like the cinema take 
shape, they are also important to the way it is received and understood. Louis Delluc is notable as an enthusiast of the purely 'artistic' travelogue, a film critic who transposed the vocabulary and aesthetics of the Romantic sensibility nearly wholesale onto his impressions of the cinema, and his projections about its future. In his 1917 article, "Beauty in the Cinema," Delluc describes his experience of witnessing the screening of a travelogue film with unabashed wonder and an utter lack of interest in whatever the particular film was called, or what it had to offer in the way of 'useful' knowledge. ${ }^{29}$ What is of importance is that this film:

is, in fact, astonishing. Who has not yet seen the passage of that military convoy of ships in stormy weather. It is beautiful. I have had occasion to see this film three times, in three different cinemas, with three kinds of audiences. The enthusiasm has been the same in all three. As well as the heavy sigh at the end, which came all too soon. There, that's beauty, real beauty -I I would say the beauty of chance, but the cameraman must be given his due. He has learned how to see with such skill that we have exactly the same experience of the sea, sky, and wind as he himself had. It is not just a film. It is natural truth (Delluc 1988, 138, original emphasis).

On the basis of his experience seeing this mysterious film, Delluc speaks of the cinema as promising "impressions of evanescent eternal beauty...impressions of grandeur, simplicity, and clarity which suddenly cause you to consider art useless" (Delluc 1988, 137). What can be made of this rejection of 'art,' something that seems antithetical to the Romantic valuation of the artistic as an alternative to the merely empirical? This screening, Delluc informs us, "gave me such extraordinary artistic pleasure that it seemed to have nothing at all to do with art" (Delluc 1988, 137). Delluc continues:

The cinema is rightly moving toward the suppression of art, which reveals something beyond art, that is, life itself. Otherwise, it would merely be a median term between stylization and transient reality.... Already much more than a reflection of this vibrant natural beauty has been revealed to us here and there (Delluc 1988, 137).

\footnotetext{
29 "I am not even speaking of the films; that would be criticism, and today I am not trying to pass for a critic, let alone a contented critic. I am satisfied, that's all, for I have seen beautiful things" (Delluc 1988, 138),
} 
While he differs from the Romantics in his use of the term 'art,' Delluc demonstrates here that he shares their consistent interest in making 'art' and 'life' inseparable. This travelogue film Delluc takes such pleasure in presents not merely a representation of beauty, but is beautiful in itself. Rather than indexing an absent or distant beauty (a 'reflection'), beauty is present in the presentation itself, recalling De Quincey's criteria for High Romantic literature.

Delluc's article excitedly speculates on cinema's potential to instruct in the art of perception and of the spiritual edification one might receive from it. In a passage directed at cinema owners and producers, Delluc pleads for more travelogues, citing their substance and likelihood for profitability - they are "significant in subject matter and intelligently exhibited...[they have] provided evidence of the public taste for these armchair voyages" (Delluc 1988, 137). However, Delluc makes this appeal not out of a desire for academic knowledge or pedagogic instruction, but rather as a means to try to satisfy his insatiable hunger for "the profound beauty of the passing moment" (Delluc 1988, 137) that these images provoke in him fleetingly. Luckily for Delluc, there was an abundance of such films to get excited about. 


\section{Chapter Two:}

Unseen Energies: The (Experimental) Travelogue in Early Cinema

Alongside its influence upon cultural criticism of the twentieth century, as was discussed at the end of the preceding chapter in the case of Louis Delluc, the aesthetics of Romanticism were likewise imbued in a plethora of film productions in early cinema. Romanticism's diffusive influence upon early films is partly explained by the pervasiveness of the travelogue film during this period $(1985-1906) .{ }^{1}$ As Charles Musser (1990) attests, travelogues were among the most popular genres in early film, and one of the most "developed forms of film practice in the pre-nickelodeon era" (Musser 1990, 123). ${ }^{2}$ By examining these travelogues' relationship with Romanticism, certain patterns in their construction of perspective, and in their treatment of time and space will emerge to illuminate the ways in which our key issues of vision and subjectivity come to be articulated and developed in the context of early cinema. This discussion will be supported with examples from several early films, and from the work of a school of historians that in the 1980 s began to critically reevaluate the practice of early cinema studies. ${ }^{3}$ To begin, it will be illuminating to look at how the 'New Historicist' critics' privileging of aesthetic factors enables a consideration of Romanticism's role in turn-of-the-century visual culture. Echoing Thomas De Quincey's (1813) criteria for Romanticism, Tom Gunning (1990a) claims that an immediately evident limitation upon previous cinematic genre studies is their "almost exclusive attention to the aspect of content in films rather than expression (of signifieds

\footnotetext{
${ }^{1}$ These are the dates given by Roberta Pearson (1996), with 1907 - 1913 representing cinema's subsequent 'transitional phase.'

${ }^{2}$ Musser also notes that travelogues comprised approximately half of the headline 'feature' attractions in Vitagraph's 1903 exhibition catalogue.

${ }^{3}$ As identified by Thomas Elsaesser (1990) and Bart Testa (1992) they are: Tom Gunning, Noël Burch, John L. Fell, Charles Musser, André Gaudreault, Thomas Elsaesser, Miriam Hansen, Robert C. Allen, Douglas Gomery, Russell Merritt and others.
} 
rather than signifiers)" (Gunning 1990a, 87). As I will argue, beyond representing a crucial influence, Romanticism served as an active vocabulary of signifiers in use by early

filmmakers. However, the processes of adapting the aesthetic codes of Romanticism to the logic of motion pictures was by no means confined to early cinema, and in anticipation of the shift to experimental cinema in the following chapter, we will conclude by expanding on the experimental status of some early films.

\section{Early cinema \& Romanticism}

New Historicism involves a materialist and archeological approach that devotes attention to the contingencies of production and the "social existence of film located in time" (Testa 1992, 32). These studies have frequently devoted attention to the various facets of nineteenth century popular or mass culture that coexisted with and may have in various respects given shape to emergent cinematic practices. ${ }^{4}$ According to critics like Noël Burch (1982) and Tom Gunning (1982), these popular arts represent a set of more prominent influences upon the early development and language of cinema than the bourgeois arts of painting, theatre and the novel. Earlier historians have cited these bourgeois forms as the prime determinants of early cinema's eventual transformation into 'classical' narrative style. ${ }^{5}$ Burch and Gunning each claim that these associations do little to accurately represent

\footnotetext{
${ }^{4}$ Gunning (1982) and Burch (1982) list comic strips, political cartoons, magic lantern slides, popular songs, vaudeville, melodrama, pantomime, conjuring, music hall, circus, caricatures, street entertainers, fairground acts and waxwork shows as being popular at the time.

${ }^{5}$ To prioritize the domineering influence of painting, theatre and the novel upon early filmmakers misleadingly posits the history of early cinema teleologically, by presenting a linear genealogy that situates cinema's industrialization and narrativization as either inevitable, natural, or necessary for its establishment as an 'art.' Testa points out that this so-called 'primitive' cinema is even typically considered 'pre-historical', in that a forceful distinction has been constructed between "the origins of cinema and the true historic genesis of film art" (Testa 1992, 23). Typically, this genesis is attributed to the narrativization of cinematic form developed by D.W. Griffith. New Historicist critics like Burch and Gunning seek to dispose of such myths, suggesting that the narrativization of cinema occurred not on account of the fulfillment of some inherent property of the medium or apparatus, but rather as a historically situated response to certain economic and cultural pressures.
} 
the cultural stake of early cinema, the constituency of its audiences, or its modes and contexts of presentation. ${ }^{6}$ Although difficult to simply identify as 'proletarian,' the emerging cinema was certainly more involved with turn-of-the-century culture at large than with the elitist and exclusionary practices of 'high culture. ${ }^{7}$ Despite its pervasiveness, Burch claims that:

the bourgeois ideology of representation...secured little purchase on the nascent cinema; one could even say that during this so-called Primitive period the cinema was largely immune to it and that one result of the immunity, and of the contradictions it entailed, was the development of something else (Burch 1990b, 7- 8).

What is the character of this 'something else'? The simple answer is that early cinema was not a mere imitation of preexisting genres and forms, whether they be 'bourgeois,' like painting, theatre or the novel, or 'proletarian,' like the lantern show or the boxing ring. Rather, early cinema transmuted and intertwined its influences and sources, forming a distinct, if perhaps volatile type of cinema of its own. The New Historicist critics attempt to describe the aesthetics, styles and modes of production apparent in early cinema on their own terms, and they remain sensitive to the ambiguous and often contradictory ways in which languages, genres and forms in the cinema have evolved and mutated. ${ }^{8}$ With this in mind, it becomes plausible to look at the ways in which the languages, genres and forms typically associated with 'high culture' were manifested within early cinema when placed alongside popular arts, and subsequently transformed by them.

\footnotetext{
6 "The picture postcard, political cartoons, non-bourgeois theatre, folktales, and other proletarian forms were the sources and the early filmmakers recast them into a distinct system of images that owed comparatively little to the serious bourgeois culture of the period" (Testa 1992, 55).

${ }^{7}$ Burch (1979) is critical of the idea of early cinema's 'working-class' character, which he perceives to be a largely mythical image. "Much of the otherness of the films of this era is patently overdetermined, often due to the contradiction between the aspirations - conscious and unconscious - of middle-class investors and entrepreneurs on the one hand and the influence of such plebian or otherwise 'alien' art forms as the circus, the carnival sideshow, the picture postcard, or the lantern show on the other" (Burch 1979, 77, original emphasis). While certainly bearing much influence from these forms, early cinema "cannot be said to be a literal or monolithic translation of any of these" (Burch 1986, 486). See also: Hansen (1983).
} 
Among the various sites of cultural production that constitute an influence upon early cinema, Romanticism functions for early cinema practitioners as an available aesthetic language and a semiotic and conceptual discourse, of equivalent relevance to vaudeville, amusement parks and the other popular art forms often cited by early cinema critics. Sites of turn-of-the-century cultural production like waxworks or melodramas are perfectly appropriate phenomena to examine for their correspondence with more anthropocentric types of early cinema practice that privilege the human element, like Edison's performanceoriented studio films, or the chase film. It is arguable, however, that Romanticism takes some precedence in being able to provide a template of discursive operations for films in which anthropocentric concerns play less of a structuring role. ${ }^{9}$ In other words, it is arguable that travelogues in early cinema were steeped, self-consciously or otherwise, in the languages Romanticism had provided to describe features of both natural and urban landscapes and phenomena. Although travelogues as we have defined them in the Romantic period depended heavily on rhetorical models of subjectivity and an idea of the witnessing presence of the author, in early cinema travelogues, these tendencies are typically displaced onto the figure of the lecturer, and not necessarily located in the celluloid counterpart. ${ }^{10}$

\footnotetext{
${ }^{8}$ For example, what Gunning (1982) calls early cinema's 'non-continuos style' and Burch (1990a) labels the Primitive Mode of Representation (PMR).

${ }^{9}$ This distinction also underscores the difference between the sort of travelogues addressed by this study and what are usually identified by critics as 'anthropological' or 'ethnographic' films, both in the realms of early cinema and experimental cinema (See Introduction).

${ }^{10}$ As Jeffrey Ruoff (2006) notes, the 'travel lecture film,' which involved the presentation of silent films accompanied by live narration by itinerant lecturers, was the archetypal form of the travelogue in early cinema. However, despite their popularity and ubiquity, relatively few of these films have survived or been archived. Musser also notes the historical invisibility of the travelogue, and admonishes early cinema critics preceding him for having "focused on the film as an object, not cinema as a practice" (Musser 1990, 123). In addition, the performance aspect of this type of presentation is ephemeral, and the remaining travelogues from the early period are mostly lacking in any semblance of what guiding presence their accompanying spoken narrations might have contributed, thus adding to their 'depersonalized' impression today. That this is a matter of identity is confirmed by how the few surviving manuscripts "indicate that these images could be made to carry rich and often disturbing meanings - assumptions about imperialism, racial and cultural superiority, sexism and Social Darwinism" (Musser 1990, 123).
} 
Imagistically, early film travelogues tend to favour the display of 'sights' rather than the onscreen presentation of the actions of traveler-protagonists. ${ }^{11}$ Early cinema travelogues were inclined to offer a plethora of views of city skylines, of urban street life, and especially of views enabled by technological conveyances; films shot from the perspectives of subway cars, trams, Ferris wheels, and the like. ${ }^{12}$ The depersonalized appearance of many of these films to the contemporary historian does not, however, prevent them from being enmeshed with Romanticism's ideas of the sublime and the picturesque, and their implications for subjectivity. In addition, the emergence of the cinema within the context of modernity was similarly imbricated with the discourses of curiosity and wonder of the Romantic period, and their implications for vision, experience and knowledge.

It may at first appear that Romanticism belongs to the set of 'bourgeois' cultural forms that critics like Burch and Gunning dismiss, on the basis of its associations with 'high art' practices (poetry, landscape painting). By the time of the emergence of cinema, however, Romanticism can be argued to be much more a part of the general cultural consciousness. The language of Romanticism had become thoroughly integrated into popular or mainstream culture, as had many of its key proponents and major works. ${ }^{13}$ The ideas of experience and knowledge associated with the sublime and the picturesque had pervaded the rhetoric of mass tourism and leisurely travel. Their aesthetic signifiers had

\footnotetext{
11 "Not only are there no stars in live travelogues, there are frequently no characters at all ... the emphasis is on actuality footage and scenics" (Ruoff 2006, 4). 'Scenics' was the colloquial term used by early film exhibitors to designate travelogues that emphasized landscape views (Gunning 1983, 365).

12 "Any reputable travelogue will feature as many modes of transportation as possible, not only in the image, but also, of course, as ways of representing movement. Adventure Along the U.S./Canadian Border includes POV shots taken from a train, hot air balloon, river boat, dog sled, wagon train, canoe, freighter, plane, and automobile" (Ruoff 2006, 8 - 9). Also significant within this trend are Hale's Tours, an attraction that simulated the experience of train travel. Among many other effects, these exhibits featured motion pictures traversing a selection of landscapes projected onto the carriage windows, and mechanically-simulated rocking and swaying movements to replicate the train's movement through space. See: Gunning (1983), esp. $362-$ 363, and Burch (1986), esp. 491.

${ }^{13}$ De Botton (2003) remarks on how Wordsworth's poems were frequently the subject of parody in nineteenth century popular culture.
} 
taken on a centralized role within the iconography of picture postcards, magic lantern shows and slideshow lectures depicting foreign lands and accounts of travels. As an example of Romanticism's generalized cultural diffusion, we might point to the film European Rest Cure (Edison Manufacturing Company, 1904), which parodies precisely the sort of 'restorative' journeys undertaken by tourists through picturesque locales described in the previous chapter. ${ }^{14}$ By staging its narrative action before obviously artificial trompe d'oeil painted backdrops and two-dimensional sets, the film offers a "burlesque of the romantic aura of travel" (Musser 1990, 126), thus undermining ideas of 'genuine' or authentic experience promised by touristic rhetoric. ${ }^{15}$ However, the film also incorporates footage from earlier 'actuality' travelogues, shot on location, which employ the language of Romanticism without cynicism and to a poetic effect. European Rest Cure includes shots taken from S.S. 'Coptic' Running Against a Storm (Edison Manufacturing Company, 1898), a film taken from the bow of a ship that aesthetically depicts the tumultuous waves of the sea using the language of the sublime. ${ }^{16}$ The immense waves vertiginously cast the tiny vessel up and down, and frisson is generated by how the waves are only partially visible when they intermittently bring the ship back down to sea level. These images go beyond representing experience, as the narrative portions of European Rest Cure do, towards producing experience in the manner idealized by the Romantics. The juxtaposition of these two sorts of images within European Rest Cure establishes that both stylistically and conceptually, early film culture recognized a crucial difference between commercialized, conventional or mundane touristic experience, and the enlivened, poetic perception of space

\footnotetext{
${ }^{14}$ See: Musser (1990), esp. $125-126$.

${ }^{15}$ Speaking of a similar technique in Waiting for Bill (Biograph, 1903), Gunning (1982) remarks: "One wonders whether the painted backdrop the actors stand before is intended as a representation (unconvincing) of a forest, or as a rather convincing representation of a vaudeville stage" (Gunning 1982, 221).

${ }^{16}$ European Rest Cure also includes footage from Sky Scrapers of New York City from the North River (Edison Manufacturing Company, 1903), which will be discussed in depth later in this chapter.
} 
and time advocated by figures like Wordsworth and Coleridge. ${ }^{17}$ Romanticism is taken up not merely as a set of aesthetic or stylistic signifiers, but as an active cultural discourse and site of debate, wedded to commercial enterprises and the dynamics of an exchange economy and commodity culture as much as to artistic modernism and elitist cultural practices.

Jonathan Crary (1990) observes how studies of the deployment of 'subjective vision,' especially in art history, have erroneously kept ideas of a Romantic type of vision separated from developments in popular culture at large. A major misconception lies, Crary attests, in considering subjectivism to be "somehow unique to artists and poets...distinct from a vision shaped by empiricist or positivist ideas and practices" (Crary 1990, 9). The observing subject formed by the rationalist aspects of modernity has been thought to be incompatible with the experimental modes of perception associated with counterEnlightenment culture and consequently, the types of experience and learning each represent have been considered mutually exclusive. Crary argues, however, that both 'artistic' and 'scientific' modes of perception are mutually dependent on and enabled by being "part of a single interlocking field of knowledge and practice" (Crary 1990, 9). They are equally enabled by a major epistemic shift happening in the culture of modernity, which is heralded by a wider and "immense reorganization of knowledge, languages, networks of spaces and communications, and subjectivity itself' (Crary 1990, 10). Physical space and time were being literally redeveloped through processes of urbanization, industrialism and imperial expansion. At the same time, vision was also reorganized, which had implications for the conceptualization of space, time, knowledge and experience. Vision was 'uprooted' by modernity and divorced from the ideas of stable and fixed spatiotemporal relations

\footnotetext{
${ }^{17}$ In this respect, European Rest Cure curiously anticipates the operations at work in an experimental film like Sifted Evidence (Patricia Gruben, 1982) (see Chapter Three).
} 
associated with Enlightenment positivism and forms like the camera obscura. Whereas these forms and institutions conceived of spatiotemporal relations in terms of an objective ground of visually confirmed truth, Crary claims that in modernity visual experience is just as often made mobile, "abstracted from any founding site or referent" (Crary 1990, 14), and frequently relocated into the body.

These dynamics inform Gunning's (1983) discussion of the trend in early cinema for films that exploit the camera's moveable tripod in a panoramic fashion qualitatively different from narrative filmmaking. Whereas films like The Great Train Robbery (Edison Manufacturing Company, 1903) deploy camera movement in the service of following narrative action by keeping characters within the borders of the frame, in other films camera movement functions primarily as a "display of the camera's ability to mobilize and explore space" (Gunning 1983, 362). As noted above, early cinema is populated with films in which the camera is moved by a technological conveyance. Films taken from aerial balloons, gondolas or elevators, for instance, counter the 'grounded' perspective of the camera obscura by literally taking vision up off the ground. ${ }^{18}$ Films such as these do not merely represent the mobilization of vision, but rather produce a mobile form of vision. In this respect, they fulfill the 'memory function' Wordsworth had assigned to his poetry, offering either a means of revisiting a past mode of perception or of inducting that mode in a new viewer. "The experience to be reconstituted in these films is the thrill of motion and its transformation of space. Although a large part of their appeal was clearly as a cheap form of vicarious tourism for the masses, the experience was also uniquely cinematic" (Gunning $1983,363)$. Beyond their commodity function, these films presented, to paraphrase Alain-

\footnotetext{
18 "Film historian Charles Musser has found a lecture from 1901 which accompanied a showing of a film of a tilt up the Electric Tower at the Pan American Exposition... which explains the camera movement as the rising and descending of a balloon" (Gunning 1983,363).
} 
Alcide Sudre, a world of sense and enjoyment that might have contributed to emerging perceptual models for experiencing modern urban space. Moreover, that Gunning would associate the uprooted and abstracted forms of vision and space with the thrill is significant in light of how these films enact a reorganization of subjectivity.

As normative ideas of vision in turn-of-the-century culture were renegotiated beyond the geometric and objective principles established by forms like the camera obscura, subjective vision became an increasingly important area of study within the empirical sciences with an emphasis upon the physiological capacities of the body. Interest grew in the 'idiosyncrasies' of human vision. In scientific as well as in popular culture, phenomena like retinal afterimages, peripheral vision and binocular vision were demonstrated and exploited in forms like stereoscopes and panoramas. While these practices empirically validated 'anomalies' of perception that did not figure within objectivist models of visuality, they also worked towards managing and defining normality by formalizing and determining the quantifiable parameters and capacities of vision. The limits and thresholds of vision were sought out, and investigations were made as to how attention might be procured, sustained, broken or shocked. Techniques for managing attention were developed - what Crary calls a set of "anti-nomadic procedures" (Crary 1990, 18) - in which shocks or distortions do not so much represent a 'break' from attention, but rather form a part of its structure and its continual production of the 'new.' These experiments with perception had an impact upon the emergent cinema and its arrangement and regulation of vision, as well as upon the way in which early cinema was later historicized.

Gunning (1989) examines the tenacity of the film history myths surrounding the initial popular reception of the cinema and deconstructs the standard account given of the 'first' exhibition of the cinématographe by the Lumières at the Grand Café in Paris in 1895. 
The well-known anecdote purports that audiences were supposedly roused to flee the venue by the sight of the onrushing train in L'arriveé d'un train à la gare du Ciotat. Gunning argues that this myth depicts early film audiences as panicked, hysterical, naive, and defenseless, without the necessary models of experience through which to understand the spectacle of the moving image presented to them. The experiences of early film audiences are described almost precisely in the same terms used to designate 'wonder' in the Enlightenment, as the obtainment of 'sense' rather than 'knowledge.' Film reception is historicized as a passage towards knowledge in the same way that 'curious' perception was semantically associated with the maturation and disciplining of vision:

The absolute novelty of the moving image therefore reduced them to a state usually attributed to savages in their primal encounter with the advanced technology of Western colonialists, howling and fleeing in impotent terror before the power of the machine (Gunning 1989, 31 - 32).

By positing the turn-of-the-century spectator as experiencing cinema before understanding, without distanciation or reserve, the experience is depicted in entirely physical or affective terms, as reflex, or even as a sort of temporary psychosis. In debunking this myth, what Gunning does is less defend or reclaim debased 'wonder,' but rather relocate early cinema audiences and legitimize their response to films within the discourse of 'curiosity.'

Gunning asserts that the emergence of cinema was far from unprecedented, and that it occurred within a related set of developments and traditions in visual entertainment in which the image's appearance of reality was not received with total credulity, but rather enjoyed and valued for its ability to produce an uncanny spectacle. That such spectacles frequently referred to the image's verisimilitude by 'breaking' frame space and suggesting that the worlds of the image and of the observer might collide in no way negates the likelihood that the observer always kept "a conscious focus on the fact that they were only 
illusions" (Gunning 1989, 34). Early cinema audiences were not "primarily gullible country bumpkins, but sophisticated urban pleasure seekers" (Gunning 1989, 33), already 'prepared' for the cinematic experience by their familiarity with visual culture at large at the turn of the century and by the proliferation of similar spectacles. These audiences, Gunning observes, also would have been prepared for the structure and logic of cinematic thrills by the introductory remarks of barkers, lecturers and showmen. ${ }^{19}$ Early cinema audiences can be considered connoisseurs of such shocking spectacles, and were experienced in the codes of presentation and display and versed in the protocols of reception and behaviour. This is to say that if indeed audiences at the Grand Café did run in 'fear' from the sight of the oncoming train, it was likely because they were engaging with the presentation as one who screams on a rollercoaster ride would do. Whereas in the Romantic period, 'wonder' was thought to be unaware of itself, uncritical and entirely credulous, "the cinema of attractions solicits a highly conscious awareness of the film image engaging the viewer's curiosity... aware of the act of looking, the excitement of curiosity and its fulfillment" (Gunning 1989, 36).

Gunning's article locates the beginnings of the cinematic observer within an array of cultural phenomena that had already been involved in the production of a 'modern' consciousness. Gunning portrays the audiences at the Grand Café as observers equipped with the critical and visual skills valued by the Enlightenment. Just as the Enlightenment scientist maintained his distance from the intoxications of the 'primitive' cultures he visited, early cinema audiences are presumed to have been protected from the fantastical content

\footnotetext{
${ }^{19}$ These guiding presences may have taken the form of a 'live' film exhibitor present at the screening, or, as is the case in certain Meliès films, in the form of an on-screen showman.
} 
conjured before them. ${ }^{20}$ Yet, at the same time, the social purposes and functions of early cinema went far beyond empirical investigation into the reproduction of reality or the observation of movement, just as film spectatorship went beyond the acquisition of 'knowledge' in the strict Enlightenment sense. The way in which early cinematic exhibition was structured and styled according to the logic of the thrill, in the interest of producing an affective response, suggests that the destabilization of knowledge and the self were established and expected features of the presentation.

Whereas the Enlightenment discourse of curiosity could be considered to repress or defer any possibility of crises or instabilities about knowledge and being, in early cinema's arrangement of the observer such epistemological and ontological shocks form the very basis of the thrill. The cinematic experience here represents "a moment of crisis, prepared for and delayed" (Gunning 1989, 36), a system of shocks that is contained and regulated by the conventions of display and presentation. Operations like the breaking of frame space in $L$ 'arriveé d'un train produce an anticipated and desired commingling of pleasure and anxiety. ${ }^{21}$ In contrast to the teleological structure of Enlightenment curiosity, where observation is figured in terms of a linear progression towards pedagogic knowledge, the thrill, in a more non-functional, non-instrumental fashion, creates 'sense.' Rehearsing a contingent set of relations between the body and 'the world,' the thrill creates knowledge in the observer of the limitations of their ability to receive both pleasure and anxiety, in intensity or duration, as a body and as a psyche. The thrill constructs identity and gives the observer meaning as a subject, despite ostensibly unsettling identity and subjectivity. By

\footnotetext{
${ }^{20}$ 'Méliès' theatre is inconceivable without a widespread decline in belief in the marvelous, providing a fundamental rationalist context. The magic theatre laboured to make visual that which is was impossible to believe" (Gunning 1989, 33).

21 "The vertiginous experience of the frailty of our knowledge of the world before the power of visual illusion produced that mixture of pleasure and anxiety which the purveyors of popular art had labeled 'sensations' and "thrills"' (Gunning 1989, 37).
} 
'shocking' identity, exposing its limitations and sending it into crisis, the thrill also subsequently redraws identity, eventually building the subject's resilience to being shocked. These dynamics, however, are not universal to all early films. While certain pictorial codes circulating in early cinema sometimes work towards the production of shocks, there are also instances where vision is organized to produce a sense of security, stability and mastery over space and time, both on and off screen.

\section{Staging Perspective}

Burch considers film history as a history of the construction of perspective and makes the claim that early cinema was a site of negotiations between different pictorial codes for representing vision. ${ }^{22}$ Early cinema was a contested site, wherein the representational system for staging perspective was accumulated from and negotiated among "intersecting tensions and collisions" (Testa 1992, 48) between different pictorial codes, some of which systematize representations of space/time relations in radically incongruent ways. Jean-Louis Comolli (1971) proposed that cinema inherited from the Renaissance strict principles of constructing perspective known as the Quattrocento system, and while Burch acknowledges that this influence is certainly historically evident in many cases, it is also not the sole method in circulation either. ${ }^{23}$ Burch rejects the notion that cinema was either predisposed to arise from Renaissance codes of pictorial representation, or that "cinema is enfolded by these codes from its very start" (Testa 1992, 48). In addition to the "dominant cultural master-code" (Testa 1992,48) of the Quattrocento system, early films comprised sometimes contradictory codes circulating around turn-of-the-century

\footnotetext{
${ }^{22}$ See also: Testa (1992).

${ }^{23}$ See: Comolli (1990), esp.pg. 215.
} 
culture. Yet, far from being disorganized, these heterogeneous instances of staging

perspective were more constellatory, operating in groups and trends.

In developing this idea, Bart Testa (1992) makes the claim that there are two key styles of perspectival organization apparent in early cinema - the centripetal and the centrifugal - and that these meta-categories characterize the way in which certain groupings of pictorial codes manage attention differently. ${ }^{24}$ By trying to separate as distinctly as possible the groupings of these pictorial codes into two visible camps, Testa imagines a division between the studio films produced by the Edison Manufacturing Company, and the actualities of the Lumière Company films, with each representing a typical embodiment of each respective style. ${ }^{25}$ The Edison films are those that can be called the centripetal, which work towards constructing perspective around a center of interest, "privileging selected elements of the message material and constructing a hierarchy among the plurality of possible meanings" (Stoneman 1981, 52). The Lumière films, in contrast, are identified as centrifugal, constructing a more fragmentary perspective that keeps attention in a consistent state of emergency through their potential to offer a "polycentric plentitude that is essentially dispersive in its compositional dynamic" (Testa 1992, 88).

Testa points to certain Edison films, like Sandow, the Strong Man (1894) and Annabelle Butterfly Dance (1894), as examples of a centripetal tendency in early cinema, in

\footnotetext{
${ }^{24}$ See also: Stoneman (1981).

${ }^{25}$ It should be noted that Testa is careful not to posit these two sets of films as forming a dichotomy. Pictorial codes in early cinema frequently intermingle amongst themselves and between 'camps' of filmmaking, which are themselves permeable and temporary categories. The point of using the Edison and Lumière films is not necessarily to construct oppositions between shooting in the studio and shooting on-location, actors and pedestrians, staging performance and observing the unfolding of reality. Even the catalogues of either company do not display any such neat division: certain Lumière films were staged with actors, just as certain Edison films were actualities of daily street life. It is not uncommon to find in early cinema films that freely combine pictorial codes that contribute towards the construction of a centripetal perspective, alongside those that support a centrifugal perspective within the same text. The usefulness of using Edison and Lumière as totems lies in their applicability as exemplars of the ways in which certain arrangements of pictorial codes did once congeal within a specific historical and technological context.
} 
which the arrangement of pictorial codes draws attention 'inwards,' toward a center or axis, not unlike the cross-section of a tree trunk. Given that Burch maintains that such groupings of pictorial codes can incorporate ideas from sometimes culturally contradictory discourses, the Edison films display a confluence of perspectives belonging to scientism and humanism. By using a selection of pictorial codes that privilege what is typically a human subject placed in mid-frame, the Edison films create an aesthetic environment in which human locomotion is made most clearly apperceivable to the observer, recalling positivistic ideas of the image as readable evidence. In these films, a distinct figure-ground relationship is established by the use of high-contrast lighting, the characteristic 'plain' black backdrop, a traditionally 'theatrical' maintenance of distance between camera and subject, and a theatrical organization of foreground action across the horizontal plane. At the same time, these pictorial codes also foster the projection of "anthropocentric constructions" (Stoneman 1981, 54) onto the image. Performance codes present in the Edison films like direct address, frontal display, and a containment of action within choreographic structures support an interpretation of what is perceivable in humanistic terms. It is additionally significant that some of these films featured performances by popular public figures and celebrities, as it might be said that the centripetal image constructs perspective along lines of familiarity. The cultural security of the centripetal image is intimately tied to the ways in which the arrangement of pictorial codes conspires in the image to manage and sustain attention towards certain privileged elements, creating an idea of intimacy and stability between spectator and image.

Conversely, in certain Lumière films, like La sortie d'usine (1895) and New York, Broadway et Union Square (1896), the arrangement of pictorial codes disperses attention across the surface of the image, constructing a centrifugal perspective that is not grounded 
by a center of interest, but rather is left to wander. ${ }^{26}$ Many of the pictorial codes that contribute to the production of this type of perspective are specifically tied to the context of filming 'actuality.' Shooting outdoors in available light conditions often has the incumbent effect of producing a low-contrast ratio of lights and darks in the image, resulting in less visual hierarchy among the visible elements. Undirected pedestrians traverse freely from the extreme foreground to the very limits of the camera's depth-of-field making the distance between camera and subject come under continual renegotiation. In contrast to the theatrical style of control over action in the centripetal image, it is typical for figures in the Lumière films to spontaneously enter and exit the frame from various points across multiple planes. The centrifugal image thus becomes characterized by accident, by departure and arrival, the sustained unpredictability of which fosters a 'panoramic' reading strategy which Burch calls the 'free-floating scan.' This difficulty in capturing the activity in a Lumière film in any totalizing sense has the effect, as Testa puts it, of making them 'less readable." "The image in La sortie d'usine does not, any more than the street scenes and other 'general views' which followed, offer a spontaneous key to a reading enabling one to itemize the complex content, especially after a single viewing" (Burch 1990b, 16). Also important to this resistance to instrumentality is the way in which the Lumière films display what might be called mass activity, rather than directing attention towards the movement of a singularized subject. Within this context, pictorial codes like direct address become less about ideas of intimacy and familiarity than about novelty, and possibly even hostility, directed towards

\footnotetext{
${ }^{26}$ Although Burch and Testa are attempting to suggest that the image in a Lumière film either does not have a clear center of interest, or is composed of many multiple competing centers, this term suggests movement directed 'outwards' or away from a center, presupposing the existence of a singular point of reference to deviate from.

${ }^{27}$ The role played by the lecturer in early cinema is significant in this respect, weaving an idea of narrative or continuity across and within the films that recuperates the potential unreadability of that which occurs in simultaneity by translating it into a linear, successive form.
} 
the apparatus. This is a type of image that can produce a potentially unsettling effect. The pictorial codes that contribute to a polycentric construction of perspective conspire with the tendency to display that which is in a sense uncontainable within the frame, creating an environment in which shock and instability can form the basis of the relationship between spectator and image.

Testa's discussion of the centripetal image invokes an intertwined set of ideas concerning centering, fixing, locating and cohering identity and subjectivity through the ways in which space and time in the cinema are similarly stabilized and secured. ${ }^{28}$ The Edison films construct the space of the film image as a conceptually self-contained unit by literally locating aesthetically all of the supposedly 'relevant' visual information concisely within the borders of the frame. Even when figures do enter and exit the frame, these arrivals and departures are safely located within the pictorial codes of theatrical staging. The potentially threatening inability to know and apperceive offscreen space becomes assuaged by its imaginary annexation by onscreen space. Offscreen space becomes merely 'stage left' or 'stage right,' incorporated into the theatrical body and figured as an ancillary space of performance. By contrast, the presentation of action within the frame in the Lumière films consistently refers to the space beyond its borders, aesthetically abandoning relevance to what might be crudely labeled as 'chance operations.' The centrifugal image is incapable of conceptually territorializing offscreen space, at once suggesting an impulse to photograph as much as possible, as well as the inherent limitation of perspective that the frame imposes in its inability to summarize the vast totality of place. However, Testa, Burch and Gunning

\footnotetext{
${ }^{28}$ Stoneman (1981) makes a similar claim in noting that devices like eyeline cuts, the $180^{\circ}$ rule, and the codification of entrances and exists from the frame work towards "the naturalization of (a) social reality. Systems of continuity efface the processes of selection and construction and effect a comprehensive orientation in diegetic time and space" (Stoneman 1981, 53). See also: Burch $(1988,1990 \mathrm{a})$.
} 
also identify a trend in the centripetal image that consistently undermines its totalizing ambitions. The implication is that, in the words of W.B. Yeats, "the centre will not hold," (Yeats 1963,210$)$ and that the devices for stabilizing perspective, identity, control or power cannot recuperate the threat of potentially infinite space and time increasingly imposing itself upon cultural awareness. ${ }^{29}$ Or, overwhelmed by sense and affect, these systems inadvertently malfunction and produce their own excesses and 'blind spots.'

Stephen Heath (1981) invokes this line of argument in detailing the ways in which both photography and the cinema inherited principles of visual organization from the Quattrocento, the mode of 'central projection' introduced and developed in Italy in the $15^{\text {th }}$ century. ${ }^{30}$ The Quattrocento system involves the rectilinear organization of represented three-dimensional elements upon a plane surface in such a manner as to construct the 'eye' as the central point of perspective. ${ }^{31}$ Heath alludes to the way in which this system also centralizes the eye in an ideological sense by positing it as that which stabilizes and organizes space centripetally. Not only is the eye that which is 'in place,' thereby making the view (and, by extension, the space it creates) "framed, centred, harmonious" (Heath $1981,28)$, but it is also that which ideologically normalizes the spatial dynamics this type of representation constructs. Perspective, in the Quattrocento system, takes place "at a definite distance with definite lights and a definite position of centre in space and a definite place in respect to the observer" (Heath 1981,28). This is a type of vision that is congruent with the principles of what would later be identified as the Cartesian epistemology of the Enlightenment: "eye and knowledge come together; subject, object and the distance of the

\footnotetext{
${ }^{29}$ This is a line from Yeats' poem "The Second Coming" (1919).

${ }^{30}$ Although it has been effectively argued that early cinema is indebted more to things like vaudeville, magic theatre and stage melodrama than classical art forms, Heath notes how these 'low' cultural areas still relied on the basic fundamental principles of constructing perspective inherited from classical art.

${ }^{31}$ Heath also notes how the development of the Quattrocento system was inseparable from the introduction and standardization of the frame to painting.
} 
steady observation that allows one to master the other" (Heath 1981, 30). The fixity of spatial relations purported by this system of visual organization thus also extends outwards to thinking about and organizing 'real' space:

In the fifteenth century, the human societies of Western Europe organized, in the material and intellectual sense of the term, a space completely different from that of the preceding generations; with their technical superiority, they progressively imposed that space over the planet (Francastel 1970, quoted in Heath 1981, 29).

The imperialistic associations made here are not absolutely tied to this system of visual representation; however, it is plausible that an imperialistic order might make use of such a system as a way of continuing to 'fix' certain imaginative models of space. In the late $19^{\text {th }}$ century, the imperialistic forces of modernity were manifested in cultural phenomena like World's Fairs, international exhibitions, botanical and zoological gardens, and other amusements designated with the surreptitious purpose of mastering, ordering, demarcating, and indeed, framing 'real' space. ${ }^{32}$ Just as the Quattrocento system visually constructs a "scenographic space, space set out as spectacle for the eye" (Heath 1981, 31), so there is a sense in which reproductive technologies arrange the 'rest of the world' as spectacle for the Western observer, "a suggestion of the world as a kind of sum total of possible photographs" (Heath 1981, 32). The notion that the cinema might be complicit in such processes is difficult to validate directly; early cinema was not nearly as involved with operations of the state as these 'authorized' entertainments, yet it often shows signs of taking up partisan rhetoric. ${ }^{33}$ Heath, however, notes that almost invariably and inevitably,

\footnotetext{
${ }^{32}$ See also: Costa (2006).

${ }^{33}$ Helen Carr (2002) notes that while much travel writing of the nineteenth and early twentieth centuries is complicit with larger cultural process of imperialism and modern progress, it is also frequently the site where complex and ambivalent sentiments about imperialism and progress are enunciated. Modernization and the invention of the urban space (and, of course, the urbanite) was not a period of unilateral consensus. Carr claims that the process of imperialism was in itself haphazard and fragmented, and that even in what are allegedly partisan texts there still exists room for anxieties, uncertainties, dissent, and "profound doubts about the continuation of Western progress, indeed doubts about the possibility of progress at all" (Carr 2002, 73).
} 
the Quattrocento perspectival system comes with its own deviancies and distortions, a group of tendencies that might be tentatively identified as anamorphic. ${ }^{34}$

Far from being monolithic in its totalizing ambitions, Heath argues that the Quattrocento system allows for a variety of 'accommodations.' In cinema in particular, Heath observes, imagistic properties like angle and distance undergo continual change, causing the 'centre' of the image to undergo continual disruption and renegotiation. Anamorphosis in this sense can be readily detected in Interior New York Subway, $14^{\text {th }}$ Street to $42^{\text {nd }}$ Street (Biograph, 1905), a film taken from the front of an underground subway car. Ostensibly, this film secures a centripetal anchor of attention by following the movements on the same length of track of a second train, which generally stays in the in centre of the frame. However, a centripetal perspective is continually unhinged as the position of second train undergoes a number of minor variations. The underground track sometimes curves, and the trains often alternately speed up or slow down when approaching or leaving platforms. ${ }^{35}$ These factors cause the second train to variate in size and depth on the picture plane, as well as wander back and forth from the centre to the peripheries of the frame. ${ }^{36}$ According to Heath, the presentation of movement can at once stabilize the eye onto a centre of attention, and simultaneously 'pull' it away towards the edges, to what is uncontainable, and to the indeterminate or unknown spaces both inside and outside the borders of the frame. Interior New York Subway embodies these contradictory dynamics in the way that the camera's

\footnotetext{
${ }^{34}$ Anamorphosis, strictly speaking, relates to a specific historical set of practices involving the use of curved mirrors and glass to skew the proportions of perspectival images, but it is being used here to refer more generally to perversions and deformations of linear perspective. See Stafford (2001), esp. "Crystalline Machines," pg. 28-29, for further discussion of the implications of anamorphosis.

${ }^{35}$ Although the film appears to be a single, continuous shot, cameraman Billy Bitzer apparently paused the camera for platform stops in order to shorten the film (Simmon 2000, 97).

${ }^{36}$ Moreover, attention is also competed for by the visual syncopation provided by the pillars in the tunnel, and by the intermittent visibility of a third train running on the parallel track carrying equipment to light the tunnel for filming purposes.
} 
near-constant forward movement continually produces and simultaneously 'swallows up' space. ${ }^{37}$ The cinema's introduction of 'life' into the image, as Heath puts it, always makes the 'mobility' in cinema 'difficult.'

Anamorphosis is often used as a means to subvert, parody, question or undermine the basic cognitive assumptions underpinning systematic, linear perspective and, by turn, the conceptual models of 'real' space that they work for. Such deviations of perspective expose "the ideal of a steady position, of a unique embracing centre... [as] precisely that: a powerful ideal" (Heath 1981, 29). Yet, they are also always bound back to ideas of centre. ${ }^{38}$ Just as anamorphic lenses inevitably constitute themselves as variations of 'normal' perspective, exploitations of anamorphosis of the sort Heath refers to typically function as "a kind of playful liberation from its constraints that remains nevertheless entirely dependent on its system, a ceaseless confirmation of the importance of centre and position" (Heath 1981, 29). In a related vein, Crary describes the processes of modernization as a continual oscillation between deterritorialization and reterritorialization. ${ }^{39}$ The loosening or uprooting of vision, social structures and practices characteristic of modernity's production of mobility, Crary asserts, is always countered by the subsequent or simultaneous formation and consolidation of new hierarchies, hegemonies and institutionalizations. Just as properties are abstracted or made 'democratic,' and just as bodies and vision become 'mobile' and divorced from centralized arrangements, they are transformed into commodities, assigned a use-value, and subjected to more dispersed and heterogeneous mechanisms of power. Historical and ritual

\footnotetext{
${ }^{37}$ A critic for the New York Mail and Express described a similar film of a camera moving through the Haverstraw Tunnel as an "unseen energy [that] swallows up space and flings itself into the distances" (Niver 1971, 28).

${ }^{38}$ Similar things have been said about the position of experimental filmmaking vis-à-vis mainstream or culturally dominant film practices. See: Sitney (1979). These arguments echo Crary's contentions that far from being radically separate, oppositional practices are always enabled by the same knowledge and assumptions that make their shadow a possibility to begin with.

${ }^{39}$ Crary employs these terms in the sense that Deleuze and Guattari utilize them in Anti-Oedipus (1977).
} 
forms of regulation are replaced by scientific and disciplinary ones, which continue to exert policies determining the formation of the subject:

As individuals became increasingly torn away from older regimes of power, from agrarian and artisanal production, and from large familial setups, new decentralized arrangements were devised to control and regulate masses of relatively free-floating subjects (Crary 1990, 15).

Although status is superseded by principles of 'measurement' and the value systems of the ancestral are replaced by ideas of the 'normal,' the observer in modernity is no less made manageable, calculable, and exchangeable. This all applies to the travelogue insofar as despite the plethora of new possibilities for movement found in modernity, as Heath says, 'mobility' remains difficult.

\section{Images of mobility}

Travelogue cinema can be identified by its production of an image of mobility. This trope can be defined as having two essential components: (a) a visual aspect, conveyed through a discursive or linguistic operation, and (b) a cultural and economic embodiment of an idea of privilege, as related to discourses of movement and travel. The visual aspect is important because it performs the idea of mobility within a coded aesthetic form; an enunciation of a certain idea of travel and movement through pictorial codes for producing affect and pleasure. Mobility frequently manifests itself in the travelogue film in a literal sense. It is apparent in the movement of the apparatus, as in a pan, tilt or tracking shot. It is apparent in attempts to capture and visualize movement through use of the apparatus, as in time-lapse photography, which may be considered a sort of temporal, rather than spatial mobilization. It is also apparent in movement produced about and around the apparatus, in instances where it has been placed on a mobile conveyance. Conventional interpretations of 
such early films typically dictate that the spectacular qualities and the affective pleasures they produce depend upon the dual novelty of seeing the technologies of the apparatus and of the mode of transportation present in the image. ${ }^{40}$ It might be offered, however, that the thrill and pleasure of these projects have a more conceptual basis, relating to the revaluation of perspective and experience encountered in modernity discussed by Crary.

Not unlike the situation of Alexander Von Humboldt (Chapter One), early cinema travelogues correspond with a set of larger cultural operations at work in turn-of-the-century Europe and North America, involving the demonstration and performance of knowledge about space and time. In a context of space and time being literally redeveloped through processes of urbanization and industrialism, ideas of space and time were also reevaluated and redrawn through various approaches to indexing and categorizing experience. An abundance of new possibilities of movement through space and time, as well as the production of new types of space and time, each encouraged the invention and expansion of new conceptual and practical models for mapping, navigating and traversing them. ${ }^{41}$ These operations involve technological developments, but are by no means entirely defined by them. Rather, what frequently informs the technological aspect is how these cultural and historical changes brought about the production of a distinct sensibility or condition. Ford Maddox Ford (1930) described it as an "ease of locomotion," and a "habit of flux" (Ford $1983,9)$. Cinematic explorations of space and time show the tendency to embody this fluidity by being conceptually open to the widening or closing of distance, and either the expansion or reduction of the intermediacies or intervals of time and space. These

\footnotetext{
${ }^{40}$ See: Burch (1986), Cornwell (1980).

${ }^{41}$ Carr notes, for example, how the standardization and expansion of steamships and railways in the $19^{\text {th }}$ century grows in proportion to the production and circulation of traveler's guidebooks. Similarly, the boom in empire building, where over one quarter of the world's landmass changed hands between 1876 and 1915 , is proportionate to a dramatic increase in the frequency of cartography and census reporting (Carr 2002, 71).
} 
operations typically occur within 'mechanizations' of perspective, contributing to a growing set of aesthetic codes that intertwine cinematic affect and pleasure with the imaginative construction of space and time as visually accessible.

Compare, for instance, Paris Exposition (British Mutoscope \& Biograph Company, 1900), a film taken from a hot air balloon, against Microscopic Pond Life (Edison Manufacturing Company, 1915), a science film examining insects. The former presents a bird's-eye view, transforming people into miniscule dots and allowing whole buildings to be seen in groups, while the latter magnifies the innards of water fleas, hydra, and amoebae during digestive activity, allowing what would have been normally inaccessible to the human eye to appear colossally huge. ${ }^{42}$ Each film engages and refers to distance as part of its aesthetic code, whether it is the closing of distance or its expansion. Each also engages with an idea of interval, with the innate separation, distance or mediation at hand in measuring and valuing distance. Both films embody a principle of scalability, that is, an adjustable mobility of distance and interval, which implies a degree of not merely technological but also imaginative freedom to travel between the proximate and the remote, the microscopic and the telescopic.

This brings us to the second component of the trope of mobility in travelogue cinema: the ability to instrumentalize both the economic and cultural as well as the imaginative ability to travel as such. It refers to the ability, opportunity or desire to traverse across and through space and time, and the conditions that make such movements possible. This is demonstrated in Paris Exposition (Biograph \& Mutoscope Company for France Ltd.,

\footnotetext{
${ }^{42}$ Anticipating a sequence in streets in a monster movie shown on television, Standish Lawder (1975) describes the fantastical sight of "tiny crustaceans and insects, magnified enormously on the screen...transformed into prehistoric monsters" (Lawder $1975,12)$. Also popular were films featuring medical views of the interior of the body and its mechanisms, like Circulation of the Blood (Italia Scientific Studios, 1913), which featured spectacular X-ray photography.
} 
1902), a two-shot film made of visitors to the 1900 Paris Exposition riding the moving walkways. ${ }^{43}$ The first shot shows leisurely urbanites travelling past the stationary camera, admiring the view of the Seine. The second shot simulates the perspective of those urbanites by placing the camera upon the moving walkway, inviting the observer to adopt this mobile perception. Perspective in this case is both imagistically and conceptually aligned with the possibility of refiguring space and time from a position of privilege. However, it cannot necessarily be assumed that mobility, as a 'habit of flux,' is or was available universally, despite its widespread cultural diffusion and commodification. In this sense, it is important to reinforce that mobility, especially in its second aspect, is crucially involved with issues of identity, especially class. It is not so much that film production and reception were restricted to the privileged, but that they will often refer to ideas of privilege and access, even if as a contested site. While mobility in the visual sense produces affect and pleasure, what sometimes occurs is that mobility in the conceptual sense produces a contradictory anxiety over identity and class status. To cite an example, in Panorama of the Flatiron Building (Biograph, 1903), "the camera imitates the gesture of the rube in the big city craning his neck to see the top of the first skyscraper" (Gunning 1983, 361). While the literal or visual mobility of the apparatus is the conduit for constructing identity, at the same time, identity is precisely the obstacle to mobility in a social sense, thereby conflating the affect of the visual spectacle with the concomitant anxiety over class and perspective it simultaneously produces. The confluence of pleasure and anxiety in this sense resonates with the ideas of the 'miniature' and the 'gigantic' outlined by Susan Stewart (1984), as parallel modes of description that will further illuminate the travelogue's mobile operations.

\footnotetext{
${ }^{43}$ Note that this is a different film than the aforementioned Paris Exposition (British Mutoscope \& Biograph Company, 1900).
} 
In Stewart's definition, the miniature and the gigantic are two complementary modes of analogizing space and time, two mutually interpenetrating ways of thinking about these elements that either transform or display spatiotemporal relations "in an exaggerated relation to the social construction of reality" (Stewart 1984, 74). Whereas the miniature privileges closure, proportion, control, and balance, the gigantic emphasizes infinity, disproportion, chaos and disorder. Miniatures tend to be 'known' as a spatial whole, that is, they are observed from an omniscient or otherwise transcendent viewpoint that allows the apperception of all of their 'parts' in simultaneity. The gigantic, on the other hand, is typically known only partially, and as such tends to undermine vision, or cannot be 'mastered' by vision in any totalizing sense.

Exemplifying the fluidity typical of the travelogue is Sky Scrapers of New York City from the North River (Edison Manufacturing Company, 1903), a one-shot film that depicts the Manhattan Island skyline from the deck of a ship sailing along the coastline. Beyond its purely representational dimension, Sky Scrapers of New York City oscillates between the miniature and the gigantic in that it stages the imaginative adjustability of scale. The film always conceptually remains in flux between the proximate and the remote, the widening and closing of distance, and the expansion and contraction of spatiotemporal intervals. Sky Scrapers of New York City depicts the skyline from a vantage point 'exterior' to the city, a perspective from which "the observer, in order to frame the scene, does not stand within it at all but in midair, on a bridge outside and over against it as a whole" (Stewart 1984, 78). This has the effect of miniaturizing the city in a conceptual sense, irrespective of the indexical or mimetic properties of the object represented. Rather, perspective is scaled outwards in the sense that the film produces a nearly transcendent vision that is able to mediate and arrange 
space in the manner of a garden. ${ }^{44}$ The city is constructed as an island, and its observation takes place precisely on its 'outsides,' circling around its perimeter. ${ }^{45}$ Yet, at the same time, it does not seem as if the skyline has an end, or a beginning; the circuit could never be completed, and the camera could continue to circle the perimeter indefinitely. ${ }^{46} \mathrm{Sky}$ Scrapers of New York City and Interior New York Subway each open up to the gigantic by not merely being 'mobile' in the literal sense of physical movement, but by also inviting the possibility of floating, of unstructured fluctuation. These two films appeal to an idea of pure time and space, without fixed points of beginning or end: time without chronology, and space without geography. Even as the frame in the film contains space and makes it benign, space is also consistently unsettling this perspective, continually producing and simultaneously 'swallowing up' unstable and uncontrollable elements. ${ }^{47}$

Stewart notes that the gigantic is historically intermingled with ideas and representations of the sublime as a deeply affective relation to space and as an ambiguously awed response to the vast grandeur of the available landscape. Sublime experience shares with the gigantic a basis in the aesthetic appreciation of the potentially destructive and overwhelming capacities of nature as embodied in the features of landscape. In turn, Stewart aligns the picturesque with the principles of miniaturization. ${ }^{48}$ Whereas the sublime is

\footnotetext{
44 'Poetry, painting, gardening, architecture, and the 'the art of travel' make up an art of landscape, an art of meditation and arrangement" (Stewart 1894, 75).

${ }^{45}$ "As is the case with all models, it is absolutely necessary that Lilliput be an island. The miniature world remains perfect and uncontaminated so long as its absolute boundaries are maintained... eliminat[ing] the possibility of contagion, indeed of lived experience, at the same time that it maximizes the possibilities of transcendent vision" (Stewart 1984, 68).

${ }^{46}$ Structured not unlike a Möbius strip, Sky Scrapers of New York City could have been well adapted to being looped on an Edison Kinetoscope.

${ }^{47}$ In addition to this dynamic created by the movement of the conveyance carrying the apparatus, in the film the camera also reframes frequently, creating a series of counterpoints in perspective in a similar fashion to Interior New York Subway.

${ }^{48}$ The gigantic represents "a violator of boundary and rule; an overabundance of the natural and hence an affront to cultural systems... while the miniature 'works,' coordinating the social, animating a model universe, the gigantic unleashes a vast and 'natural' creativity that bears within it the capacity for (self-) destruction" (Stewart 1984, 73, original emphasis).
} 
experienced in an explicitly individual or subjective fashion, the picturesque represents the ordering, the social cultivating, and essentially, the description of 'untamed' nature. By taking into account the intense pace of change undergone in urban space at the turn-of-thecentury, as well as the immense reorganization of social practices, it is plausible to suggest that the appeal of a miniaturized, transcendent viewpoint would have offered the opportunity to apperceive such change 'in perspective.' Too rapid and difficult to apperceive in its totality, the processes of modernization were typically only available to the observer partially and in fragments. ${ }^{49}$ Miniaturization offers a means of detachment and removal from the overwhelming transience of modern urban existence, and also provides a conceptual model through which to experience it.

In the same way that Claude glasses impose regularity, rhythm and proportion, and in the same way that the Quattrocento system linearizes perspective, the act of picturesque description enacts "the transformation of nature into art and thus the manipulation of flux into form, infinity into frame" (Stewart 1984, 75). ${ }^{50}$ Yet, while Sky Scrapers of New York City assuages vision by encapsulating the city into a system of "harmony of form, colour, and light, of modulation" (Stewart 1984, 75), it simultaneously tugs at the threshold of vision's intelligibility. As with the panorama, the presentation cannot fully contain whatever aspirations to a transcendent viewpoint are imposed upon it, thus producing an instance of ontological uncertainty, in the form of a shock: the gigantic causes "our bodies [to] erupt into a confusion of before-unrealized surfaces" (Stewart 1984, 70). ${ }^{51}$ Nevertheless, as Gunning demonstrated in his discussion of the exhibition at the Grand Café in 1895, the

\footnotetext{
${ }^{49}$ Ben Singer (1995) notes how the "fractured perceptual intensity of urban experience" in modernity was typified by a disorienting "combination of multiple spacio-temporal perspectives in a single, instantaneous view" that defied intelligibility (Singer 1995, 75).

${ }^{50}$ This is the sense in which both the gigantic and the miniature are defined in terms of metaphors of containment: "the miniature as contained, the gigantic as container" (Stewart 1984, 71).

${ }^{51}$ See Stafford (2001), esp. "Bright Oramas," pg. 90 - 98, for more on panoramas.
} 
admixture of pleasure and anxiety and of knowledge and sense was typically embodied in the form of the thrill, and Sky Scrapers of New York City is no exception. As a thrill, it demonstrates 'mobility' in both the visual and the conceptual meanings outlined above, and it is this multifaceted flexibility that reflects its experimental status.

Films like Interior New York Subway and Sky Scrapers of New York City construct mobile, experimental and temporary arrangements of space and time and reconfigurable relationships between the observer, the text and the "world.' Chiefly, though, they experiment with vision, in their constructions and manipulations of perspective, and with subjectivity, in their conceptual staging and unsettling of identity. Vision and subjectivity in these early travelogues are impermanent, unpredictable, and open to subsequent redefinition and negotiation - they are both experimented upon and are the conduits of experimentation. In the next two chapters, we will see how ideas of vision and subjectivity are further developed in the field of contemporary experimental cinema. Subversions of perspective and anamorphic dynamics will reappear in Chapter Three as integral parts of a school of experimental travelogues that concern themselves with opening up epistemological problems and crises of knowledge. Fragmentations of subjectivity and shocks to identity will similarly return in Chapter Four, as concepts like the thrill, the miniature and the gigantic will help describe the activities of an ontological school of experimental travelogues that attempt to evoke the intensities of being and presence. 


\section{Chapter Three:}

Centres of Calculation: Tourism and Epistemological Crises of Knowledge

The two remaining chapters of this thesis will be devoted to analysis of travelogues in the field of contemporary experimental cinema. These experimental travelogues generally fall into two categories: an 'epistemological' school and an 'ontological' school of practice, each of which reflects groupings of issues and concepts introduced in the previous two chapters. Films included in the 'epistemological' school, which will be the focus of this chapter, tend to problematize ideas of knowledge and undermine notions of authentic experience. The 'ontological' school, on the other hand, tends to be more preoccupied with representing intensities of experience and being, and does not concern itself as much with deconstructing the imperialism of the culture of exploration or of modern tourism. By conducting an in-depth analysis of the films Sifted Evidence (Patricia Gruben, 1981, 42 min.) and (Mike Hoolboom \& Steve Sanguedolce, 1992, 35 min.), and also drawing examples from Somewhere Between Jalostotitlan and Encarnation (Philip Hoffman, 1984, 6 min.), I will show how the epistemological experimental travelogues subvert the original purposes of both the colonial travel narrative and the touristic visit, by introducing problems of presence and authenticity. The motivation behind these filmmakers' critical repurposing of the travelogue format is to reflect on the ethical dilemmas inherent in traveling to and describing 'other' places and peoples, as their reflexive critiques are informed by postcolonialist discourse. Nigel Leask (2002) notes that the current wave of interest in reexamining colonial literature of the Romantic period is due in part to the popularization of ideas of postcolonialism and Orientalism by critics like Edward Said and Homi Bhabha. Postcolonialist discourse has made historically separate fields of practice like 
exploration narratives and modern touristic practices mutually legible to each other. It has therefore generated not only a series of reevaluations of historic literature, but has also shaped responses and investigations of modern phenomena, and altered the shape of the travelogue itself. One way in which the experimental travelogues discussed in this chapter reflect postcolonialist discourse is in their resemblances to travel narratives of the Romantic period.

The experimental travelogues of the epistemological school have certain narrative characteristics and generic conventions that link them to the style of travelogue advanced by George Forster and Alexander Von Humboldt (see Chapter One). Affective description and elements of subjective response are incorporated into the narrative and stabilized by the reasoning subjectivity of the traveler, which is understood as the organizing center of the text. The author's subjectivity is indicated by the location of the autobiographical 'self' of the traveler in the diegesis of the text and in the rhetoric of its production. 'slideshow' montage of images of a series of individual sites, with an accompanying voice-over narration by Hoolboom commenting on the sights shown onscreen (and sometimes on what is absent from the picture). ${ }^{1}$ Somewhere Between is an affecting attempt to describe the traveler's experience of allegedly seeing a dead boy on the roadside between two towns. The traveler ('Philip Hoffman') is inserted into the film through autobiographical intertitles placed in between shots of Mexican towns, and although again these intertitles reflect on the imagistic content, in this case the sights and the narration have a more allusive and disjunctive relationship. Sifted Evidence is a

\footnotetext{
${ }^{1}$ This narration performs a function as a guiding presence similar to that of the lecturer accompanying many early cinema travelogues (see Chapter Two).
} 
journey narrative that follows an academic as she searches for some ancient ruins in the village of Tlatilco. A narrator, who also appears onscreen in the opening and closing scenes, comments upon her movements and activities in voice-over, although to some degree they both represent facets of the same woman.

Sifted Evidence especially is similar to Romantic travel narratives in that it marries the autobiographical and subjective elements to an ostensibly 'scientific' (or otherwise disciplinary) goal and motivation for travel. The protagonist of the film, Maggie, is conducting anthropological research, and she travels under the auspices of conducting a feminist analysis of the relics she collects. Sifted Evidence is also similar to the works of Forster and Von Humboldt for adopting the generic convention of beginning the work with a prologue in which the traveler appears to introduce the journey. The film is introduced with a slideshow lecture sequence, in which a voice-over provides some historical context about Tlatilco over photographic images of the sorts of relics and statuettes unearthed at the site. The narrator eventually appears onscreen alongside a tableau of academic books, more photos of relics, some small artifacts laid out on a table, and a half-packed suitcase. As with Romantic travel narratives, this introductory sequence outlines the itinerary of the journey, demonstrates the research that had preceded it, acknowledges its predecessors, and makes a prediction of the expected results of the endeavor. ${ }^{2}$ Like the introduction to Forster's Voyage Round the World (1777), the prologue of Sifted Evidence frames the narrative and invokes the conditions of its production, including the sensibility of the authorial figure that informs the remainder

\footnotetext{
${ }^{2}$ This introductory sequence even mentions Von Humboldt's expedition to Vera Cruz as a model for the journey undertaken by the film's protagonist.
} 
of the text. ${ }^{3}$ By establishing a critical feminist background of study, the prologue proposes that the increasing prominence of Christian imagery in Mexican art demonstrates that the process of colonial expansion is tied to the repression of female sexuality. The slideshow shows how the chaste icon of the Virgin Mary gradually replaces that of the Aztec goddess of fertility. ${ }^{4}$ However, for a number of reasons, the expectations for the journey laid out in the prologue are never met, and the academic pretenses the prologue establishes are likewise undermined.

The use of narrative in the epistemological group of experimental films is conspicuous in undermining the linearity of conventional travel accounts. ${ }^{5}$ Everything in the travel narrative of the Romantic period is directed towards the production of knowledge. It teleologically progresses from 'here' to 'there,' from 'then' to 'now,' from an undefined self to a fortified self, and most importantly, from ignorance to understanding. Despite undoing all of these conventions, the films in the epistemological group are nevertheless sequential in their design. One of the ways in which Sifted Evidence displays the progress towards uncertainty is in the way the film deteriorates ideas of distance and any claims to 'scientific' authority. In addition to the academic format of the slideshow lecture, an idea of authority is instilled in the film's opening shots of the circumference of the Earth viewed from space, aerial images of the Gulf of

\footnotetext{
${ }^{3}$ Nadaner (1987) identifies these self-reflexive characteristics as conducting a number of 'meta' operations. These include metaphysics ("to move to a speculative level of consciousness"), metacognition ("to stand outside of one's own thought, as if an observer"), and metacriticism ("to be aware of systematic influences on one's way of knowing") (Nadaner 1987, 114).

${ }^{4}$ "To her, this country is a text that she approaches with a very clearly delimited set of ideas and presuppositions... She will and, if we consider the introductory sequences of the film, already has imposed a certain interpretation on the Mexican figures [and] the events of her journey" (McHugh 1990, 113).

${ }^{5}$ In contrast, the films discussed in Chapter Four are not narrative-based, nor do they feature 'characters.' They more closely resemble the depersonalized 'views' of many early cinema travelogues (see Chapter Two).
} 
Mexico, and a map of the region where Tlatilco is located. ${ }^{6}$ However, as the narrative develops, perspective increasingly fails to be as transcendent as these first few images suggest, and vision becomes obscured by proximity. ${ }^{7}$ Perspective becomes more like that of the idlers and gawkers inspecting objects of wonder than like that of the Enlightenment observer, 'too close' to receive and understand relevant fragments of meaning from the object. The narrator informs us that Maggie "cannot observe herself from far enough away to stay out of trouble." Maggie subsequently becomes entangled with her guide/travelling companion, Charlie, who effectively holds her hostage by exploiting her ignorance of the local language. Later, Maggie fails to realize that Charlie, who initially presented himself to her as 'Jim Lilly,' is addressed as 'Charlie' by several of his friends in her presence. She also fails to notice when the pair drive right past the Tlatilco ruins in a taxi. The academic goals of her expedition completely fail to materialize, as "she cannot negotiate the foreign terrain, cannot locate the site" (McHugh 1990, 113). The momentum of the narrative disintegrates as Maggie circles around the villages surrounding Tlatilco, incorporating more and more digressions and detours. Despite not wanting for 'previous knowledge' of her surroundings, Maggie's journey devolves into aimless wandering. ${ }^{8}$ As the film's narrative comes to a close, the initial objective of reaching Tlatilco is largely forgotten, and a series of conflicts ensue between Maggie and Charlie, based in racial and gendered tensions. These conflicts continue to cloud Maggie's understanding by miring and complicating the relatively neat parameters of the

\footnotetext{
${ }^{6}$ Nadaner notes how the opening sequences establish the narrator/Maggie as 'the paradigm case of the detached observational consciousness of the West" (Nadaner 1987, 118).

${ }^{7}$ The tension between transcendent and partial views recalls Susan Stewart's (1984) comments on the viewing styles offered by the miniature and the gigantic.

${ }^{8}$ Preparation and research were the criteria for Reginald Heber's (1813) distinction of traveling from mere wandering (See Chapter One).
} 
feminist methodology outlined in the prologue. Charlie interprets Maggie's unwillingness to have sex with him as racial snobbery, and at the same time Maggie interprets Charlie's insistence on intercourse as sexist machismo. The film "fashions these issues in such a way that an interpretation of racial injustice precludes a feminist interpretation and viceversa... If we judge Maggie to be racist or Charlie to be sexist, the film demands that we realize our reading is based on a point of view that inherently suppresses an other's reading" (McHugh 1990, 114, original emphasis). The narrative ends before these conflicts are ever resolved. As the narrator suggests, "in the end who knows what they meant to each other." In all of the ways described above, Sifted Evidence advances the notion that experience cannot be untangled from presence, and presence can therefore not be successfully instrumentalized towards an end. In the context of travel narratives from the Romantic period, this end typically represented the obtainment of knowledge. However, while at once referring to the traditions of Romanticism, the experimental travelogues examined in this chapter also update their narratives to the context of modern tourism, which has a congruent ultimate purpose: the obtainment of authentic experience. The representations of modern touristic practices in Sifted Evidence and are generally informed by the distinction made by various critics between mass tourism and Romantic travel proper (See Chapter One). The dichotomy constructed between enlivened perception and the artificial, cliched, and overdetermined language of tourism is similarly upheld (See Chapter Two). In these distinctions, tourists are thought to have 'no perspective,' no art to their vision, and are thus aligned with the otiose and 'stupid' gaze of wonder. They experience things only superficially and are unable to retain aesthetic edification or lasting satisfaction. However, the protagonists and narrators of 
these films (and the filmmakers, for whom they are doubles) are themselves identified as tourists to varying degrees. ${ }^{9}$ In Sifted Evidence there is a consistent confusion between the anthropologist's methods of investigation and the tourist's typical engagement with the foreign and the unfamiliar. As Mike Crang (1999) notes, "the academic gaze often replicates the practices of tourism. So much of what is produced is couched in a rhetoric of 'peering beneath the veil,' seeing what is really going on" (Crang 1999, 253). ${ }^{10}$ Yet, access to unmediated culture or direct experience is established as impossible, as embodied in the way that Maggie uses an audio Spanish-English phrase guide on a tape recorder to interact with the Mexican locals. Along similar lines, includes scenes set in hotel rooms and lounges, and the voice-over makes it explicit that these Canadianowned properties are built for visiting tourists and businessmen. Another example of foreign culture being mediated comes early in the film when there is a mention of tour guides shepherding groups of visitors around historical sites. The film even begins with the narrator sitting in a travel agent's office. ${ }^{11}$ In contrast to the deliberation and preselection of Maggie's journey, the narrator in destination simply by pointing "vaguely towards the heap of brochures on the desk." Much like Maggie, the narrator in quickly gets lost and experiences a failure of

\footnotetext{
${ }^{9}$ Nadaner notes that Gruben herself was a student of anthropology, thus making an association between her and Maggie at least as plausible as and Somewhere Between's more explicit uses of first-person narration (Nadander 1987, 118).

${ }^{10}$ Crang also notes the similarities between tourism and academic investigation in that they share "the trip into the field to acquire knowledge, the gathering of material, the souvenirs as strips of deceased experience, the presentation of pictures as proof of having been [there] to authorize our stories" (Crang 1999, 253).

${ }^{11}$ In line with Forster's introduction to Voyage Round the World, the travel office, as a place of departure, is appropriately decorated with maps of the globe and informative pamphlets on foreign destinations. These constitute the accumulated 'research' that precedes the journey, just as the inflatable models of transport carriers that are hung from the office's ceiling reflect the means of the journey's production.
} 
observation and of memory. The reason why the narrators, protagonists and filmmakers are self-consciously implicated in the practices of mass tourism is that these films suggest that tourism is the vehicle for the imperialistic and colonizing tendencies once ascribed to travel writings of the Romantic period. In order to conduct a critique of these tendencies, these films conduct a series of deconstructions of an idea of the 'centre.'

The 'centre' is the term Bruno Latour (1987) uses to describe the seat of power in networks of cultural sites. ${ }^{12}$ Within these networks, information and objects are collected and transported from 'periphery' to 'centre,' where they come to represent not only material wealth but also consolidate the reaches of imperial power. Not unlike Jonathan Crary's (1990) depiction of vision in modernity, information and objects circulating in the network must be uprooted from their original context and mobilized before they can be compiled and instrumentalized by the centre. This process, which Latour calls the 'cycle of accumulation,' abstracts information and objects and transforms them into commodities that can be freely recombined in various new arrangements. Examples of such 'combinables' might include physical objects, like anthropological artifacts or biological specimens, which can be collected, preserved and transported. Non-modern cultural traits and artifacts like folk music, décor, dress, medicine, and language can be separated from the modes of production and distribution in which they are found. Land itself can be translated into cartographic symbols and maps. As displaced forms, they represent both trophy and spectacle. It is thus that Leask describes the collecting impulse of Western institutions as "the progressive mobilization and accumulation of distance" (Leask 2002, 19). Dean MacCannell (1989) more explicitly looks at the accumulation

\footnotetext{
${ }^{12}$ Latour's use of the term bears similarities to the idea of 'centre' advanced by Stephen Heath (1981) to describe centripetal perspective and the consolidating of identity, observerhood, space.
} 
process in Marxist terms of alienated labour. "Modernization... separates these things from the people and places that made them, breaks up the solidarity of the groups in which they originally figured as cultural elements" (MacCannell 1989, 13). The cycle is perpetuated when the traveler's activities work towards consolidating network relations. The establishment of trade routes, for instance, cements pathways and connections through which information and objects are moved, so that "others might be sent back again to bring other things back" (Latour 1987, 220). The production of diaries, maps and dictionaries similarly ease the path of future travelers by translating local knowledge and therefore transforming the unfamiliar into the familiar. The spoils of accumulation eventually constitute the research and preparation of later travelers. Ultimately, the power of the centre to act upon the distant, the foreign or the unfamiliar crucially depends upon the centre's ability to transport and/or recreate it at home. ${ }^{13}$

There are numerous instances in which places have been effectively territorialized (or, more accurately, reterritorialized) by having been recreated in major North American or European cosmopolitan cities. Zoological and botanical gardens, for instance, rearrange the accumulated combinables of the peripheries for the eye of the Western observer in an accessible and legible manner, as do World's Fairs and Pan American Expositions. ${ }^{14}$ These are what Latour calls 'centres of calculation,' the sites where the combinables are reassembled, such as museums, universities, and libraries. Also to be included on this list are travelogues themselves, which similarly translate the foreign and

\footnotetext{
is "The best indication of the final victory of modernity over other sociocultural arrangements is not the disappearance of the nonmodern world, but its artificial preservation and reconstruction in modern society" (MacCannell 1989, 8).

${ }^{14}$ Costa (2006) gives an in-depth account of World's Fairs as miniaturized 'trips around the world.'
} 
the distant for domestic readerships. ${ }^{15}$ refers to these dynamics in a sequence where the narrator visits the waters of San Obispo,

...the great aquarium where they have gathered a fantastic variety of tropical sea dwellers... They move together in schools, collected according to genre and subject heading, gathering their gene pools beneath the practiced eye of the marine biologist. You try to picture them swimming in the other place, in the salt waters of the Gulf of Mexico, and find that you can't. They are only real for you here, in the numbered tanks of the floating encyclopedia.

As this passage indicates, the increased legibility of the combinables in their new context does not fully compensate for a loss of what Walter Benjamin (1968) would call their 'auratic' status. Despite being reconfigured as pleasing spectacles, they inevitably speak of inauthenticity and overt mediation.

Across various manifestations of tourism, expressions of desire for singular and auratic 'genuine' objects and experiences are commonplace. In late eighteenth century tourism, these desires are manifested in souveniring, which was sometimes organized in forms like the Grand Tour. ${ }^{16}$ For young upper class men, the Grand Tour represented an aesthetic education, where evidence of the accumulation of taste and worth would be confirmed by the collection of souvenirs and artifacts. In contrast to World's Fairs and zoological gardens, however, souveniring outwardly serves the interests of the individual

\footnotetext{
${ }^{15}$ In films, photographic images become the combinable elements in a montage, which is typically assembled after the return home. The editing suite functions equally as another 'centre of calculation.' Eastern Avenue (Peter Mettler, 1985) refers to this tendency by concluding with a shot of the streetsign in Toronto after which the film was named and which signals the place where it was finally constructed (White 2006, 12). The process of editing and assembling individual film frames further resonates with the notion that combinables are rendered abstract by the process of their removal from their original context, "so whatever stuff they are made of, they can be cumulated, aggregated, or shuffled like a pack of cards" (Latour 1987, 223). Appropriately, the narrative structure of Alexice resembles a discontinuous, 'shuffled' series of postcards.

${ }^{16}$ James Buzard (2002) identifies the Grand Tour as being an active paradigm of travel roughly between the historical landmarks of the Restoration (1660) and the crowning of Queen Victoria (1837), with the height of its popularity being between 1780 and 1840 .
} 
antiquarian, rather than being organized for state purposes. ${ }^{17}$ Later, sightseeing emerges from the picturesque tradition, moving beyond the acquisition of physical objects but still taking part in the appropriation of the foreign. MacCannell suggests that for the tourist, the modern world seems disorganized and alienating, chaotic and fragmented, thus producing a desire for holistic experience, and therefore for sights that promote ideas of wholeness, finishedness, and unification. "Sightseeing is a kind of collective striving for a transcendence of the modern totality; a way of attempting to overcome the discontinuity of modernity, of incorporating its fragments into a unified experience... This effort of the international middle class to coordinate the differentiations of the world into a single ideology is intimately linked to its capacity to subordinate other peoples to its values, industry and future designs" (MacCannell 1989, 13). In the twentieth century, the functions of sightseeing are further enabled by the availability and popularity of photographic media. Postcards, for instance, serve as convenient summations of an idea of place onto a pictographic plane, condensed to fit securely within the borders of the frame. ${ }^{19}$ Photographic tourism also continues modernity's incorporation of disparate fragments in its conversion of places into images, its "making sights out of sites" (Crang $1999,240)$, which can be synthesized into a coherent form in family albums upon returning home. ${ }^{20}$ The activity of taking snapshots transforms places into commodities,

\footnotetext{
${ }^{17}$ Buzard claims that the structure of the Grand Tour reflects desires for maintaining fantasies of Britain's continuing colonial authority. Requisite stops at Rome, symbolizing the origin of classical civilization, and various sites of Renaissance culture where classicism was reappropriated, construct continuities with Britain's own aspirations to neo-classicist aesthetics.

${ }^{18}$ See also: Crary (1990), Stewart (1984).

${ }^{19}$ The final image of Joyce Wieland's experimental travelogue Reason over Passion (1967 - 68) is a static shot of a picture postcard as an ironic comment on the oversimplified reduction of an entire nation, its geography and culture, into a single iconic image. The observer's awareness of the cross-Canada journey Wieland has just completed across a landscape made up of an unquantifiable amount of regional characteristics playfully subverts the postcard's retrospective imposition of an image of a 'unified' country. ${ }^{20}$ Home video has been increasingly serving this purpose as well, and 'video diaries' of trips are now commonplace.
} 
uprooted and mobile, yet paradoxically, its production of authenticity to an extent depends upon place being 'fixed,' as the taking of the picture requires a set of 'grounded' objective spatiotemporal relations. Despite not necessarily 'removing' the actual object of the photograph from its original context, photography nevertheless necessitates actual physical presence at the site where the object is found. 'Authentic' snapshots are produced though an indexical relationship between the eye/camera and the world, in order to compensate for the non-auratic quality of the mass-produced photo. This is why pictures are so often taken with the tourists in them, to confirm "I was there."21 This is also partly the reason why tourists must venture 'elsewhere,' as the foreign and the distant provide reliable sources of 'auratic' cultural sites.

It was (and to an extent, still is) typical for tourists to seek out transcendent experience by staging visits to the 'peripheries,' because "for moderns, reality and authenticity are thought to be elsewhere: in other historical periods and other cultures, in purer, simpler life styles” (MacCannell 1989, 3). 'Genuine' or singular' objecthood is located in exotic cultures and pre-modern societies because they seem to alleviate the homogeneity of the industrial, mass-produced culture of replication. ${ }^{22}$ Tourism's chief priority, then, and its measure of success, is the pursuit and obtainment of authenticity, which MacCannell claims are intimately linked to the empirical and ideological expansion of modernity. "[Tourist's] nostalgia and their search for authenticity are not merely casual and somewhat decadent, though harmless, attachments to the souvenirs of destroyed cultures and dead epochs. They are also components of the conquering spirit of modernity - the grounds of its unifying consciousness" (MacCannell 1989, 3).

\footnotetext{
${ }^{21}$ See: Crang (1999).

22 See: Benjamin (1968).
} 
In the period of colonial expansion Latour describes, the 'unifying' spirit of modernization meant a synergizing tendency. As a way of strengthening network relations, following an expedition some aspect of the 'centre' was typically left behind at the 'periphery,' like a garrison, an institution, or some other modernizing force. In the modern context MacCannell describes, ongoing patterns in touristic practices propagate this homogenization as well, producing more conditions under which future tourism is made possible. 'unifying' spirit, as the first location the narrator visits on his guided tour is the Museo Nacional de las intervenciones, the 'Museum of Invasions,' "whose exhibitions detail the more than one hundred invasions of the country." There is also the continued implication that Mexico is being gradually remade over into a model of Toronto for the pleasure and comfort of visiting tourists and businessmen. The narrator's room at the Holiday Inn in Los Michos is such a precise replication of its Canadian counterpart that the images we see of it could well have been shot in Toronto. The narrator comments that "this architecture is a uniform for travelers, an image of home, but also a reassurance that the tongues of a thousand races can be laid to rest here, beneath the folded sheets of Canadian linen, its bodies scrubbed to a uniform shine beneath the shower heads of North American plumbing."

Crang notes how the construction of 'auratic' objects and sites appeals to ideas of unmediated and direct experience. Yet lexice, like Sifted Evidence and Somewhere Between, performs a deconstruction of the photographic image that underlines its illusory tendencies and its material status, making representation of the foreign and the distant 
explicitly mediated and 'distanced' in the Brechtian sense. ${ }^{23}$ The hotel room sequence suggests that rather than let their images continue to play a complacent part in the mystifying and imperialistic culture of tourism, Hoolboom \& Sanguedolce actively point out the mediation of culture and the alienation of foreign peoples at hand. These experimental films manage to subvert the original purposes of both colonial exploration narratives (the obtainment of 'useful' knowledge) and touristic travel (the obtainment of authentic experience) by problematizing the status of the image and introducing epistemological problems around it.

Dan Nadaner (1987), in the introduction to his analysis of Sifted Evidence, summarizes this bundle of operations as a tendency towards "reflexivity":

The reflexive attitude in film and the visual arts has functioned as a sign of an epistemological crisis of the century, the crisis of confusion which follows the discovery that objective knowledge is unattainable. The reflexive attitude has succeeded in conveying the message that popular forms of representation are still burdened by illusions of objectivity (Nadaner 1987, 114).

Nadaner's statement could apply equally well to all of the films described in this chapter. The crisis of 'objective knowledge' is synonymous with the crisis of 'authentic experience,' and the 'popular forms' Nadaner mentions could refer equally to travel narratives of the Romantic period and to touristic practices. Yet, Nadaner claims that much 'reflexive' art typically counters claims to objectivity with a claim to the revelation of the 'truth' behind the deceptions of popular forms of representation that itself recalls rationalist objectivist principles:

\footnotetext{
${ }^{23}$ Martin Walsh (1981) concisely defines Brecht's use of 'distanciation' as the "calculated disjunction of conventional theatrical illusion" (Walsh 1981, 5). Distanciation serves the artistic purpose of being a "deliberately interruptive mechanism, a mechanism that demands that the audience sit up and reflect upon its significance" (Walsh 1981, 6).
} 
Most reflexive artists have acted, in spite of their apparently revolutionary systems of representation, like good-old fashioned objectivist scientists, crusading through swamps of popular representation in order to cast aside demons and reveal truth... What has been missing is the willingness of the artist to fully immerse himself in the more amorphous realm of subjectively experienced uncertainty (Nadaner 1987,114$){ }^{24}$

According to Nadaner, Sifted Evidence fulfills this function chiefly through its characteristic formal and stylistic approach of placing characters in front of rearprojections and painted backdrops depicting the locales they are meant to inhabit, an approach "that is both painterly (constructionist) and meta-representational (deconstructionist)" (Nadaner 1987, 116). Oscillating back and forth between an 'uncovering' of the illusory, material status of the image and the production of new illusions and obstructions to understanding, "the traditional limits of reflexivity are transgressed as the film begins to exemplify rather than point to the constructed nature of knowledge and representation" (Nadaner 1987, 115). Both and Somewhere Between stage similar operations, problematizing ideas of presence and authenticity by introducing problems of observation.

In these films, problems of observation sometimes involve distortions of perspective in the sense that Stephen Heath (1981) describes in his discussion of anamorphosis (see Chapter Two). In Sifted Evidence, the construction of a centripetal perspective is used prominently as a metaphor for a certain conceptualization of travel, putting forth the notion that 'centering' is instrumental in mediating stable transitions from place to place. In the opening sequence in particular, centripetalism is evoked as a tool for retaining an idea of the distinctiveness of 'home' and 'away.' The film begins

\footnotetext{
${ }^{24}$ Nadaner's use of 'amorphous' to contrast with more rationalist forms of experience is not dissimilar from Heath's description of anamorphosis as a style of perspective that deviates from the Cartesian grid of the Quattrocento system (see Chapter Two).
} 
with an image of the curvature of the Earth, shot from an orbiting satellite, over which is superimposed a crosshairs, of the sort familiar from photography and weaponry. The voice-over explains:

First priority is to fix the frame. To line the crosshairs as accurately as possible. To set the zoom. Hesitation in the moving hand will cause retrograde motion in the elements, or a slight deflection in the field of vision. But strict attention to the crosshairs is the guiding principle to correct the spiral of wandering attention.

The camera trained on the Earth correspondingly zooms forwards, and the picture dissolves into an aerial view of the waters of the coast of Mexico. The transition is mediated by the presence of the crosshairs, which only fade once the 'there' of the destination is reached. Travel, when considered as a framework of mobility that supposes the possibilities of concepts like 'here,' 'there,' 'then,' and 'now,' must rely, it seems, upon an idea of emplacement that refers to a geographical awareness that posits points in space and time as fixed and immobile. This emplacement subsequently becomes embedded within the textual system, through the dispatching of various pictorial codes that secure 'strict attention,' and also in the activity of the apparatus itself. ${ }^{25}$ The voiceover's reference to 'fixing the frame' extends this idea of emplacement to the ways in which travel is staged cinematically, suggesting a correspondence between the activity of 'fixing' place and 'fixing' photographic images. This model is problematized, however, in that movement (of the Earth, in the photographing hand) creates 'retrograde motion in the elements,' producing contingencies and constellatory relations. The tension is

\footnotetext{
${ }^{25}$ This operation is similarly evident in the processes of narrativization undergone in early cinema's latter days. Rod Stoneman (1981) earmarks such devices as the eyeline match in positioning the spectator as "the relay between two interlocutors" (Stoneman 1981, 53). In other words, the process of constructing a centripetal perspective delineates meaning not only within images but also across montage. It is a practice that involves the spectator's comprehension of narrative as an agent in conceptually stabilizing movement across space.
} 
irreconcilable, for while the film experiments with visual disorientation as much as being about a 'lost' traveler, any investigation it is poised to conduct "must proceed from where we are at the moment."

Problems of observation also manifest themselves in the films in the form of false visions, explicit artificiality, illegible abstractions and unreadable surfaces. In addition to the rear-projection techniques, Sifted Evidence freely juxtaposes studio-made material with images shot on location in Mexico, creating an unstable dialectic between representational modes that discredits any notion of the authenticity of the film's representation of geographic space, and does not privilege any representational mode over another. According to Nadaner, the rear-projection techniques produce "a sense of a nervous, vibrating dialectic between [the characters] and their surroundings rather than a simple separation" (Nadaner 1987, 118). ${ }^{26}$ Somewhere Between similarly produces such an ambiguous dialectic in the way it disperses the central subject of the film across its imagistic content without representing it directly. The film is about seeing a dead boy by the roadside, which Hoffman passed by on the bus and declined to film, despite apparently having a camera at the ready (Hoolboom 2001a, 99). The boy is not shown onscreen and only described in intertitles, yet the images inevitably refer to him. They do so through associative editing, "whereby details noted in the intertitles are presumed to refer to the images they immediately follow or anticipate by the simple virtue of proximity" (Rigsby 2001, 37). By using consonant images in place of indexical ones, the relationship between elements of 'story' and 'image' is sometimes 'synchronous' but often more allusive. "The cop car that speeds by the boy's corpse must be the very one 
just seen passing the Coke billboard. Likewise, the beggar girl who is conceded a peso is identified as the beggar girl who then appears. And the girl with the big eyes awaiting her dead brother? There she is, her presence lingering by symbolic association with the image of a snail” (Rigsby 2001, 37). ${ }^{27}$ Despite being comprised of entirely 'real' elements, a written testimonial of an event Hoffman experienced, and sightseeing footage shot in Mexico, the film's "reliability as documentation is severely undermined by its imperative to simulate fiction" (Rigsby 2001,38 ) ${ }^{28}$ In the end, the film offers nothing that might validate or 'prove' the actual happening of Hoffman's story. To commemorate the boy's death, Hoffman included images of a funeral procession, but like the hotel room images in Aexice, they look conspicuously like they were shot in Toronto. These operations undermine authenticity, doubting the objective validity of observation ("is that what I saw?") so important to the Enlightenment scientist-observer, and deconstructing the imaginary holistic reality of place (in a physical as well as a cultural sense) that is crucial to substantiating touristic practices. ${ }^{29}$

\footnotetext{
${ }^{26}$ Because of the way the front-projection technique incommensurably separates Maggie from 'entering' space, Sifted Evidence's general aesthetic strategies are at least partially responsible for frustrating her ability to reach the ruins of Tlatilco and retrieve the artifacts she desires.

${ }^{27}$ This relationship also extends to the dynamic between the image track and the music. The saxophone solo performed on the soundtrack twice appears to synchronize with images of a man playing the trumpet. Although the sound and the image appear to 'match' rhythmically, the source of the sound is plainly not diegetically recorded, and produces an additional dissonance on account of the clash between cultural musical forms.

28 cFor testimony to be what it is, to remain precisely testimony and thus retain its character as something other than a direct access to 'truth,' it must necessarily be haunted by what it excludes... Testimony is inevitably haunted, even possessed, by the possibility of fiction" (Cartmell 2001, 231).

${ }^{29}$ As Nadaner observes, in addition to Sifted Evidence's visual strategies, an idea of 'authenticity' is problematized in several narrative instances as well. At one point, Maggie wants to know the precise moment that Charlie allegedly fell in love with her, sarcastically wondering whether it was when she was standing in three feet of water in the pool, drinking a tequila. As the narrator intones, "it was a pose I'd copied from a travelogue." Later, Charlie sings Maggie a song with the refrain, "you led me on last night, you led me on," which casts doubt on her previous assertion that she is not romantically or sexually interested in him whatsoever. In both scenes, the authenticity of emotions and the state of human relations cannot be validated, and the characters hold opposing views.
} 
In addition to the confusion of locations in the film presents difficulties

of legibility that confound the instrumentality of images, and of the journey itself, suggesting that legibility is connected to the consolidation of network relations and the propagation of the cycle of accumulation. Over an image of abstract high-contrast white lines, the narrator describes driving at night, examining the lines on the road:

Your eyes are trained on these lines of flight which lead you from one village to the next. You study the lines like a palmist who discovers in the markings of a hand, the secrets of the inner life. You think: you can always tell a book by its cover, as you look down into the Mexican asphalt, its long dark brow creased with the weight of travelers and forgotten alphabets. But these worried lines running the length of the Mexican highway - what are they saying exactly? Whose story is being told here? Alone in Mexico, in the middle of the night, you retrace the marks of all those who have gone before you, as if committing to memory a history of flight. If these lines are illegible it is because they were made by people who never learned to read, who failed to understand that the automobile was less a method of travel than a way of life. That these lines were a chronicle of change, bonding the country with a life beyond its borders, marrying its unfinished geography with the auto factories of the north.

Similarly, an idea of illegibility is invoked in a sequence where the narrator watches smoke pluming from an industrial smokestack:

With a start you realize that the factory produces nothing, only smoke. Fed by its jungle surround, the factory crafts an alphabet of vapour, which travels around the world on currents of air. You look on, trying to find some way to read these hieroglyphs, this writing in the sky. You decide to sit and wait at the window until it comes to you: these clouds are saying yes to Canada, to the merchants of Toronto.

What these commentaries attempt to establish is that the precise relationship between industrialization or urbanization and the territorialization of Mexico by Canadian business interests is often obscure and difficult to describe. The processes of modernization are dispersed and sometimes unconscious, making critical assessments of them troublesome, and casting doubt upon the ability of the traveler-critic to produce any 
change in these relationships. Distanced from utopian sentiments about the possibility of decisive intervention, Mexice suggests that the best the traveler can manage is to "retrace the marks of all those who have gone before you," and remain sensitive to the ethical dilemmas of being present to witness at all.

The experimental travelogues belonging to the 'epistemological school' are all involved in sketching out an 'ethics of travel,' a set of practices for presence, witnessing, experiencing and observation. They are conscious of the fact that they may not be able to 'escape' the hegemonic or domineering tendencies of exploration and visitation, but they attempt nevertheless to engage critically with issues of mobility and privilege that arise in encounters between cultures. It is for this reason that it is significant that all of the films described in this chapter are set in Mexico, as Gruben, Hoolboom \& Sanguedolce, and Hoffman all attempt to reevaluate ethically the history of representation of that space within the tradition of experimental filmmaking. Rigsby notes that Mexico has previously been a popular destination for experimental filmmakers seeking to subvert the moral and aesthetic boundaries of 'good taste,' and that their repeat visits contribute to the imaginative construction of Mexico as a transgressive space. Citing films by Bruce Baillie, Bruce Conner, Richard Myers, Larry Jordan and Chick Strand, Rigbsy claims that the tendency to use Mexico as the location for exotic, liminal, magical, surreal or phantasmagoric experiences mystifies it in the same manner as conventional touristic practices. "As the avant-garde film canon attests, south of the border has been a popular destination for filmmaking tourists, the special condition of their alienation in Mexico circumscribed by this imperative to solicit visionary experience" (Rigsby 2001, 39). As has been demonstrated, however, Gruben, Hoolboom \& Sanguedolce, and Hoffman, are 
conscious of their implicated status as tourists (and as explorers in the colonial mould), and of the complicity of their texts in the cycle of accumulation. Despite not being fully able to replace these existing models, they attempt to construct an ethical position of observation and interaction. Hoffman's decision not to film the dead boy in Somewhere Between not only seeks to maintain a sense of privacy about the incident, but also highlights the difficulty of the tourist's sense of self-emplacement and the justification of his presence in Mexico. ${ }^{30}$ Sifted Evidence employs its various techniques of disorientation to imply the imperialistic and exoticizing tendencies of the scientist/tourist, and to perform its critique of mobility and privilege, of travelers with, as the narrator puts it, "the time and money for our adventures." attempts to invoke the difficulties of criticism and observation of processes of industrialization and modernization as a way of introducing doubt over contemporary relations between Mexico and Canada. ${ }^{31}$ However, as we will see in the following chapter, these types of engagement with ideas of movement and travel are not necessarily indicative of the practices of the entire body of experimental travelogues, as a substantial portion of this corpus moves 'beyond' tourism to investigate the nature of time and space in a manner more aligned with the principles of Romantic poetry.

\footnotetext{
${ }^{30}$ Peter Harcourt (2001) claims that Somewhere Between "conveys a feeling of an impenetrable territory, a space of suspension between two worlds" (Harcourt 2001, 84, my emphasis).

${ }^{31}$ In the last sequence of the film, this specific context is revealed: "You drive on towards the arched towers of the necropolis where the bones of the revolution lay wrapped in flags and crushed flowers... That's when you see them together - the liar from Bay Como and the other one, the one who always smiles, the Canadian Prime Minister and the President of Mexico united beneath the banner of free trade."
} 


\section{Chapter Four:}

Experiments in Disorientation: 'Spots of Time,' the Sublime and Ontological Intensities

This chapter will be concerned with the features of the second grouping of films briefly outlined at the beginning of Chapter Three. Rather than be occupied with opening up problems that relate to the status of empirical knowledge, the films under discussion here involve themselves with what will be termed 'ontological intensities.' Ideas of selfhood, subjectivity and the status of the observer will be introduced into a discussion of how certain principles of Romanticism apparent in the experimental travelogue promote the proliferation of multiple, unfixed and heterogeneous identities. By focusing textual analysis primarily on Eastern Avenue (Peter Mettler, 1985, $58 \mathrm{~min}$.), and incorporating discussions of Chimera (Philip Hoffman, 1995, 15 min.) and Reading Canada Backwards (Steven Topping, 1995, 12 min.), this chapter will outline how the experimental travelogue seeks to 'shock' the observer in the pursuit of exploring new and unverified models of experiencing space and time. This chapter will conclude by arguing that these functions and purposes amount to the proposal of an experimental mode of geography. To begin, it is important to trace the connections between the experimental travelogue and the styles of presentation that inform Romanticism's position on ideas of experience.

On a basic structural level, Eastern Avenue resembles pre-modern museological forms like the wunderkammer and the cabinet of curiosity, in that as a document of travels, the film functions as an arrangement or assembly of heterogeneous elements and artifacts. Eastern Avenue is a diaristic recollection of the sights and sounds Mettler experienced traveling through Switzerland, Berlin and Portugal. Neither a narrative of 
travels nor an essayistic disquisition on travelling, the flow of images and sounds in Eastern Avenue continually traverses traditional literary and pedagogic boundaries of subject matter, style and form. Yet, a system of order is not necessarily absent. The ephemera collected in Mettler's film are not itemized or compartmentalized in an indexical or encyclopaedic system of order, but rather, according to what Barbara-Maria Stafford calls a 'prismatic' system, in which combinations of and associations between elements amount to a theory or hypothesis on their possible interconnectedness and significance. This is one aspect in which Eastern Avenue is 'experimental,' in that despite its ordering of time into a sequential film form, the elements of which the film is comprised retain their combinable qualities. Like a wunderkammer, the experience of Eastern Avenue could never produce any particular arrangement of artifacts that could ever be called definitive. Instead, the observer is presented with a plethora of mutually relatable chains of associations, the construction of which follows only partially discernable motivations. In a sequence early in the film, for instance, Mettler's camera zooms in on the frozen branches of a tree in winter. This shot is immediately followed by a zoom out from a tight framing of a human face, which reveals a person standing facing a window (the window facing the tree?). The film then cuts to another image of a human face, this time of an old man, in a similar tight framing, but in black and white, and then to a shot of folded hands, also in black and white (the hands of the old man?). Images in the film are often connected in short 'sets' such as this, and modulations and variations on these associative chains will sometimes reappear later in the film. Portrait-style shots of the faces of human subjects are among the most prevalent. Similarly, there are recurring graphic and compositional patterns that intermittently reemerge throughout the 
film and there is a sustained interest in textural surfaces. Unlike the modern museological practices standardized in the nineteenth century, however, neither the inclusion of these ephemera into the system of order nor their repetition typifies or standardizes them; the commonalties they share do not negate their singularity.

According to Stafford, prismatic arrangements of artifacts are not based upon impersonal and rigid systems of order, as in botany or zoology, but are constructed around the central referent of the traveler, according to individual taste, aesthetics and experience. ${ }^{1}$ This makes arrangements such as these often intensely personal, with a diaristic quality. Appropriately, Eastern Avenue's subtitle is 'Notations in Image and Sound," in the manner of the Romantic convention of 'writing to the moment,' meaning that the form of the work itself represents a record of subjective impressions. ${ }^{2}$ The images and sounds in the film communicate the affective impact they had on the traveler simply by virtue of being included in the first place. ${ }^{3}$ Like Kinglake's description of the Sphinx, the object or event is 'written' about because its interest or attraction lies in some sense of elusive mystery behind the object or event, which cannot be represented or is inaccessible to rational description. Instead, the gestalt of the impression can only be approached through a poetic device. ${ }^{4}$ While Kinglake uses metaphoric description, Mettler uses a

\footnotetext{
${ }^{1}$ However, as will be discussed later, the awareness instilled in the observer of the presence of an authoring subjectivity does not necessarily reconfirm a definite or united framework through which the text is engaged.

${ }^{2}$ The title card that opens the film announces this principle of collection, stating that the film/journey is structured by intuitive processes and impulsive decisions: "In the spring of 1983 I took a trip into my intuition through Switzerland, Berlin and Portugal. The following images are, for the most part, impulsive intuitive reactions to the people and places I saw. They are cut together in chronological order with the same impulsive approach, as is also the sound."

${ }^{3}$ This approach is also a key feature in Chris Marker's experimental travelogue Sans Soleil (1983), in which a list is made of "things that quicken the heart."

${ }^{4}$ The audio track in the film was not recorded on location synchronously with the image track, although some 'live' sound is mixed in at various points. Instead, Fred Frith's score for the film often attempts to approximate or interpret the subjectively experienced qualities of being witness to whatever is shown onscreen. In reference to this relationship between the picture and sound tracks, Jerry White (2006) claims
} 
variety of cinematic devices that attempt to evoke the filmmaker's own sense of marvel before the objects and events he films. ${ }^{5}$

Not unlike the magical and the alchemic discourses of the Renaissance that genealogically precede forms like the wunderkammer, the arrangement of elements and artifacts in Eastern Avenue is directed towards the production of wonder, rather than 'curiosity' as it was defined by Enlightenment science. ${ }^{6}$ Rather than foster an itemizing or catalogical perspective that typifies its subject and classes it within defined parameters, the perspective elicited in Eastern Avenue aestheticises and prizes its subjects for their rare, singular, intangible or indescribable qualities. ${ }^{7}$ In taking objects and events out of their original context and placing them within this constellatory system, the film is able to transform the everyday into a series of spectacles or shocks, restoring or embalming their 'momentariness.' Eastern Avenue's operations therefore occupy a different set of priorities than films like Sifted Evidence and wexice, which actively deflate representation by presenting experience and being already overdetermined by description and cliché. Mettler's film functions instead like a Wordsworth poem, teaching an art of perception that seeks to enliven everyday experience. ${ }^{8}$

that "what Mettler seems to be trying to accomplish in Eastern Avenue is not such simple illustration or equivalence... but rather... an attempt to - as Charles Sanders Peirce might put it - make the images and the sound both vivid and approximate, iconographic and indexical" (White 2006, 13).

${ }^{5}$ Although these will be discussed in depth later, the most salient of such devices are framing, tracking and panning camera movements, and long takes.

${ }^{5}$ The search for and production of wonder is a consistent theme throughout Mettler's work, including his more 'mainstream' documentaries like Gambling, Gods and LSD (2002) and Picture of Light (1994), in which Mettler plainly admits this purpose in the voice-over narration. This is also a key argument underlining Tom McSorley's (2005) discussion of Mettler's work.

${ }^{7}$ In Mettler's more conventional documentaries, especially Picture of Light, these operations sometimes amount to satisfying a touristic desire for capturing and containing the anomalous and the ephemeral into a fixed state, onto the surface of the film and inside the borders of the frame. Eastern Avenue is notable for its lack of such picturesque imagery, making the foreign or distant in the film more difficult to appropriate or instrumentalize in the sense Leask describes.

${ }^{8}$ This operation counters modernity's/tourism's relentless production of the 'new,' which Wordsworth railed against as an ineffective way of satisfying desires for aesthetic nourishment. 
One of the cinematic devices Mettler uses prominently for these purposes in the film is the long take, which frequently creates what Deleuze termed 'time-images. ${ }^{9}$ Not unlike Wordsworth's 'spots of time,' these 'slices of time' attempt to restore the vibrancy and intensity of the experience they in part represent, to restore their "distinct preeminence" (Wordsworth 1998, 216). The film embodies the Romantic principle of the renewal of perception, in that its time-image operations register the minutiae of 'microoccurrences' happening in the mundane or the everyday that would be typically overlooked or taken for granted in ordinary experience. ${ }^{10} \mathrm{~A}$ long take of steam rising from a coffee cup, for instance, works against the experiential models and habitual forms of perception that would fail to take notice of such fleeting ephemera by aesthetically recoding the mundane as singular or unique, thus arousing a sense of wonder over the potentially infinitesimal permutations of shape and form lying within. In the opening image of the film, the observer is invited to invest in the special way that a flap on an airplane wing minutely rises and falls in response to the changing currents in the wind pulsing around it. Its time removed from chronology, the object acquires its own unique rhythmic dynamics. ${ }^{11}$ In a sense, this image functions not only as a poetic evocation of Mettler's travel experience, but also as a primer for the experience of travel itself. ${ }^{12}$

\footnotetext{
${ }^{9}$ Deleuze succinctly summarizes the concept of 'time-images' as instances where "time is no longer subordinated to movement, but rather movement to time" (Deleuze 1989, XI), and where "we are plunged into time rather than crossing space" (Deleuze 1989, XII).

${ }^{10}$ Deleuze describes the priority of the time-image as "making visible these relationships of time which can only appear in a creation of the image" (Deleuze 1989, XII).

${ }^{11}$ As will be discussed later, other cinematic techniques in the film, especially Mettler's approach to framing and camera movement, produce an equivalent removal of space from 'geography,' in the traditional sense of the term.

${ }^{12}$ Unlike standard tourist guidebooks, however, Eastern Avenue instructs in the art of aesthetic observation, rather than delineating an itinerary of prerequisite locations and stops. Mettler's introductory image incorporates the means or process of travel into the film's repertoire of experience, rather than privileging only the eventual destination.
} 
Like a Wordsworth poem, the record of subjective impressions presented in the film denotes experiences of aesthetic transportation, of the traveler being 'moved' to write, or, in this case, to take a moving picture. This effect of transportation is not only divorced from the requisite of being present at a culturally-confirmed touristic location, but also potentially 'moves' the reader/viewer without the necessity of physical movement or literal travel across geographic space. The aesthetics of transportation championed by Romantic poetry and experimental travelogues alike make travel a conceptually abstract enterprise, and therefore mutually embody transportation as a principle, rather than strictly as an act. ${ }^{13}$ Subsequently, travelogues in the Romantic tradition tend either to disregard the specificity of place, or obscure it entirely behind the represented intensity of being, in space and time and at the moment. While the locations visited in Eastern Avenue are revealed at the outset of the film, and while some images can be more easily ascribed to a certain place and time, the majority of the geographic locations in the film are 'hard to place.'

This is partly because of the way that Mettler's approach to camera framing has the tendency to abstract its subjects, making their specific context and origin frequently indiscernible. Sometimes, these abstractions are 'unraveled' to reveal the identity of the object represented, as in one sequence where it is eventually clear that the sharp diagonal shapes passing across the expanse of the frame are the undersides of highway overpasses, filmed from a low angle from the window of a moving car. More often, though, no 'resolution' is given, making the object-hood of what is shown on-screen less important

\footnotetext{
${ }^{13}$ As discussed in Chapter One, this position owes itself to ideas popularized by John Locke's writings on philosophical empiricism, which advanced the notion that sense is equivocal, subordinating the specificity of location to the obtainment of experience.
} 
than the aesthetic vibrancy it generates at the moment of observation. A shot roughly halfway into the film, to cite but one example, shows light reflecting off the permutations on the surface of a vaguely spherical metallic object, but preserves its obscurity. Even when the immediate context is supplied, however, as in the shot of the overpasses, the film still refuses to identify or fix the majority of its images into a preestablished cartographic grid of landmarks, cities and countries, except in a few isolated circumstances. Images of the Berlin Wall, for instance, are identifiable by the graffiti drawn on it in German, and are further confirmed by the visible presence of sightseers, pointing and taking photographs. The presence of tourists and touristic activity is also what sometimes confirms the geographic identity of certain locations in Chimera, where only a handful of locales are immediately recognizable, like an Egyptian sphinx and the $\mathrm{CN}$ Tower, and it is again in these shots that touristic activities are most prominent. This is not to say that either film depicts these spaces in a typically touristic fashion (i,e. using the language and approaches of the picturesque), as each of these films is committed to discovering new ways of experiencing and describing space, even at the expense of legibility. ${ }^{14}$ It is more accurate to suggest that the presence of tourists points to the way in which these specific sites have been coded, worked upon, and made 'universal' by touristic activities, which enhance their superficial accessibility. Eastern Avenue and Chimera, alternatively, eke out a more deconstructive and less linguistically determined approach to making 'the world' accessible to the observer.

Chimera is, like Eastern Avenue, a series of recollected impressions of travels through various countries, and the specific formal methodology Hoffman employs

\footnotetext{
${ }^{14}$ As Martin Schaub (1995) notes, Eastern Avenue consists of a collection of intuitive responses "to places and people [Mettler] does not want to define, nor pass on neatly packaged"' (Schaub 1995, 30).
} 
similarly not only makes the notion of place abstract, but also literally abstracts place. ${ }^{15}$ Hoffman shot the film by exposing a frame at a time while zooming or otherwise moving the camera forwards, and then slowing down the image track by re-photographing it using an optical printing technique, which effects "a Cubist kind of taking apart of the world. It splays the frame, making the image move." (Hoffman, in Hoolboom 2001b, 211). The images become impressionistically blurred or 'smeared,' causing places to be either indistinguishable from each other, or to literally 'blend' into one another. ${ }^{16}$ In each film, the divisions and separations between individual sites or 'minor' locations is mired or unclear, as are the points of separation between entire countries. ${ }^{17}$ Moreover, there are numerous instances where spaces and times directly overlap one another.

In a sequence in Eastern Avenue, Mettler's camera settles itself onto a close framing of windowpane, only to pull back and subsequently reframe the view over and over, perhaps imitating the movements of an insect, to provide multiple perspectives on the smatterings of snow frozen onto the glass. This image track is then superimposed over another shot, where Mettler similarly keeps reframing a view of a portrait being sketched of a woman's face. The sequence creates a series of modulations between these

\footnotetext{
${ }^{15}$ As disclosed in an interview between Hoffman and Mike Hoolboom, the film was shot in Banff, Finland, Russia, Egypt, England and Australia, and took seven years to shoot and edit (Hoolboom 2001b, 212).

${ }^{16}$ This technique resonates with the prismatic system of order that underlines Eastern Avenue, in that it formally traces commonalties among the elements it presents, irrespective of the surface differences of place and time that ostensibly separate them. Hoffman claims that Chimera "shows a world breaking down, and the images express the energy of change. The film doesn't insist that market people in Cairo's Khan Khalili and London's Portabello are the same, but that they share an energy related to colour, shape and form. That's why some of the film is abstract, to evoke these pleasures of sharing" (Hoffman, in Hoolboom 2001b, 212).

${ }^{17}$ While Eastern Avenue's introductory title card makes it plain that the film is constructed chronologically, there are many 'local' loops, superimpositions and fragmentations of time and space. Nevertheless, the title card infers that there are points in the film where images originating from one country cease and images from another begin. Yet, Mettler's techniques do not provide any clear demarcation of the borders between them. Mettler's later film Gambling, Gods and LSD, however, breaks the flow of the image track to insert black title cards that introduce each new segment of the film, bearing the name of the place in which it will be set.
} 
two 'sheets' of time that suggest, in the manner of the wunderkammer, a plentitude of possible spatiotemporal combinations between these constellatory points. ${ }^{18}$ It is not so much the case that one image track 'precedes' or 'follows' the other either in geographic space or chronological time, but rather that they mutually coexist on a plane where such distinctions are irrelevant. ${ }^{19}$ Arrangements like this one recur frequently throughout the film, even within spaces and times that are holistically contained within a single unbroken shot. While studying the reflection of a woman's face in the window of a darkened subway car, Mettler uses the semi-transparency of her reflection to create a counterpoint of simultaneous forms of space and time, as the minutiae of her changes in expression are set against the polyrhythms created by underground signal lights and passing trains on the adjacent railway track. Even in a moment located entirely within the 'present,' Eastern Avenue hints at the transitivity and impermanence of presence and Being at any given moment or place. These priorities reemerge in the experimental travelogue's approach to constructing perspective, as it relates to ideas of presence and stability.

As we saw in the case of early cinema (see Chapter Two), the 'anti-nomadic' procedures for centralizing perspective and managing attention on the representational plane exemplified by the Quattrocento system intertwine with ideas of fixing, locating and cohering identity and subjectivity. The imagistic techniques for constructing a

\footnotetext{
${ }^{18}$ Following the prismatic system of organization that shapes the film, this sequence closes with the camera panning up the arm of the woman painting the picture and then framing her face in a composition that not only recalls the portrait she is working on, but also the portrait shots of other human subjects that came earlier in the film. It also recalls the association made early in the film in a set of images, discussed above, that connects the portrait of a face to an image of folded hands.

${ }^{19}$ According to Deleuze, the time-image "goes beyond the purely empirical succession of time - pastpresent-future. It is... a coexistence of distinct durations, or of levels of duration; a single event can belong to several levels: the sheets of past coexist in a non-chronological order" (Deleuze 1989, XII).
} 
centripetal arrangement of vision bear significance as to how spaces and times are both imaginatively constructed and literally worked upon in the 'real' world. However, as Heath demonstrated in his discussion of 'anamorphosis,' these centralizing devices are prone to frequent collapse, producing excesses and 'blind spots' in vision as well as producing an unsettling awareness of the potential infinities of time and space beyond the borders of the frame. Much like the depiction of imperialistic and colonizing forces advanced by post-colonial theory, these centralizing devices are understood by critics like Heath and Burch to be unable to recuperate fully space and time into the representational plane, thus making their monolithic and totalizing ambitions, to paraphrase Leask, at least partly rhetorical in function. Rather than being able to maintain a stable, fixed 'ground' of place, time, observation, attention, subjectivity and identity, the 'center' often tends to undergo continual change, disruption, and renegotiation.

The dynamic Heath describes presents itself in Reading Canada Backwards, a travelogue that condenses a cross-Canada train journey from Vancouver to Halifax into a twelve-minute timespan using a time-lapse technique that records one frame of film for every three miles of train track (Thompson 2001,4). The image of 'Canada' presented here corresponds in some respects to expectations laid out by a tradition of touristic representations featuring the standard 'postcard' iconography. ${ }^{20}$ In another important sense, however, aspects of this space remain inaccessible to representation and cannot be summarized as neatly as picture postcards might suggest. The recognizable or iconic features of landscape in Reading Canada Backwards 'resist' being fixed or stabilized within the frame, on account of the way in which Topping's approach to time-lapse

\footnotetext{
${ }^{20}$ As Thompson notes, "Topping's camera witnesses most of the archetypal Canadian landscape: Rocky Mountains, prairie grain fields, Great Lakes, and on to Halifax Harbour" (Thompson 2001, 4).
} 
photography keeps them constantly unstable. Not unlike L'Arrivée d'un train à la gare $d u$ Ciotat, the perspective arranged in Reading Canada Backwards continually oscillates back and forth between a strongly 'grounded' and a more polycentric or centrifugal form of vision. The stable and relatively constant presence of the train within the image is juxtaposed against the variable and unpredictable elements of the passing landscape, creating an internal tension within the frame that keeps vision in a state of simultaneous fixation and dispersion. Despite the way in which the film's compositional strategy adheres to the principles of the Quattrocento system, the centripetal point of attention keeps unpredictably shifting, disallowing the containment of the available landscape into the stable proportions of picturesque imagery. ${ }^{21}$

Additionally, the way in which the movements of the train along the rails, which are registered in the image, are exaggerated by the condensation of time, causes the image to 'vibrate,' giving an elastic quality to whatever is represented within the frame, and also to the borders of the image itself. This effect is enhanced by Topping's decision to shoot the film without a tripod. ${ }^{22}$ Stylistically, the effects produced by these techniques are analogous to Hoffman's approach to shooting in Chimera, where objects similarly take on a 'flexible' quality. To this effect, Eastern Avenue contains several 'trombone' shots, filmed from the rear of a moving train, which similarly elasticize the properties of the object represented, and also importantly destabilize the spatiotemporal relations

\footnotetext{
${ }^{21}$ Ordinarily, these aspects of recognizable Canadian iconography would provide a stabilizing point of access, and would enter and then vacate the frame slowly enough to allow a more contemplative or 'distanced' appreciation. However, Topping's relatively extreme condensation of time and space causes these elements to rotate much faster than would be expected of a journey taking place in 'real time,' making these potentially readable elements pass by 'in a flash,' thus divorcing them of much of their legibility, and hence, their potential to be efficiently appropriated.

${ }_{22}^{22}$ Topping's shooting methods are described on the film's page in the CFMDC catalogue (www.cfindc.org).
} 
between observer and object. ${ }^{23}$ In suggesting the uncontainable character of space, which either deconstructs itself or persistently escapes every time it is introduced into the borders of the visible, these elastic qualities have a significant impact upon the imaginative conceptualization and mapping of 'real' spaces. By making the frame itself unstable, these films suggest an inherent limitation upon perspective for representing 'real' space. In Reading Canada Backwards especially, the supposed authority and totality of representation imposed by the perimeter of the frame is ultimately unable to summarize the vast and unimaginable totality of both Canada (space) and the length of the journey (time) ${ }^{24}$ While at once, the 'whole' of Canada is made available or 'brought closer' to the observer through a condensation of time, that space is kept 'at a distance' by remaining somewhat inaccessible and obscure. Similarly, the brevity of the represented movement through space cannot possibly communicate the extent of the time taken to complete the physical journey it describes, despite ostensibly making that time more tangible. ${ }^{25}$

If 'real' space/time can be named and defined, and if it can be mapped, in the conventional sense of 'usefully' aiding future travelers to coordinate themselves, then territorialization can be achieved, even if only on a conceptual plane, by way of successful and 'accurate' description and delineation. This was precisely the aim of explorers making their discoveries under the banner of Enlightenment science. The idea

\footnotetext{
${ }^{23}$ The technique informally known as the 'trombone' shot involves combining a zoom in with a tracking movement outward, introducing a retrograde movement that dramatically rearranges the apparent size and scale of the objects represented, as well as the relative distance between observer and object. It is most famously used in Vertigo (Alfred Hitchcock, 1958).

${ }^{24}$ The film documents a journey of approximately 4000 miles (www.cfmdc.org).

${ }^{25}$ These dynamics are also prominent in Joyce Wieland's experimental travelogue Reason Over Passion (1967 - 68), in which the impossible task of summarizing 'Canada' geographically is related to Prime Minister Pierre Trudeau's promotion of an image of Canada as a neatly bilingual and bicultural nation.
} 
of 'centre' used to discuss the construction of perspective and the arrangement of vision apparent in the image is therefore not unrelated to the idea of 'centre' advanced by Bruno Latour in his model of 'centres of calculation.' If an image of a place makes that place legible, and secures the spatiotemporal coordinates connecting place to traveler to text to observer, then that place can be successfully 'brought back,' reconstructed, and synthesized. ${ }^{26}$ When perspective is constructed in a more polycentric, dispersive, fragmentary or panoramic fashion, however, relations of 'here' and 'there,' 'then' and 'now,' subject and object become muddled, and subsequently the foreign or distant, or, in the case of Topping's film, the domestic, become less accommodating to instrumentalizing impulses. Eastern Avenue and Chimera extend this operation even further by opting to abstain from positing a 'centre' from which to deviate, save for the authoring subjectivity that serves as the text's central referent. Imagistically as well as conceptually, these two films do not stage the centre's breakdown or dissolve (as in Sifted Evidence and Mexice), as their impression of elsewhere is already dispersed, polycentric, fragmentary, etc. Mettler and Hoffman seek out and explore the 'edges,' the unknown or indeterminate spaces and times that resist attempts at containment as much as they sometimes defy description. While the process of applying fixity onto flux and frame onto infinity is often taken up as self-reflexive discourse, Mettler and Hoffman are more concerned with promoting an imaginative conceptualization of the transitive and

\footnotetext{
${ }^{26}$ Darrell Varga notes that the setting of 'the north' in Picture of Light "refuses submission to this commodity logic," and that rather than attempt to impose such a logic upon space, Mettler instead presents it as a heterotopia that refuses "to be fully encompassed within the act of signification, [and] undermines the naming and ordering function of language" (Varga 1999, 80). In Eastern Avenue, we see a similarly non-instrumental deployment of Romantic vision that is resigned to its inability to name, and thus delineate and territorialize the foreign and the distant.
} 
permeable character of space and time, and of the variability of the circumstances of observer and object/event. ${ }^{27}$

The idea that the observer is produced in these films under a contingent arrangement of spatiotemporal concepts, which are subject to sudden change or renegotiation, recalls the tendency of the experimental travelogue to stage the adjustability of scale. This willingness to relinquish the stable grounds of objective spatiotemporal relations on which empirical observation is traditionally conducted is a feature common to all three films under consideration here. The relations established in Reading Canada Backwards between the passing of miles (space) and the recording of film frames (time) creates a temporary and rhetorical arrangement between the two that conceptually keeps the observer in flux between the expansion and contraction of the proximate and the remote. A parallel operation is apparent in Chimera, in that the ratio of the spatiotemporal intervals presented on the image track is not set at a fixed rate. The length of shots as well as the relative speed of the frame rate often varies from shot to shot, thereby erasing any sense of stability or constancy in the relation of observer to 'world' soon after it is introduced. Eastern Avenue takes up the adjustability of scale in a similar fashion to how Sky Scrapers of New York City combines elements of the miniature and the gigantic, and sets them against each other in a similar kind of oscillation. Eastern Avenue opens, not unlike Sifted Evidence, with a sequence of aerial

\footnotetext{
${ }^{27}$ In speaking of Picture of Light, Varga remarks, "Mettler's project acknowledges the unknowable excess of the north while operating as a self-conscious reflection on the desire to frame this world via the cinematographic apparatus, and the process by which the technological frame delimits and shapes that which we presume to see, and ourselves as seeing subjects" (Varga 1999, 79). This statement could easily apply to Eastern Avenue as well, as the matter of mediating 'the world' is embodied in numerous shots interspersed throughout the film where aspects of landscape or human activity are seen through the aperture framing created by windows, car doors and rear-view mirrors, and glass shopfronts. Shots such as these form an acknowledgement of the difficulties of working 'beyond' pre-established paradigms of experience and vision.
} 
images that Mettler shot from the window seat of a passenger airplane. The last of the images shows the grid-like patchwork of the 'miniature' landscape below slowly growing in size as the airplane descends before landing. What is to be made of this introductory sequence when the perspective of the explorer becomes notably less omniscient and transcendent once on the ground? What follows are extreme low-angle shots that dwarf the traveler beneath the towering expanses of domed cathedral roofs, images that speak of a Swiftian transformation in which the giant suddenly finds himself in a terrain of vastly unpredictable surfaces that radically alter his preconceived notions of relative scale, suddenly transforming him into a diminutive Lilliputian. Yet, the process of readjustment is kept open and ongoing, as shown in one sequence midway through the film, where Mettler demonstrates the impermanence and fluidity of scale as it relates to the experience of space. Mettler presents a small child on the beach who places a tiny toy truck on the summit of a mountain he has built from sand, juxtaposing coexisting principles of scale in a single spatiotemporal 'event.' This sequence also invokes the simultaneously constructive and destructive capacities of the gigantic, embodied in folk tales in the figure of the giant, and manifested in the depiction of the sublime forces of nature in Romantic painting (Stewart 1984, $79-80$ ).

The sublime is, appropriately, associated with sub-rational or otherwise indescribable experience, in that description of sublime experience tends either to avoid intellectualization or explication in rational terms, or is ultimately not reducible to such extrapolation. While it is more a quality of feeling and of experience than a definable object, the sublime has been typically evoked on the representational plane by a lexicon of signifiers standardized by both Romantic writings as well as the touristic practices they 
inspired (see Chapter One). The presence of the sublime is conventionally alluded to with references to ruins, defacements, decay, roughness, irregular lines, and asymmetries, which disturb 'polite' classical and neo-classical aesthetics which privilege proportion and symmetry while appealing to an idea of timelessness. There are many examples of the deployment of a sublime 'iconography' in Eastern Avenue. Ruins and decayed spaces are especially prominent in the portion of the film presumably set in and around Berlin. In these sequences, Mettler's camera finds a plethora of debris strewn on the grounds of abandoned buildings, piles of rubble, smashed out and bricked up windows, remains of vehicles in auto scrapyards, and the emptied barracks and towers of what appears to be a former concentration camp. ${ }^{28}$

Whereas the picturesque offers the observer an opportunity to apprehend the object of vision in an imaginative totality, and thus achieve a sort of ocular dominance and security over perspective itself, the sublime in its 'pure' form denies the observer any pretense to a transcendent or omniscient viewpoint. ${ }^{29}$ Varga explains that "the sublime is beyond pleasure and scale; it emerges at the border of our aesthetic imagination coextensive with displeasure. The sublime, as boundless chaos, serves the (non-Hegelian) dialectical function of negating pre-established assumptions of harmony, coherence, and order" (Varga 1999, 81). Like the gigantic, the sublime tends to offer only partial views that carry with them the potential to overwhelm the observer. Mettler's film appeals to

\footnotetext{
${ }^{28}$ The graffiti visible on the Berlin Wall adds, much like the images of the concentration camp, an enigmatic historical dimension to the Romantic attraction to 'defacements' and 'ruins,' as well as to Romanticism's ideas of transitivity and impermanence. As McSorley (1995) says of Mettler's work: "Everything is in motion, everything is shifting and changing constantly: nature, itself in a constant cycle of renewal and decay; identity, unstable and frail; perception, tentative and personal;... political arrangements, tentative and vulnerable, as we... see the now erased Berlin Wall in Eastern Avenue" (McSorley 1995, 108).

${ }^{29}$ The picturesque dynamic of observation and engagement with the 'world' is evident in forms like Claude glasses (Chapter One) and miniatures (Chapter Two).
} 
this quality with techniques like camera movement which often present a fragmentary view that does not disclose or invent borders at which the observer might attain a level of distance. Two alike sequences from Eastern Avenue illustrate this position, each from the final third of the film, in what appears to be Portugal. In the first sequence, which examines in close detail the cracks in the rocks that cover a beachfront, Mettler's camera scurries across this infinitely expanding surface, at times following the irregular lines of fissure, and at other times diverting to find a new pathway. In the second sequence, Mettler's camera roams chaotically around the interior of a cathedral built with human bones, which protrude halfway out of the walls, never revealing the larger architectural shape of the place. By appealing to ideas of the miniature and gigantic, both of these sequences evoke the unknowable forces that produced these phenomena, and the indiscernible logics that underpin both nature and death.

Beyond merely staging a dissolve of lines of separation and definition on the representational plane, another key feature of the sublime is its destabilization of the definitions and borders that demarcate the differences between observer and subject, allowing them to mutually interpenetrate each other. ${ }^{30}$ Exemplary in this respect is the shot in Eastern Avenue in which Mettler rests his camera on a table and turns it on himself. In the shot, Mettler is looking (at his camera) and his camera is filming (himself looking). Immediately, the visual presence of the filmmaker confirms their structuring activity in making the film, and yet the filmmaker is also transformed into object. Mettler

\footnotetext{
${ }^{30}$ These dynamics are also apparent in Julia Kristeva's (1982) writings on the abject and in Mary Douglas' (1966) discussion of stickiness. Kristeva writes that the abject is "what disturbs identity, system, order. What does not respect borders, positions, rules. The in-between, the ambiguous, the composite" (Kristeva $1982,4)$. Douglas, inspired by Jean-Paul Sartre's Being and Nothingness (1943), notes that "stickiness is a trap, it clings like a leech; it attacks the boundary between myself and it. I remain a solid, but to touch stickiness is to risk diluting myself into viscosity" (Douglas 1966, 38).
} 
smiles at the camera in slow motion for over a minute, becoming a poetic image on par with the other portrait shots in the film. In this instance, not being behind the camera has prompted Mettler to reproduce what he has already seen, behaving in much the same manner as the other portrait subjects. The image speaks of an acknowledgement that the conceptual imagining of the figure of the filmmaker is ultimately a product or an effect of the camera, rather than a unified, mastering subjectivity poised to master the natural world.

This is not, however, to suggest that subjectivity is in any sense radically destroyed by the operations apparent in either the film or the sublime in general, but rather that an understanding is established that concepts like identity, vision and presence are multiple and heterogeneous. The shot at the beginning of the film of ice-covered tree branches may demonstrate this notion. Mettler first presents this view out of focus, slowly bleeding the image into legibility before refocusing again on another, previously unseen 'layer' of branches that previously was hidden behind the immediately apparent view. The camera then refocuses again to reveal a third layer in this dense and potentially infinitely expanding field of vision. Perspective here is not exposed as 'blind' or unseeing in some sense, but is rather witness to the successive revelation of new layers of coexisting untapped depths, an abundance of previously unrealized surfaces.

Like Chimera, Eastern Avenue insists upon divestment into presence and immersion in the moment, but unlike and Sifted Evidence, this is not presented as a problem or a frustration of learning and knowledge. Unlike the teleological aims of vision and observation dictated by the Enlightenment, the engrossing and poetic uses of cinematic techniques in these films promote a kind of Truth based primarily on sense. 
This Truth may come at the expense of Selfhood, both in the way that Self was understood to be enhanced and fortified by rigorous and disciplined observation in the Enlightenment, and in the way that the sublime produces instances of ontological intensity.

The presence within the experimental travelogue of attempts to invoke the aesthetics of the sublime are appropriate, given that films like Eastern Avenue are so concerned with the production of wonder. Enlightenment discourses of curiosity (Leask), alongside forms such as the camera obscura (Crary) and the Quattrocento system (Heath) are alike in their mutual tendency to repress or defer the possibility of ontological crisis by grounding observation in appeals to objective distances and separations between observer, object and text. However, in the arrangement of the observer encountered in the Cinema of Attractions (Gunning), devices of wonder (Stafford), and the experimental travelogue, shocks to the observer's sense of Being typically form the basis of the thrill, which is the text's crucial organizing principle. However, this is not to suggest that the thrill destroys or performs a breakdown of selfhood and Being in any totalizing sense. Rather, the concern of the thrill is the production of ontological intensities: conditions where the Self is kept in an ideally constant state of emergency, always negotiating relations between the body, the text, the object and the 'world' that surrounds them.

Because the experimental travelogue is typified by its adjustability of scale (as embodied in the films' elastic operations), it is not so much that they cast the observer into some permanent state of chaos and uncertainty, but rather, that they stage a continual oscillation between moments of calm tranquility and shocking disorder. While at times Chimera seems to offer an infinite flow of chaotic impressions, it also regularly halts the 
picture and sound tracks for a few moments of black leader and silence to provide a brief window of closure and respite. Similarly, Eastern Avenue juxtaposes images of transcendent balance and harmony, like the image of the tree branches, with frenetic manipulations of space and time. In the discotheque sequence of Mettler's film, the camera swings freely from dancer to dancer, and as the sequence progresses, they become less like individual bodies and more a flow of interchangeable bodies and sensations, mutually connected by the rhythms of the music they dance to rather than demarcated as separate entities. As the image track gradually accelerates in speed, the soundtrack intensifies in tempo, with pizzicato violins chaotically climbing and descending chromatic scales. Not unlike Chimera, Mettler's formal approach here transmutes these bodies into undefined streaks and streams of light and colour, making them literally blend together on the picture plane, not staging the 'death' of the subject per se, but producing a proliferation of subjectivities, and performing their fragmentation into dispersed entities.

Above all, this should communicate that thrills are choreographed; they are structured and organized. Benjamin established that in cinema especially, the mechanization of shocks is a formal principle. ${ }^{31}$ This means that the thrill's production of intensities is regulated, codified and anticipated to a certain degree. Indeed, the central formal principles of the films discussed in this chapter lay down a pattern of expectation against which the observer is tested. Eastern Avenue establishes its own principles of

\footnotetext{
${ }^{31}$ Comparing the reception of a work of cinema to one of painting, Benjamin remarks: "The painting invites the spectator to contemplation; before it the spectator can abandon himself to his associations. Before the movie frame he cannot do so. No sooner has his eye grasped a scene than it is already changed.... The spectator's process of association in view of these images is indeed interrupted by their constant, sudden change. This constitutes the shock effect of the film, which, like all shocks, should be cushioned by heightened presence of mind" (Benjamin 1968, 240).
} 
arrangement in the introductory title card, and both Chimera and Reading Canada Backwards are entirely structured upon a set of rules and filmic procedures that announce their status as thrills. However, at the same time as the thrill is mechanical, its operations remain in flux, disallowing possibilities for total apprehension and security. In Chimera and Reading Canada Backwards, the formal 'rules' of engagement with the 'world' at hand keep changing, and in Eastern Avenue, the 'prismatic' system of order that informs the text's structure similarly continually redevelops the manner and arrangement of observations and spectacles. In short, these films experiment with the dynamics of engagement, emplacement and presence, and if a purpose can be ascribed to them, it is to use these experiments as a way of redefining and expanding the self, subjectivity and identity.

The teleological structure of Enlightenment curiosity figures observation within a linear progression towards pedagogic or 'useful' knowledge, and towards a singular, unified meaning. In contrast, the thrill, which is the basic unit component of the experimental travelogue, rehearses a mobile set of relations between the body and the 'world' that equivocally produce multiple and heterogeneous meanings, whose only claim to 'Truth' is based upon their production of wonder and other intensities of experience. Whereas curiosity, in Enlightenment terms, attempts to objectify the observer, placing him or her within a field of rationally defined fixed coordinates, the thrill subjectifies, creating knowledge of the tenuous limitations and boundaries separating body and psyche, text and 'world,' or pleasure and anxiety. Instead of imposing universalizing principles on these elements, the thrill insists upon their contingency. Despite ostensibly unsettling identity and subjectivity by 'shocking' it, the thrill tests the 
observer's ability to receive shocks, both in intensity and in duration, and thus gives the observer meaning as a subject.

In the experimental travelogue in particular, this subjectification occurs in the context of exploring destinations of time and space, and it is thus that it can be claimed to conduct a set of theoretical relationships to space and time. The experimental travelogue makes a priority of presenting the thrill of 'movement' through and within space and time, and although these thrills work beyond the strict Cartesian mapping of spatiotemporal coordinates, another kind of 'mapping' is nevertheless at work. They privilege travel above destination, transportation over arrival and departure, and subordinate the obtainment of 'knowledge' to the obtainment of aesthetic experience. As with Kinglake's Romantic travel writing, Truth is only accessible here in the poetic sense, as the deepening of the observer's sensitivities to aesthetic experience, and the suggestion of strategies for the enlivening of perception. The films discussed in this chapter embark more specifically upon an experimental mode of geography, amounting to a diverse and heterogeneous grouping of theories on how to experience, document, map and revisit places. This is an approach to mapping space and time that seeks to guide the movements of future travelers, but not in the traditional cartographic sense. Rather that establish secure relations of fixed points, this mode of geography allows points in space and time to overlap, dissolve, and repeat amongst themselves, and perhaps most significantly, it does so by allowing the observer to undergo the same processes. In the concluding portion of this thesis, a discussion of Philip Hoffman's Kitchener-Berlin will illuminate an analogous exploration of history and the past, by offering a sketch of an experimental method of historiography. 


\section{Conclusion:}

\section{A Veiled Flight: The Experimental Travelogue as Historiography}

The concluding portion of this thesis is concerned with historiography, a mode of writing that Stephen Bann (1995b) claims was an important feature of Romanticism, and the style of which characterizes the experimental travelogue's approach to dealing with space and time. A look at the involvement of Kitchener-Berlin (Philip Hoffman, 1990, $37 \mathrm{~min}$ ) with the processes of writing history will show another facet of Romanticism's general influence upon experimental filmmaking, and will illuminate the reasoning behind the critical methods this thesis has employed to historicize the experimental travelogue. In the way it conducts historiographic activity by freely juxtaposing different times, spaces and historical references, Kitchener-Berlin is a film that crystallizes the themes of misrecognition and pseudomorphosis that have underlined the various comparisons offered throughout this thesis between the Romantic period, early cinema, and experimental film. In its operations, methods, structure and aesthetics, Kitchener-Berlin represents an experimental approach to history, and an historical form of traveling.

Kitchener-Berlin is a travelogue in which 'movement' between points in history is performed through explicitly cinematic operations. The film attempts to unearth buried relationships between the town of Kitchener, Ontario and Berlin, Germany, with which Kitchener shared its name prior to World War One, and problems of erasure, identity, and territory implicit in the renaming of the town. Across the course of this historical journey, Hoffman 'travels' through time and space by integrating and combining visual elements associated with different spatial and temporal epochs and originating from a variety of sources. Kitchener-Berlin is comprised of footage shot in present day Kitchener, still photographs and home movies shot in Kitchener in the time when it was called Berlin, 
newsreel and military footage of Berlin, Germany during wartime, and television images of a Papal visit. That Kitchener-Berlin should 'travel' by way of montage and optical techniques immediately raises the question of the validity of its inclusion within the corpus of experimental travelogues, in that unlike the other films discussed in this thesis, it does not 'go' anywhere in a literal, physical sense. It does not stage a journey to an 'other' place, but rather, stays at 'home.' While at first seeming to challenge the parameters of the genre tentatively established by the operations of the films discussed in the previous two chapters, KitchenerBerlin can in fact be perceived as a cumulative extension of the operations of those films. Rather than represent an exception to the trends discussed in Chapters Three and Four, Kitchener-Berlin represents a further development in the experimental travelogue's deconstruction of ideas of spatiotemporal fixity and permanence. It embodies the same deemphasis on the importance of validating authentic 'presence' in the foreign land seen in Chapter Three, and presents the same possibilities for overlaps of space and time seen in Chapter Four. Kitchener-Berlin's characteristic style of 'traveling without moving' (or more accurately, 'moving without going') can be elucidated with an explanation of its formal strategies. The various streams of images in the film frequently overlap one another in superimposition, and the way in which Hoffman exploits the 'negative' or dark spaces in the source images often results in the various layers appearing as interpenetrating fragments that 'blend' together in a fluid melange. The base of these 'onionskin' layers, especially in the film's first third, is the Steadicam footage Hoffman shot in Kitchener, which remains distinctive from the home movies and newsreel footage because of its 'dreamlike' smoothness and disembodied mobility. These visual qualities also represent the 'state' of the image that makes the film's freeform temporal and spatial explorations feasible. As Hoffman notes of the Steadicam: 
It floats over surfaces, looking as if it can move without gravity, gliding in space... It's something we can't do with our bodies, except through technology... The Steadicam floats over continents, adding layers until there are three, four, five images over top each other (Hoffman, quoted in Hoolboom 2001a, 106).

The film travels through time and space in an explicitly technological manner, through camera and editing, and it is suggested that these technologies possess a potential to stage a much more conceptually expansive journey to otherwise unthinkable distant regions and remote pasts than a literal movement of bodies and materials across geographical borders. ${ }^{1}$ Hoffman's description of his camerawork in terms of fluid metaphors also echoes Gilles Deleuze's (1986) commentary on L'Atalante (Jean Vigo, 1934), in which he claims that the aquatic setting of the film promotes types of movement and vision impossible in strictly 'grounded' narratives.

Deleuze notes how a 'clairvoyant function' develops in water, "as if perception enjoyed a scope and interaction, a truth which it did not have on land" (Deleuze 1986, 79). Clairvoyance is a type of seeing that is not 'grounded' objectively in the manner of forms like the camera obscura, and can observe without the necessity of 'presence,' as it operates beyond the limitations of indexicality and physicality. On water, one has the ability to conduct 'television,' being able to see far-off movements from wherever one is, which presents the possibility of revealing hidden, obscure or ephemeral truths. ${ }^{2}$ Moreover, on water, observation does not take place from a fixed position, meaning that:

On land, movement always takes place from one point to another, always between two points, while on water the point is always between two movements: it thus marks the conversion or inversion of movement, as in the hydraulic relationship of a dive and a counter-dive, which is found in the movement of the camera itself (Deleuze 1986, 79).

\footnotetext{
'This ease of mobility parallels the early cinema travelogue's 'habit of flux,' its conceptual ability to stage journeys between the microscopic and the telescopic, and adjust scale between the miniature and the gigantic (see Chapter Two).

2 "It is in the water that the loved one who has disappeared is revealed" (Deleuze 1986, 79).
} 
Like on water, observation in Kitchener-Berlin transpires between 'two movements' rather than taking place from a stable position, further destabilizing any idea of either 'home' or 'away' as holistic, fixed sites. Thus, the Steadicam's fluid pans across modern-day Kitchener do not simply provide the context of historical investigation, but trigger the additional 'movements' across time, time and history represented by the accumulating layers of superimposed images. As the layering of images becomes progressively more dense and indiscernible, their content is transformed into material of pure sense, creating whirlpools and eddies of historical moments, thrown together in the vortex of time and producing incidental counterpoints of significance. ${ }^{3}$ In addition to imagining a mode of vision for seeing long-past historical fragments (television), Kitchener-Berlin also hypothesizes a form of observation that fragments the 'self' of the observer.

The middle sequence of Kitchener-Berlin contains extracts from The Highway of Tomorrow, or, How One Makes Two, a film made by a Canadian businessman named Dent Harrison in the 1930s. ${ }^{4}$ The Highway of Tomorrow depicts a transatlantic dirigible flight, which Harrison, who appears in the film, decides to film from two separate perspectives by splitting himself in two. Harrison's 'twin' is created in the film through a double exposure effect, multiplying his image within the frame. In compliment to the 'televisual' dynamics of the film's first and last sequences, the Highway of Tomorrow sequence stages 'telepresence,' allowing Harrison to be in two places at once so he can photograph the flight from both inside

\footnotetext{
${ }^{3}$ The interconnectedness of the images in the blend of superimposed layers in Hoffman's film recalls the recombinable organization of elements in the wunderkammer (see Chapter One) and in films like Eastern Avenue (1985) (see Chapter Four).

${ }^{4}$ Philip Hoffman, in an interview with Mike Hoolboom, recounts how he discovered the film at the National Archives in Ottawa, while doing research for Kitchener-Berlin: "I was really moved by it. It touched something in me... The film was made by Dent Harrison, a British immigrant who came to Canada in the early part of the century... He made enough money to travel and own a movie camera. He made what I think is the first, Canadian, surrealist film" (Hoffman, quoted in Hoolboom 2001a, 106).
} 
the cockpit of the dirigible and from the ground. ${ }^{5}$ The sequence provides a suitable container for many of the activities of the experimental travelogue discussed throughout this thesis. Like the epistemological travelogues, it denies any singular or 'authoritative' view of events, distributing observation across two mutually incompatible perspectives. ${ }^{6}$ Like the ontological travelogues, it presupposes no singular or 'authoritative' idea of selfhood, dispersing identity and subjectivity outside of the original witnessing "body. ${ }^{77}$ As will be demonstrated, Kitchener-Berlin's construction of an exploratory form of observing fragments of history, through a fragmentary understanding of self, owes itself to the developments made by the Romantic movement, and in particular, the changes made to the practice of history in the Romantic period. Some of the features of Romantic historiography will be familiar, as the principles behind them are common to Romantic travel writing and poetry. Most pertinent to the development of historiography is Bann's analysis of how in the nineteenth century history became more widely accessible in an imaginative or conceptual sense, as a material for representation and as a vehicle for speculation.

Bann claims that Romanticism marks the moment that history became self-conscious, "and to that extent established itself, at least potentially, as an autonomous vehicle for imaginative reflection" (Bann 1995b, 11). Just as in the Renaissance 'Age of Discovery,' where space became conceptually more accessible, in the Romantic period, time is no less opened up to possibilities for exploration, figured in terms of relationships with artifacts and relics of the past. ${ }^{8}$ Bann claims that the 'sense' of history encountered in the Romantic period

\footnotetext{
${ }^{5}$ Later scenes simply crosscut from one Harrison to another as they take up their respective viewing positions.

${ }^{6}$ This is especially evident in that Harrison and his double appear in the film as scientists, signaling a deconstruction of the disciplinary form of vision discussed in Chapters One and Three, as well as the ideological implications of control and mastery associated with it.

${ }^{7}$ As with the sublime, identity and subjectivity here are not reducible to representation by a singular perspective, as discussed in Chapters Two and Four.

${ }^{8}$ Space was 'opened up' in the 'Age of Discovery' in the sense that explorers, travelers and empire builders were literally and physically traversing 'new' and 'virgin' territories, and also in the sense that for the general public,
} 
was so qualitatively different from what preceded it that the form through which history was written and presented was able to multiply and diversify representations of the past to the extent that a new code was formed. The Romantic period, in other words, produced a distinct mode of historiography, which parallels Romantic literature and poetry. Just as critics like S.T. Coleridge and Charles Baudelaire defined Romanticism as the prioritization of the form of communication above the matter communicated, Bann notes that figures like G. W. F. Hegel in The Philosophy of History $(1830-31)$ came to define history as that which "comprehends not less what has happened, than the narration of what has happened" (Hegel 1956, original emphasis, quoted in Bann 1995b, 12). However, not unlike the way the Enlightenment defined and privileged a certain style of 'curiosity' as a mode of study, a substantial amount of historiography in the Romantic period was characterized by objectivist rhetoric. The Enlightenment's prized form of historiography involved a presentation of the facts without any apparent intervention of the historian in the text. ${ }^{9}$ Some writing of the period presents history along the lines of the nineteenth century museum, where the order of things is supposedly intrinsic and artifacts possess a quality of already having been 'put into the past.' Other types of historiography, however, incorporate rhetoric that describes the process of writing, recording or observing into the presentation, which subsequently "bears the marks of the speaker's agency" (Bann 1995b, 80). Romantic historiography, not unlike the work of Alexander Von Humboldt and George Forster, attempts to 'integrate' this agency into

\footnotetext{
the imaginative perimeters of what constituted 'horizon' - the limits of space - were dramatically increased by news and stories of the 'New World.' As discussed in Chapter One, these developments were paralleled by the Romantic's 'interior' exploration of new horizons of consciousness and feeling.

${ }^{9}$ It is worth noting that despite the Enlightenment's prioritization of the 'removal' of the author from the account, there was at the time a long-standing genealogy of writers inserting 'themselves' into the text, albeit in the appropriate and ordained place and manner. Acknowledgements of patrons, tributes to God, and citing of the writer's sources were conventions that dated back to the Middle Ages, and were still in circulation in the nineteenth century (Buzard 2001). However, as shown in Chapter One, the writings produced as well as the approaches to writing in the Romantic period were heterogeneous and diverse, and consequently, 'subjectivity' was deployed to different degrees and in a different fashion across various sites of cultural production.
} 
narrative and, moreover, into the structure of the work in the form of a rhetoric of intense or vivid response to places and objects. These changes in priorities reflect the wider cultural context of modernity, in which, as discussed in Chapters One and Three, subjective interpretation begins to become privileged when knowledge is discovered to be ultimately unaccountable. Bann draws upon Michel Foucault's The Order of Things (1970) to trace a connection between this epistemic crisis and the proliferation of history, noting that a growing awareness of the limitations of 'man' causes historiography to become more experimental.

Foucault hypothesizes that the transformation of the Western episteme enacted by the forces of modernity in the early nineteenth century was intimately connected to the deconstruction of the Cartesian principles that privileged 'man as the measure of all things.' The expansion of disciplines like natural history and linguistics in this period reflect this crisis of knowledge. Alongside the growth of paleontology and the increase in discoveries of fossilized prehistoric remains, civilization and language, once thought to be uniquely human enterprises, were revealed to have their own long-standing and outlasting genealogies, as well as systems of development that worked independently of 'man's' intervention. History was no longer thought to be exclusively created by 'man,' nor exclusively documented and recorded by 'man.' In this context, the practice of history becomes, according to Bann, "a strategy of recuperation" (Bann 1995b, 10), a way of recovering, appropriating and reimagining something already completely, irretrievably lost to the historian. This sensibility, akin to mourning, is what lies behind the expansion of historical awareness and curiosity in the Romantic period, as well as the production of the desire for relics, antiques and artifacts of the past. What is common to all of them is an acute sense of dispossession, the idea that 'man' has 
been dispossessed from history, unable to 'enter' into it with agency. ${ }^{10}$ Foucault observes, however, that the nineteenth century also saw the development of a new strategy: "All this makes manifest on the surface the naked fact that man found himself to be devoid of history, but that he was already working on the rediscovery deep inside him... of a historicity which was bound essentially to himself' (Foucault 1970, quoted in Bann 1995b, 10). A Romantic strain of historiography emerged in which subjectivity was deployed as way of participating in history, rather than being restrained in distanced observation. The self-implication of the historian within the act of documenting and recording history placed its production in the empowered hands of the individual historian.

Bann describes Romantic historiography as a form of writing "whereby the very nature of history is to participate in, and make explicit" (Bann 1995b, 13) the linkages that connect the distant past to the 'here' and 'now' of the moment of observation, and to the wider conditions of the present in which observation takes place. Hegel described the ideal historical account as one that "presents subject-matter that is not only adapted to the prose of History, but involves the production of such history in the very progress of its own being" (Hegel 1956, original emphasis, quoted in Bann 1995b, 12). Romantic historiography is both a deep investigation of the distant and the remote and a localized phenomenon, the juncture between which may reveal an "immanent tendency" (Bann 1995b, 13) or a repetition of patterns in history. The discovery of such patterns may even point to instances of historical forgetting and of absences in history.

Kitchener-Berlin embodies these characteristics of Romantic historiography by inserting the 'self' of the filmmaker into the rhetoric of the production of history. Hoffman

\footnotetext{
${ }^{10}$ Bann notes, referring to Freud's idea of 'mourning,' that historical practice in the period 'achieves the displacement of one type of dispossession (the loss of the centrality of 'man') onto another (the loss, or absence, of the past)" (Bann 1995b, 10).
} 
incorporates his own activity of 'witnessing' history in a mode of practice that appeals more to ideas of interaction, involvement and immersion in the course of events than a more typically distanced style of observation. In the Steadicam footage of Kitchener, Hoffman's shadow is frequently visible reflected onto the ground, and the movements of the mobile camera register his affected responses to the environment surrounding him. ${ }^{11}$ Both of these elements signal the filmmaker's presence, even as ideas of the 'present' and of the stability of place are being dissolved. It is also significant that Hoffman incorporates autobiographical elements of personal family history into the film and uses them in some cases as the basis of investigation. The father's side of Hoffman's family hailed from Kitchener, and was of Germanic heritage. Some of the home movies seen in Kitchener-Berlin were even shot by Hoffman's uncle (his father's brother). ${ }^{12}$ Rather than let history simply 'take place' objectively in the world, not unlike Hegel's ideal of history, Hoffman's film traces its connections between the World Wars, the renaming of the town and other subjects from the originating point of the historian.

Like the work of Von Humboldt, Kitchener-Berlin takes up an intensely subjective approach that demands historical knowledge and understanding be 'tested' and re-performed by the individual empiricist. In general, this insistence upon not relying on received facts and 'accepted' knowledge fosters an experimental approach that hypothesizes possibilities for rewriting and reshaping popular or dominant histories. As Bann suggests, Hoffman's experiments with history are also suited therefore to seek out absences in history and instances of forgetting. Kitchener-Berlin suggests that the town's former identity is to some extent unknown to its current inhabitants, and invisible to the unaided eye of the visitor. By making

\footnotetext{
${ }^{\text {II }}$ Varga makes the claim that Hoffman's films in general depend "upon the immediacy of intuitive and physical response" (Varga 2001, 110).

${ }^{12}$ See: Hoolboom (2001a).
} 
images from the past obscure or only partially discernable (through the superimposition techniques), Hoffman's film speaks of erasures and lacunas in historical awareness and gaps in record and memory. These 'holes' are precisely the passages Hoffman uses to traverse through time and space in an exploratory fashion. The specific manner in which the film is able to discover these absences can be expanded upon by looking at Bann's discussion of Goethe, whose descriptions of his journeys to Strasbourg Cathedral are evidence of a deployment of subjectivity in the service of articulating and producing a lost German cultural identity.

Autobiography (1811 - 1813) details Goethe's ambivalent response to Strasbourg Cathedral, and his struggle to see and 'read' it when the space does not neatly conform to the normative classical aesthetic values of proportion and symmetry Goethe is most familiar with. As a strategy for making sense of his discordant response, Goethe invokes the (recently popularized) rhetoric of the sublime, 'reuniting' the irreconcilable aspects of Strasbourg Cathedral's Gothic architecture into a more legible image. Beneath the matter of Goethe's aesthetic preconceptions and confrontation with stylistic dissonance, however, Bann identifies an undercurrent of nationalist sentiment. In his earlier work On German Architecture (1772), Goethe attempts to dramatize his response to Strasbourg Cathedral as a panegyric to its architect, Erwin Von Steinbach, by appealing to ideas of their shared national identity and heritage. Bann claims that Goethe was intending to posit Strasbourg Cathedral as an "emblem of a specifically German form of architecture" (Bann 1995b, 83). Yet, as Bann observes, Goethe would have no doubt been aware that the cathedral was, and had been for some time, on French soil, thus divorcing it from German ownership. There is an acute feeling of dispossession in Goethe's writings, a loss of connectivity to a symbol of cultural identity. Moreover, Goethe finds Von Steinbach's memorial stone absent from the site, making 
Goethe's writings a recuperative effort to prevent the architect's work from going unrecognized and unremembered. These two factors raise a number of issues around territorialization and identity, which reappear in Kitchener-Berlin as a result of a similar sense of historical dispossession.

Hoffman compares his Steadicam's tendency to produce "an emptiness and separation from anything it shows" to the "emptiness' of history and memory, and to the separation of "the remnants of German history from the present" (Hoffman, quoted in Hoolboom 2001a, 106). This sense of separation is similarly reflected in the use of hyphenation in the film's title, which suggests an ambivalent set of relations between 'past' and 'present,' 'here' and 'there,' and old and new. Rather than simply miring or confusing these categories, like the films discussed in Chapter Four, Hoffman employs the ambivalence between them to suggest at once an inherent and insurmountable distance or separation, and at the same time an irresistible, magnetic connection. This commingling of ideas of attraction and repulsion mirrors Goethe's unsettled response to Strasbourg Cathedral, and his invocation of the sublime to describe his experience of that space.

Beyond Goethe's adoption of sublime rhetoric to aid him in his description of Strasbourg Cathedral, Bann points out that it is precisely Goethe's subjective investment in the past that produces a new way of engaging with space. Whereas Von Humboldt and Forster advocated the acknowledgement of the uniquely subjective perspective of the author, the deployment of subjectivity in Goethe's writings functions more specifically as a matter of constructing identity. It is a mode of response that has bearings upon both the past and the immediate present of Strasbourg Cathedral as a place. Goethe's achievernent, according to Bann, was the production of "new, imaginatively accessible symbols through which the concrete experience of history could be interpreted and revised" (Bann 1995b, 88). Goethe 
established a relationship with the past that not only values and assigns meaning to its traces (as with antiquity), but further links the culture of the past from which those traces originate to the culture of the present. Kitchener-Berlin reflects this attempt at reading the past by overlapping images of Kitchener's present-day condition with stock footage and archive material showing its prior appearances, often highlighting the differences and mutations wrought upon this space by both the decay of time and by the imposed changes of political history. It is therefore appropriate that Goethe's assessment of the cathedral did not posit it as a completely authentic example of Middle Ages German architecture, that is, as a site of unproblematic heritage. (Goethe's texts mention several modifications made to the cathedral after it was ruined by a fire). While in general, like A.W. Kinglake's description of the Sphynx, Goethe's encounters with Strasbourg Cathedral are dramatized, and his responses are affected and emotive, unlike Kinglake, Goethe does not mythify the object or make similar appeals to timelessness. Neither does Goethe treat the site like a museum by placing it outside of time and context. For Goethe, Strasbourg Cathedral represented a site of difficulty, which persisted in being problematic. This persistent dissonance, Bann claims, was crucial to the significance of Goethe's writings as a form of historiography that drew attention towards unresolved historical disputes and erasures.

Not unlike the principle of 'enlivening' the senses that informs Romantic poetry, Goethe's writings represent a mode of engagement with space that fosters an appreciation of its overlooked significance, giving it a "renewed visibility" (Bann 1995b, 88). In this sense, Romantic historiography intersects with the practices of archeology: "What was offered to view was what has been brought to the surface, after remaining for many centuries under the 
ground" (Bann 1995b, 89).$^{13}$ A similar commitment to retrieving the overlooked contestation of place, identity and belonging that comprise the history of place forms the basis of the 'journey' in Kitchener-Berlin. According to Varga, the interpenetrating and fragmentary landscapes that populate the surface texture of the film are "overlaid with a discourse of territorialism" (Varga 2001,112), which shows the signs of struggles, both personal and political, over space, language and meaning. Although the change of the town's name at first seems like an innocuous historical revision, the binding or fixing of the name to the place is an act of (re)territorialization that effaces one cultural history, identity and memory in the same stroke as it constructs and consolidates another. ${ }^{14}$ This act of erasure is apparent on many more levels of the film, as Hoffman explores "the complicit relation between the name, the regimentation of territory, the onslaught of time, and technologies of mass destruction" (Varga 2001, 112). However, the precise connections between them are left problematic and somewhat obscure. For instance, one sequence in the film overlaps archive footage of nighttime airplane bombings of Berlin, Germany with home-movie footage (possibly of the Hoffman clan) opening Christmas presents. Here, a seemingly benign instance of the commodification of 'home' is juxtaposed with images of "brutal contestation for the control of nation-state territory - the bloodbath over who gets to name this space as 'home"' (Varga 2001, 113). The act of binding land to discourse can be an act of effacement, concealment or even destruction, and Kitchener-Berlin "evokes this brutal gesture of erasure" not only with regard to the renaming of the town or to the reorganization of nations during the World Wars, but moreover to "the legacy of colonization under which a discourse of Canadian space must

\footnotetext{
${ }^{13}$ While archeology and antiquarianism predate the developments of Romanticism, being long associated with the uncovering of unearthed relics and remains for trade and touristic profiteering, Bann asserts that this does not negate the importance of Romanticism's infusion into archeology and antiquarianism a distinct sense of historical identification.

${ }^{14}$ The bombing and destruction of space effects an uprooting, which, according to Jonathan Crary (1990), is a deterritorialization typically followed by a subsequent reterritorialization.
} 
begin" (Varga 2001, 112). Images Hoffman shoots with the Steadicam of Kitchener Cathedral, for instance, are overlaid with a superimposed image of a forest, perhaps not unlike the one that previously stood in its place. Hoffman's inclusion of television images of the Pope cordially greeting Aboriginal Canadians similarly enforces that while it may not be apparent on the surface, unacknowledged erasures of language, culture and territory are invisibly taking place.

Without presenting the film's activity as a sorting out or recovery of these obscure and sometimes lost contestations of space and identity, Kitchener-Berlin often allows the past to infiltrate or 'haunt' the present, and also allows them to mutually interpenetrate each other to the point that they are frequently indistinguishable. For instance, over images of contemporary Kitchener, Hoffman includes superimpositions of still photographs depicting inverted deer carcasses bleeding dry after a successful hunting trip, suggesting an unspoken, unacknowledged presence of violence 'beneath' the 'peaceful' life of Kitchener. The name of the town was changed in the first place as a way of distancing its residents from the violence of the war, but by allowing the past to shine through in the present, this image suggests that the process of erasure is never complete or total. It is furthermore difficult to ascertain with any finality the 'true' spatiotemporal identity of many of the images in Kitchener-Berlinwhich represent home or away, past or present? Towards the end of the first sequence, the mixture of superimposed layers even blots out the characteristic Steadicam images, which had previously signaled the 'present' of Hoffman's shooting of the film. Rather than allow its images to be assigned to a clear chronology or sequence, Kitchener-Berlin enters them into a dialectic of various co-existing points in space and time, thus opening up the possibilities for various contrapuntal relationships between them. This dialectic does not proffer a synthesis which could possibly reconfirm presence and perspective as being grounded in any one space 
and time, by looking 'out' at the distant or looking 'back' at the remote from fixed spatiotemporal coordinates. Varga therefore suggests Kitchener-Berlin is not a work of remembering, in the sense of sorting, organizing and streamlining the past. According to Varga, the film "is not a re-writing of history... instead, it is an offering that includes the necessary absences of forgetting and misconceptions haunting the reconfiguration of memory" (Varga 2001, 113). ${ }^{15}$ This is also the sense in which the architect Von Steinbach is absent from Strasbourg Cathedral, and again, a sense of dispossession is apparent, a sense that history is already lost, and "documents from [the] past that can never be wholly known, while the overlaid present has already begun to fade" (Varga 2001, 114). ${ }^{16}$ Hoffman's visual techniques of superimpositions that remain in the median between two images and unsettled pans across volatile landscapes extend to the film's allegorical depiction of the passage (journey) of history, and of the inability to 'fix' an historical image, identity or memory. Varga goes on to describe Hoffman's archeological project as the "translation of the past and casting forward into an unnameable future" (Varga 113), following Walter Benjamin's (1968) demand that we "brush history against the grain" (Benjamin 1968, 256 - 257). Even if memory, like experience, cannot be authenticated and confirmed (see Chapter Three), and is, like perspective, prone to failure and disruption (see Chapter Two), what is nevertheless possible is an imaginative alteration of conventional understandings of space and time. This model of engaging with space and with history may not be able to instrumentalize the understanding and the translation of the past into a naming and delineating of the future, but rather its purpose may be the production of a new unstable, unfixed space and time, an inbetween terrain. According to Varga, Kitchener-Berlin works toward producing such an

\footnotetext{
${ }^{15}$ This is also the relationship to history and memory evident in Hoffman's Somewhere Between Jalostotitlan and Encarnation (1984) in the way that the unrepresented dead boy is its central structuring absence.

${ }^{16}$ In the scene at the museum of invasions in (1992), the narrator notes how "the artifacts of past wars [are] barely visible beneath the debris of the present."
} 
'image of thought' or 'thought-movement' that stands outside of discourses that commodify and territorialize space, and does not conform to the conventional patterns of "the spatialized containment of difference" (Varga 2001, 110). If we take Hoffman's film to be engaged in visualizing the process of reconceptualizing connections between spaces and times, what is apparent is an act of misrecognition. "The art process that takes memory as canvas requires the failure of recognition (which is not the same as the absences of official history), in order to suspend instrumentalization and engage thought" (Varga 2001, 113).

This has been the purpose of this thesis, to create a new ground for observation out of the undetermined and mobile connections between different points in history, not as a way of reconciling the differences between them, but to latch onto those differences and to take part in an activity of pseudomorphosis, which is simultaneously an experimental way of learning and an aesthetic condition (see Introduction). Pseudomorphism, as we have seen, is built into Goethe's method of experiencing space, and by extension is an aspect of Romanticism, or at the very least of Romanticism's approaches to writing history. Goethe's techniques are reflected in Kitchener-Berlin as a way of avoiding the reterritorializing aspects of conventional histories. Rather than function as a simple "corrective to the positivist tendency of realist narrative and critical discourse," Hoffman's film treats space as 'open' and not 'solved' or re-fixed, producing "an alternative space in-between that which is simply given" (Varga 2001, 111).

This thesis has hopefully demonstrated the various facets of the experimental travelogue as a genre of filmic practice, covering its aesthetic, stylistic, structural and political tendencies. Following P. Adams Sitney's (1979) suggestion, Romanticism may be a founding basis of the experimental film in many of its subcategories and divisions of practice. Experimental film might even be claimed as the current residing place of many of the 
concerns, aesthetics and approaches of Romanticism. ${ }^{17}$ If this is indeed the case, then despite the wealth of meanings the experimental travelogue produces in its mobilization of the ideas of travel, movement and transportation common to Romantic literature, art and poetry, this subcategory of experimental practice is only a point of departure for exploring the rich connections to the culture of the Romantic period.

\footnotetext{
${ }^{17}$ This parallels the continuing appropriation of Romanticism by various institutions of popular culture. A visit to the Lake District tourist board's website (www.golakes.co.uk) shows how not only Wordsworth's poetry but the general features of Romanticism are still being employed to promote tourism in the region.
} 


\section{Bibliography}

Andrews, Malcolm, 1989. "Poetry and the Discovery of the British Landscape," "Traveling "Knick-Knacks," The Search for the Picturesque. Stanford, California: Stanford University Press. Pg. 3-23, 67-82.

Bann, Stephen, 1995a. Under the Sign: John Bargrave as Collector, Traveler, and Witness. Ann Arbor, MI: University of Michigan Press.

Bann, Stephen, 1995b. "Romanticism and the Desire for History," "Understanding the Past," "Taking a Subjective Stance," Romanticism and the Rise of History. New York: Twayne Publishers. Pg. $3-10,11-16,79-101$.

Baudelaire, Charles, 1965. "The Salon of 1846," Art in Paris: 1845 - 1862: Salons and Other Exhibitions. Mayne, Jonathan, trans. \& ed. London: Phaidon Press. Pg. 41 120.

Bazin, André, 1991. "The Myth of Total Cinema," Film Theory and Criticism, $4^{\text {th }}$ ed. Mast, Cohen and Braudy, eds. New York: Oxford University Press. Pg. 34-37.

Benjamin, Walter, 1968. "The Work of Art in the Age of Mechanical Reproduction," "Theses on the Philosophy of History," Illuminations. Arendt, Hannah, ed. New York: Harcourt Brace, Pg. $219-253,253-267$.

Benjamin, Walter, 1999. "On the Theory of Knowledge, Theory of Progress," The Arcades Project. Eiland and McLaughlin, trans. Cambridge, Massachusetts: Belknap Press. Pg. 456-488.

Bennett, Tony, 1995. "The Formation of the Museum," "The Exhibitionary Complex," The Birth of the Museum: History, Theory, Politics. London and New York: Routledge. Pg. $17-58,59-88$.

Burch, Noël, 1979. "Film's Institutional Mode of Representation and the Soviet Response," October, Vol. 11 (Winter). Cambridge, Mass.: MIT Press. Pg. 77 - 96.

Burch, Noël, 1982. "Porter, or Ambivalence," Cinema 1900 - 1906: An Analytical Study. Holman, Roger, ed. Brussels: FIAF. Pg. $101-113$.

Burch, Noël, 1986. "Primitivism and the Avant-Gardes: A Dialectical Approach," Narrative, Apparatus, Ideology: A Film Theory Reader. Rosen, Philip, ed. New York: Columbia University Press. Pg. 483 - 506.

Burch, Noël, 1990a. "A Primitive Mode of Representation?," Early Cinema: Space, Frame, Narrative. Elsaesser, Thomas and Barker, Adam, eds. London: BFI Publishing. Pg. $220-227$. 
Burch, Noël, 1990b. "Baudelaire versus Frankenstein," Life to these Shadows. Berkeley and Los Angeles: University of California Press. Pg. 6-22.

Burke, Edmund, 1971. A Philosophical Enquiry into the Origin of Our Ideas of the Sublime and the Beautiful, 1759 ed. New York: Garland Pub. Inc..

Buzard, James, 2002. "The Grand Tour and After (1660 - 1840)," The Cambridge Companion to Travel Writing. Hulme, Peter, and Tim Youngs, eds. Cambridge and New York: Cambridge University Press. Pg. 37-52.

Canadian Filmmakers' Distribution Centre (CFMDC). Online catalogue. Available on the World Wide Web at: http://www.cfmdc.org.

Carr, Helen, 2002. "Modernism and Travel (1880 - 1940)," The Cambridge Companion to Travel Writing. Hulme, Peter, and Tim Youngs, eds. Cambridge, U.K.; New York: Cambridge University Press. Pg. 70 - 86.

Cartmell, Mike, 2001. "Landscape with Shipwreck," Landscape with Shipwreck: First Person Cinema and the Films of Philip Hoffman. Sandlos, Karyn and Mike Hoolboom, eds. Toronto: Images Festival of Independent Film and Video with Insomniac Press. Pg. 222 - 245.

Coleridge, Samuel Taylor, 1913. "Chapter XIV: Occasion of the Lyrical Ballads, and the Objects Originally Proposed," Biographia Literaria, 1906 ed. London and Toronto: J.M. Dent \& Sons, Ltd.. Pg. 160-167.

Comolli, Jean-Louis, 1990. "Technique and Ideology: Camera, Perspective, Depth of Field," Cahiers du Cinéma, 1969 - 1972: The Politics of Representation. Browne, Nick, ed. Cambridge: Harvard University Press. Pg. 213 - 247.

Cornwell, Regina, 1980. "Progress-Discontinuous," Artforum, Vol. 18 (April). Sischy, Ingrid, ed. New York: Charles Cowles. Pg. 60-67.

Costa, Antonio, 2006. "Landscape and Archive: Trips Around the World as Early Film Topic (1896 - 1914)," Landscape and Film. Lefebvre, Martin, ed. New York: Routledge. Pg. $245-266$.

Crang, Mike, 1999. "Knowing, Tourism and Practices of Vision," Leisure/Tourism Geographies: Practices and Geographical Knowledge. Crouch, David, ed. London: Routledge. Pg. 238 - 256.

Crary, Jonathan, 1990. "Modernity and the Problem of the Observer," Techniques of the Observer: On Vision and Modernity in the Nineteenth Century. Cambridge, Massachusetts: MIT Press. Pg. 1 - 24. 
De Botton, Alain, 2003. "On Curiosity," "On the Country and the City," The Art of Travel. London: Penguin Books. Pg. $101-125,129$ - 156.

De Quincey, Thomas, 1897. "Letters to a Young Man whose Education has been Neglected," The Collected Writings of Thomas De Quincey, Vol. X: Literary Theory and Criticism. Masson, David, ed. London: A. \& C. Black, Soho Square. Pg. 9-80.

Deleuze, Gilles, and Félix Guattari, 1977. Anti-Oedipus: Capitalism and Schizophrenia. Hurley, Seem, and Lane, trans. Minneapolis: University of Minnesota Press.

Deleuze, Gilles, 1986. Cinema 1: The Movement-Image. Tomlinson and Habberjam, trans. Minneapolis: University of Minnesota Press.

Deleuze, Gilles, 1989. "Preface to the English Edition," "Beyond the Movement-Image," Cinema 2: The Time-Image. Tomlinson and Galeta, trans. Minneapolis:

University of Minnesota Press. Pg. XI - XIII, $1-24$.

Deleuze, Gilles, and Félix Guattari, 1994. "Geophilosophy," What Is Philosophy?. Tomlinson and Burchell, trans. New York: Columbia University Press. Pg. 85 113.

Delluc, Louis, 1988. "Beauty in the Cinema," French Film Theory and Criticism: Volume 1, 1907-1924. Abel, Richard, ed. Princeton: Princeton University Press. Pg. 137 $-139$.

Dolan, Brian, 2000. Exploring European Frontiers: European Travelers in the Age of Enlightenment. Basingstoke: Macmillan Press.

Douglas, Mary, 1966. "Secular Defilement," Purity and Danger. London: Routledge and Kegan Paul. Pg. 29 - 40.

Dulac, Germaine, 1978. "The Avant-Garde Cinema," The Avant-Garde Film: A Reader of Theory and Criticism. Sitney, P. Adams, ed. New York: New York University Press. Pg. $43-48$.

Edney, Matthew, 1998. "The Enlightenment Construction of Geographical Knowledge," Mapping an Empire: The Geographical Construction of British India, 1765 1843. Chicago and London: Chicago University Press. Pg. 37-118.

Elsaesser, Thomas, 1990. "Early Cinema: From Linear History to Mass Media Archeology," Early Cinema: Space, Frame, Narrative. Elsaesser, Thomas and Barker, Adam, eds. London: BFI Publishing. Pg. 1-7.

Ford, Maddox Ford, 1983. The English Novel. Manchester: Carcanet. 
Forster, George, 1777. Voyage Round the World, in his Brit. Majesty's Sloop Resolution, Commanded by Capt. Cook, During the Years 1772, 1773, 1774, and 1775, Vol. 1. London.

Goode, George Brown, 1896. "On the Classification of Museums," "The Principles of Museum Administration," Science (New Series), Vol. 3. New York: Macmillan. No. 57 , pg. $154-161$, No. 73 , pg. $783-785$.

Gunning, Tom, 1982. "The Non-Continuos Style of Early Film," Cinema 1900 - 1906: An Analytical Study. Holman, Roger, ed. Brussels: FIAF. Pg. 219-229.

Gunning, Tom, 1983. "An Unseen Energy Swallows Space: The Space in Early Film and Its Relation to American Avant-Garde Film," Film Before Griffith. Fell, John, C., ed. Berkeley, Los Angeles and London: University of California Press. Pg. $355-$ 366.

Gunning, Tom, 1989. "An Aesthetic of Astonishment: Early Film and the (In)credulous Spectator," Art \& Text, No. 34 (Spring). Pg. $31-45$.

Gunning, Tom, 1990a "Non-Continuity, Continuity, Discontinuity: A Theory of Genres in Early Films," Early Cinema: Space, Frame, Narrative. Elsaesser, Thomas and Barker, Adam, eds. London; BFI Publishing. Pg. 86 - 94.

Gunning, Tom, 1990b. "The Cinema of Attractions: Early Film, Its Spectator and the Avant-Garde," Early Cinema: Space, Frame, Narrative. Elsaesser, Thomas, and Adam Barker, eds. London: British Film Institute. Pg. 56- 62.

Hanhardt, John G., 1976. "The Medium Viewed: The American Avant-Garde Film," $\underline{A}$ History of the American Avant-Garde Cinema. New York: The American Federation of Arts. Pg. 19 - 47.

Hansen, Miriam, 1983. "Early Silent Cinema: Whose Public Sphere?," New German Critique, No. 29 (Spring - Summer). New York: TELOS Press. Pg. 147-184.

Harcourt, Peter, 2001. "Circuitous Quests: Passing Through Philip Hoffman's Family Cycle," Landscape with Shipwreck: First Person Cinema and the Films of Philip Hoffman. Sandlos, Karyn and Mike Hoolboom, eds. Toronto: Images Festival of Independent Film and Video with Insomniac Press. Pg. 80 - 94.

Hawkesworth, John, 1773. An Account of the Voyages Undertaken by the Order of his Present Majesty for Making Discoveries in the Southern Hemisphere, Vol,1. London: W. Strahan and T. Cadell.

Heath, Stephen, 1981. "Narrative Space," Questions of Cinema. London: Macmillan. Pg. $19-75$. 
Heber, Reginald, 1813. "Clarke's Travels - Greece, Egypt, and the Holy Land," Quarterly Review, Vol. 9 (March). London: J. Murray. Pg. 162 - 206.

Hoolboom, Mike, 2001a. "Pictures of Home: Hoffman in the 80's, An Interview," Landscape with Shipwreck: First Person Cinema and the Films of Philip Hoffman. Sandlos, Karyn and Mike Hoolboom, eds. Toronto: Images Festival of Independent Film and Video with Insomniac Press. Pg. 95 - 108.

Hoolboom, Mike, 2001b. "Duets: Hoffman in the 90s, An Interview," Landscape with Shipwreck: First Person Cinema and the Films of Phillip Hoffman. Sandlos, Karyn, and Mike Hoolboom, eds. Toronto: iMAGES Festival and Insomniac Press. Pg. $211-221$.

Kames, Henry Home, Lord, 1970. "Novelty, and the Unexpected Appearance of Objects," Elements of Criticism, Vol. 1. Hildesheim, New York: Georg Olms Verlag. Pg. $319-336$.

Kibbins, Gary, 2002. "Bear Assumptions: Notes on Experimentalism," Public 25: Experimentalism (Fall). Kibbins, Gary, and Susan Lord, eds. Toronto: Public Access. Pg. $148-159$.

Kinglake, Alexander William, 1920. "The Sphynx," Eothen; or, The Traces of Travel, Brought Home from the East, 1908 ed. London and Toronto: J.M. Dent \& Sons, Ltd., New York: E.P. Dutton \& Co.. Pg. $181-182$.

Kracauer, Siegfried, 1987. "The Cult of Distraction: On Berlin's Picture Palaces," New German Critique, Vol. 14, No. 40 (Winter). New York: TELOS Press. Pg. 91 96.

Kristeva, Julia, 1982. "Approaching Abjection," Powers of Horror: An Essay on Abjection. Roudiez, trans. New York: Columbia University Press. Pg. $1-11$.

Latour, Bruno, 1987. "Centres of Calculation," Science in Action: How to Follow Scientists and Engineers through Society. Milton Keynes and Philadelphia: Open University Press. Pg. $215-257$.

Lawder, Standish D., 1975. "Modern Painters Discover the Cinema," The Cubist Cinema. New York: New York University Press. Pg. 1-17.

Leask, Nigel, 2002. "Introduction: Practices and Narratives of Romantic Travel," "Cycles of Accumulation, Aesthetics of Curiosity, and Temporal Exchange," Curiosity and the Aesthetics of Travel Writing, 1770-1840: 'From an Antique Land'. Oxford and New York: Oxford University Press. Pg. 1-14, 15- 53.

Lejeune, Caroline Alice, 1931. "The Experimental Film," Cinema. London: Alexander Maclehose. Pg. 202-207. 
Locke, John, 1975. An Essay Concerning Human Understanding. Nidditch, Peter $\mathrm{H}_{\text {.s }}$ ed. Oxford: Clarendon Press.

MacCaninell, Dean, 1989. "Introduction," The Tourist: A New Theory of the Leisure Class. New York: Schocken. Pg. $1-15$.

McHugh, Kathleen, 1990. "Subjectivity and Space: The Films of Patricia Gruben," Jump Cut: A Review of Contemporary Media, No. 35 (April). Berkeley, California: Jump Cut Associates. Pg. 110-116.

McSorley, Tom, 1995. "Pilgrimage to Vision: The Cinema of Peter Mettler," Peter Mettler: Making the Invisible Visible. Pitschen, Salome, and Annette Schönholzer, eds.. Zürich: Reihe Andreas Züst Im Verlag Ricco Bilger. Pg. 88 121.

McSorley, Tom, 2005. "Paradox and Wonder: The Cinema of Peter Mettler," Take One: Film and Television in Canada, Vol. XIV, No. 50 (June - September). Toronto: Canadian Independent Film and Television Publishing Association. Pg. $42-46$.

Musser, Charles, 1990. "The Travel Genre in 1903 - 1904: Moving Towards Fictional Narrative," Early Cinema: Space, Frame, Narrative. Elsaesser, Thomas and Barker, Adam, eds. London: BFI Publishing. Pg. 123-132.

Nadaner, Dan, 1987. "Metatourist in Metaworld: Patricia Gruben's Sifted Evidence," Millennium Film Journal, No. 19 (Fall/Winter). New York, N.Y.: Millennium Film Workshop. Pg. $114-119$.

Pearson, Roberta, 1996. "Early Cinema," "Transitional Cinema," The Oxford History of World Cinema. Nowell-Smith, Geoffrey, ed. Oxford and New York: Oxford University Press. Pg. 13-23, 23-42.

Pinkerton, John, 1814. "Retrospect of the Origin and Progress of Discovery, by Sea and Land, in Ancient, Modern, and the Most Recent Times," A General Collection of the Best and Most Interesting Voyages and Travels In All Parts of the World, Vol. XVII. London: Longman, Hurst, Rees, Orme, and Brown; Paternoster-Row; and Cadell and Davies. Pg. I - XXXIX.

Pococke, Richard, 1743. A Description of the East, and Some Other Countries. London: Printed for the author.

Radul, Judy, 2002. "Just Try It: Thoughts on Art and Science Experiments," Public 25: Experimentalism (Fall). Kibbins, Gary, and Susan Lord, eds. Toronto: Public Access. Pg. $92-105$.

Rank, Otto, 1971. The Double: A Psychoanalytic Study. Tucker, Harry, trans. and ed. Chapel Hill: University of North Carolina Press. 
Rigsby, Jeremy, 2001. "Somewhere Between," Landscape with Shipwreck: First Person Cinema and the Films of Philip Hoffman. Sandlos, Karyn and Mike Hoolboom, eds. Toronto: Images Festival of Independent Film and Video with Insomniac Press. Pg. $37-39$.

Ruoff, Jeffrey, 2006. "Around the World in Eighty Minutes: The Travel Lecture Film," Cineaction!, No. 47. Toronto: CineAction Collective. Pg. 2 - 11 .

Russell, Catharine, 1999. "Preface," Experimental Ethnography: The Work of Film in the Age of Video. Durham, N.C.: Duke University Press. Pg. XI - XVIII.

Schaub, Martin, 1995. "Music and Travel: Sensing the World," Peter Mettler: Making the Invisible Visible. Pitschen, Salome, and Annette Schönholzer, eds.. Zürich: Reihe Andreas Züst Im Verlag Ricco Bilger. Pg. 22 - 53.

Sherman, William H., 2002. "Stirrings and Searchings (1500 - 1720)," The Cambridge Companion to Travel Writing. Hulme, Peter, and Tim Youngs, eds. Cambridge and New York: Cambridge University Press. Pg. 17-36.

Simmon, Scott, 2000. "Interior New York Subway, $14^{\text {th }}$ Street to $42^{\text {nd }}$ Street," (Program Notes) Treasures from American Film Archives. National Film Preservation Foundation. Pg. 96 - 97

Singer, Ben, 1995. "Modernity, Hyperstimulus, and the Rise of Popular Sensationalism," Cinema and the Invention of Modern Life. Charney, Leo, and Vanessa R. Schwartz, eds. Berkeley, Los Angeles \& London: University of California Press. Pg. $72-99$.

Sitney, P. Adams, 1970. "Structural Film," Film Culture Reader. New York and Washington: Praeger Publishers. Pg. 326 - 348.

Sitney, P. Adams, 1979. "Preface," Visionary Film: The American Avant-Garde, 1943 $1978,2^{\text {nd }}$ ed. Oxford, New York, Toronto and Melbourne: Oxford University Press. Pg. VII - XI.

Stafford, Barbara-Maria, 2001. "Revealing Technologies / Magical Domains," Devices of Wonder: from the world in a box to images on a screen. Additional author: Frances Terpak. Los Angeless, CA: Getty Research Institute. Pğ. 1 - 142.

Steinberg, Leo, 1972. "Objectivity and the Shrinking Self," Other Criteria: Confrontations with Twentieth-Century Art. New York: Oxford University Press. Pg. $307-321$. 
Stewart, Susan, 1984. "The Miniature," "The Gigantic," On Longing: Narratives of the Miniature, the Gigantic, the Souvenir, the Collection. Baltimore: Johns Hopkins University Press. Pg. $37-69,70-103$.

Stoneman, Rod, 1981. "Perspective Correction: Early Film to the Avant-Garde," Afterimage, Vol. 8/9 (Spring). Field, Simon, and Guy L'éclair, eds. London: Afterimage Publishing. Pg. 50-63.

Sudre, Alain-Alcide, 1991. "In Favour of an Exploratory Practice," The Visual Aspect: Recent Canadian Experimental Films. Lowder, Rose, ed. Avignon: Editions des Archives du Film Experimental d'Avignon. Pg. 53 - 66.

Testa, Bart, 1992. Back and Forth: Early Cinema and the Avant-Garde. Toronto: Art Gallery of Ontario.

Thompson, Leslie, 2001. "The Infinite Between," (Program Notes), Gallery 44 Centre for Contemporary Photography (Toronto). Pg. 1 - 6.

Vaarga, Darrell, 1999. "Lights Raining Down on the Imaginary: Peter Mettler's Picture of Light," The North in Film. Plumstead, A.W., ed. North Bay: Nipissing University. Pg. 77-89.

Värga, Darrell, "In/Between Spaces," Landscape with Shipwreck: First Person Cinema and the Films of Philip Hoffman. Sandlos, Karyn and Mike Hoolboom, eds. Toronto: Images Festival of Independent Film and Video with Insomniac Press. Pg. $109-123$.

Von Humboldt, Alexander, 1849. "Poetic Descriptions of Nature," Cosmos: A Sketch of a Physical Description of the Universe, Vol. 2, $5^{\text {th }}$ ed. London: Brown. Pg. 6-73.

Walsh, Martin, 1981. "The Complex Seer: Brecht and the Film," The Brechtian Aspect of Radical Cinema. Griffiths, Keith M., ed. London: BFI. Pg. 5-21.

White, Jerry, 2006. "Chapter One: Lancalot Freely, Scissere, Eastern Avenue," Of This Place and Elsewhere: The Films and Photography of Peter Mettler. Bloomington and Indianapolis: Indiana University Press, in conjunction with Toronto International Film Festival. Pg. 6-13.

Wollstonecraft, Mary, 1987. A Short Residence in Sweden. Harmondsworth: Penguin.

Wordsworth, William, 1970. Guide through the District of the Lakes in the North of England, $5^{\text {th }}$ ed. London: Oxford University Press.

Wordsworth, William, 1987. "The Sparrow's Nest," published in "Volume Two: Moods of My Own Mind," Wordsworth's Poems of 1807. Jones, Alun R., ed. Houndmills and Basingstoke: Macmillan. Pg. 88 - 97. 
Wordsworth, William, 1998. "Lines written a few miles above Tintern Abbey on revisiting the banks of the Wye during a tour, July 13, 1798," "The Prelude, Book XI: Imagination, How Impaired and Restored," William Wordsworth: Selected Poetry. Gill, Stephen, and Duncan Wu, eds. Oxford and New York: Oxford University Press. Pg. $57-61,216-219$.

Wordsworth, William, 2006a. "Advertisement," The Broadview Anthology of British Literature, Vol. 4: The Age of Romanticism. Black, Joseph et al, eds. Toronto: Broadview Press. Pg. 193-194.

Wordsworth, William, 2006b. "Preface," The Longman Anthology of British Literature, Vol. 2A: The Romantics and their Contemporaries. Wolfson, Susan, and Peter Manning, eds. New York, San Francisco and Boston: Longman. Pg. 408 - 420.

Yeats, William Butler, 1963. "The Second Coming," The Collected Poems of W.B. Yeats. London: Macmillan. Pg. 210-211. 